University of Louisville

ThinkIR: The University of Louisville's Institutional Repository

$12-2007$

\title{
The effects of psychological and biological gender on gender role conflict and mental health of gay and lesbian individuals.
}

Kevin James Herdman 1969-

University of Louisville

Follow this and additional works at: https://ir.library.louisville.edu/etd

\section{Recommended Citation}

Herdman, Kevin James 1969-, "The effects of psychological and biological gender on gender role conflict and mental health of gay and lesbian individuals." (2007). Electronic Theses and Dissertations. Paper 610. https://doi.org/10.18297/etd/610

This Doctoral Dissertation is brought to you for free and open access by ThinkIR: The University of Louisville's Institutional Repository. It has been accepted for inclusion in Electronic Theses and Dissertations by an authorized administrator of ThinkIR: The University of Louisville's Institutional Repository. This title appears here courtesy of the author, who has retained all other copyrights. For more information, please contact thinkir@louisville.edu. 
THE EFFECTS OF PSYCHOLOGICAL AND BIOLOGICAL GENDER ON GENDER ROLE CONFLICT AND MENTAL HEALTH OF GAY AND LESBIAN INDIVIDUALS

By

Kevin James Herdman

B.S., West Virginia State University, 1993

M.B.A., Indiana University, 1999

M.A., Webster University, 2004

A Dissertation

Submitted to the Faculty of the

Graduate School of the University of Louisville

in Partial Fulfillment of the Requirements

for the Degree of

Doctor of Philosophy

College of Education and Human Development

University of Louisville

Louisville, Kentucky

December 2007 
Copyright 2007 by Kevin J. Herdman

All rights reserved 
THE EFFECTS OF PSYCHOLOGICAL AND BIOLOGICAL GENDER ON GENDER ROLE CONFLICT AND MENTAL HEALTH OF GAY AND LESBIAN

INDIVIDUALS

By

Kevin James Herdman

B.S., West Virginia State University, 1993

M.B.A., Indiana University, 1999

M.A., Webster University, 2004

A Dissertation Approved on

November 5, 2007

by the following Dissertation Committee:

Dr. Namok Choi, Dissertation Co-Director

Dr. Joseph Petrosko, Dissertation Co-Director

Dr. John L. Keedy

Dr. Amy Hirschy

Dr. Ray K. Haynes 


\section{DEDICATION}

The decision to dedicate this dissertation to the love of my life, my seven year old son, Noah Nathaniel, was by far the easiest part of my entire doctoral process. Noah, being the precocious and generous boy that he is, selflessly sacrificed countless hours of "daddy" time so that I could write, revise, revise, revise, and finalize my dissertation. My new life goal is to repay him in kind with countless hours of movies, bowling, and as much scooter time as any parent can bear. 


\section{ACKNOWLEDGEMENTS}

I acknowledge and thank my dissertation co-chair, Dr. Namok Choi, for her patience, high standards, wisdom, integrity, encouragement, and maternal nurturance throughout this difficult process. I discovered that writing a dissertation is replete with emotive highs and lows. Dr. Choi was always there to celebrate the joyous moments with a huge smile and pralines. She was just as willing, however, to share her box of Kleenex when the process seemed nothing less than insurmountable. Thank you Dr. Choi. I hope I made you proud.

I extend my deepest gratitude to my dissertation co-chair, Dr. Joseph M. Petrosko for his statistical wisdom, guidance, humility, and wonderful sense of humor. Dr. Petrosko, even with multiple commitments, made time to mentor and advise me. I also acknowledge and thank the remaining members of my dissertation committee for their advisement, commitment, and words of encouragement: Dr. Ray K. Haynes, Dr. Amy S. Hirschy, and Dr. John L. Keedy. In addition, I owe a debt of gratitude to my dear friend, colleague, and mentor, Dr. Robin K. Hinkle, for her advice, support, and candor. Robin, your candor and encouragement made me smile and laugh when the road I was traveling seemed far too arduous and endless. You are truly one of a kind; and, I treasure your friendship.

Acknowledgement is given to Brandi Clark Owsley and Diane Owsley, my biggest cheerleaders, as we matriculated through the Ph.D. program together. It simply would not have been the same without your love, laughs, tears, and encouragement. 
I want to acknowledge and thank my dearest friend in the world, Nick Nosko, for the ear that I bent on so many occasions and for his tough love when I needed it most. You will never know, Nick, just how much your presence in my life means to me.

I would like to acknowledge and thank Jennifer Kochert. Steven Jones, Hernando Castro-Rivera, Brian Buford, Jason Vincent, J. Daniel Herring, Dr. Michael Compton, Ken Hogan, Bob Johnson, Matthew Chappell, and Rene' Torman. my dear friends and confidants. All of you listencd to me drone on and on about statistics, gender roles, selfesteem, and loneliness - all the while pretending to hang on my every word. I love you all for that selfless and loving act. I would also like to express my gratitude to Fred Borho and my other friends for taking care of Noah while I attended class, did homework, and wrote a dissertation. I could not have done this without your support.

Special thanks are given to my wonderful parents, Kenneth and Della Herdman, for being so openly proud of me. The two of you were always confident that your, let us just say unique. Appalachian son could do anything he dreamed of doing-even against all of the seemingly impossible odds. The two of you taught me that the only thing capable of stopping me from realizing my dreams was my own self-doubt. Thank you for believing in me enough to teach me to believe in myself. 
ABSTRACT

\section{THE EFFECTS OF PSYCHOLOGICAL AND BIOLOGICAL GENDER ON GENDER ROLE CONFLICT AND MENTAL HEALTH OF GAY AND LESBIAN INDIVIDUAIS}

Kevin . Herdman

November 05, 2007

This dissertation represented an examination of the interrelationships between psychological gender (i.e., masculinity, femininity, androgyny, and undifferentiated), biological gender (i.e., male and female). gender role conflict, self-esteem, and loneliness in a sample of gay men and lesbian women. Psychological gender and biological gender served as the independent variables in the study while gender role conflict, self-esteem, and loneliness served as the dependent variables. A two-way factorial MANOVA was used as the statistical model of choice in addition to correlational analyses. A confirmatory factor analysis was also completed on the instrument used to measure gender role conflict, the Gender Role Conflict Scale.

The dissertation was divided into five chapters. The first chapter simply served as an introduction to the study including the variables, definitions, and research questions. Chapter two introduced the literature relevant to the study. The literature relative to psychological gender was presented in chronological order, followed by a 
discussion of the literature addressing self-esteem, loneliness, and gender role contlict. Chapter three described the purpose and design of the current study in addition to all research instruments used. Research instruments included the Ben Sex Role Inventory as the measurement instrument of psychological gender. The Rosenberg Self-Esteem Scale and the Revised UCLA Loneliness Scale were used to measure self-esteem and loneliness, respectively. Finally, the Gender Role Conflict Scale was used to measure levels of gender role conflict.

The study results were presented in chapter four. No significant interaction was found between psychological gender and biological gender on gender role conflict, selfesteem, or loneliness. Significant main effects, however, were observed in psychological gender on all dependent variables. In addition, a significant main effect was observed in biological gender on gender role conflict. The resuits from the confirmatory factor analysis upheld those found in the literature. Although the fit indices used did not reveal a strong fit of the model to the data, the overall fit was moderate. Chapter five served as a discussion chapter. A summary of major findings was presented along with a discussion of the findings. 


\section{TABLE OF CONTENTS}

PAGE

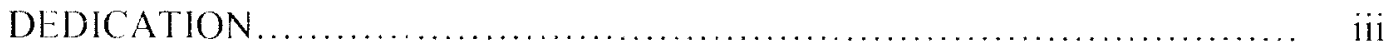

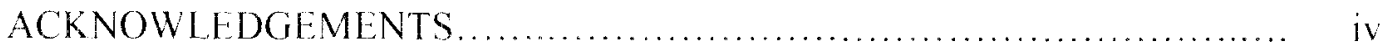

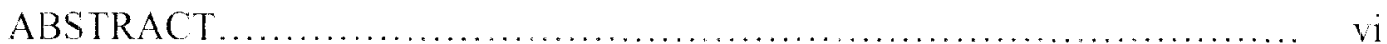

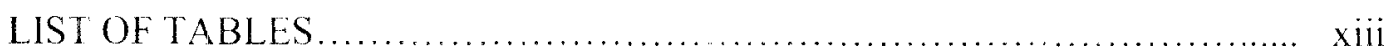

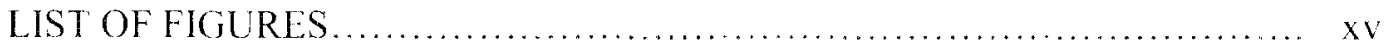

\section{CHAPTER}

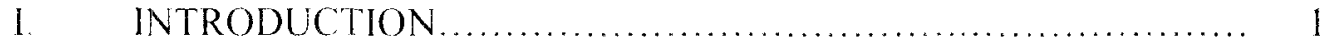

Statement of the Problem................................... 6

Significance of the Study................................... 7

Research Questions................................... 8

Limitations.............................................. 9

Delimitations......................................... 10

Definitions................................................ 12

II. LITERATURE

REVIEW ....................................................... 14

Psychological Gender Roles................................... 14

Dimensions of Gender Roles........................ 16

Gender Roles and Socialization......................., 20

Gender Roles and GL. Socialization............... 24

Workplace Heterosexism................ 26 
Gender Role Measurment.............................. 31

Bem Sex Role Inventory ........................... 31

Gender Role Categories..................... 32

Masculine........................... 33

Feminine......................... 35

Undifferentiated.................... 38

Androgynous...................... 38

Gender Roles and Mental Health........................... 41

Mental Health and Self-Esteem..................... 42

Dimensions of Self-Esteem.................... 43

Gender Roles and Self-Esteem.............. 47

Mental Health and Loneliness....................... 51

Dimensions of Loneliness.................... 52

Gender Roles and Loneliness................. 53

Loneliness and the GL Population........... 56

Gender Role Conflict.......................................... 59

Dimensions of Gender Role Conflict...................... 60

Gender Role Conflict and the GL Population................ 66

Gender Role Conflict and Women....................... 70

Gender Role Conflict and Mental Health................... 72

Gender Role Conflict and Self-Esteem.............. 73

Gender Role Conflict and Loneliness.............. 75 
Literature Review Summary

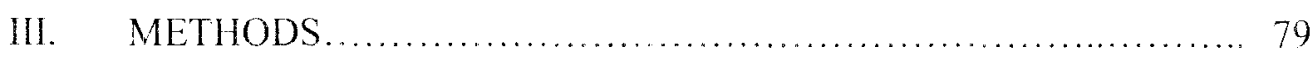

Participants............................................... 79

Design................................................. 83

Procedure................................................. 84

Instruments ............................................ 86

Bem Sex Role Inventory ............................ 86

Validity of the Bem Sex Role Inventory........... 87

Reliability of the Bem Sex Role Inventory........ 89

Gender Role Conflict Scale.......................... 91

Validity of the Gender Role Conflict Scale......... 92

Reliability of the Gender Role Conflict Scale..... 93

Rosenberg Self-Esterm Scale...................... 93

Revised UCLA Loneliness Scale....................... 94

Statistical Analysis ..................................... 95

VI. RESULTS.............................................. 100

Assumptions.............................................. 100

Independence.................................... 100

Normality....................................... 101

Equality of Covariance of Matrices.................... 101

Reliability Analysis..................................... 102

Psychological Gender Categories......................... 102

Means, Medians, and Standard Deviations by Variable......... 105 
LCLA Loneliness Scale -- Descriptive Statistics

Rosenberg Self-Esteem Scale-- Descriptive Statistics...

Gender Role Conflict Scale -- Descriptive Statistics

Psychological Gender -.. Descriptive Statistics...

Loneliness, Biological Gender, Psychological GenderDescriptive Statistics.

Self-Esteem, Biological Gender, Psychological Gender--

Descriptive Statistics.

Gender Role Conflict. Biological Gender, Psychologieal Gender-Descriptive Statistics...

Correlation Analysis

Gay Male Correlations

Lesbian Female Correlations.

BSRI Post Hoc Analysis

Biological Gender and Gender Role Conflict.

Psychological Gender and GRC

125

Psychological Gender and Loneliness

Psychological Gender and Self-Esteem

Relationship Status MANOVA

128

Relationship Status Post Hoc Analysis

Facior Analysis.

Factor Analysis Summary 137

Research Questions and Overall Results 141

V. DISCUSSION 
Summary of Major Findings $\ldots \ldots \ldots \ldots \ldots \ldots \ldots \ldots \ldots \ldots \ldots, 144$

Implications .......................................... 160

Recommendations..................................... 163

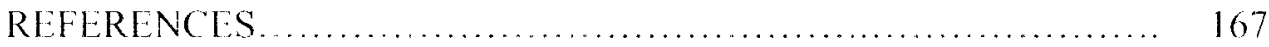

APPENDICES .............................................. 177

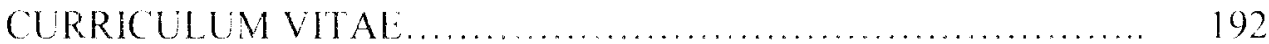




\section{LIST OI TABLLS}

TABLE

PAGL

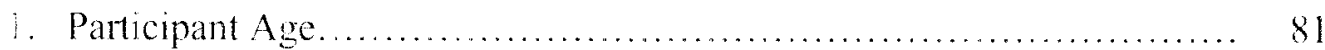

2. Participant Education.......................................... 82

3. Relationship Status......................................... 83

4. Income Level............................................. 83

5. For Research Questions 1 through 9 and 11 through 12, Dependent Variables, Effects Tested, Statistical Procedures, and Measurement of the Independent Variable Psychological Gender.................... 98

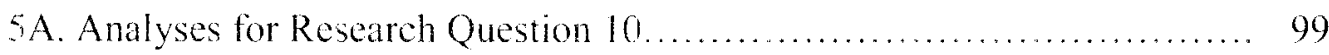

6. Comparison of Reliability Coefficients on the BSRI, RSES. UCLA Loncliness Scale, and the GRCS............................ 102

$\because \quad$ BSRI Psychological Gender Categorizations....................... 103

8. Descriptive Statistics by Major Variable - Gay Males................... 106

9. Descriptive Statistics by Major Variable -- Lesbian Females............ 106

10. UCLA Loneliness Scale Means, Medians, and Standard Deviations by Psychological Gender Category............................. 110

11. Rosenberg Self-Esteem Scale Means, Medians, and Standard Deviations by Psychological Gender Category............................ 111

12. Gender Role Confliet Scale Means. Medians, and Standard Deviations by Psychological Gender Category........................... 112

13. Gender Role Conflict Scale (SPC) Means, Medians, and Standard Deviations by Psychological Gender Category. 
14. Gender Role Conflict Scale (RE) Means, Medians, and Standard

Deviations by Psychological Gender Category.

15. Gender Role Conflict Scale (RAB) Means, Medians, and Standard

Deviations by Psychological Gender Category.

16. Gender Role Conflict Scale (CBWHR) Means, Medians, and Standard

Deviations by Psychological Gender Category.

17. Correlation Analysis (Combined Gay Male/Lesbian Female). 116

18. Male and Female Correlation Analysis

19. MANOVA Summary Table

20. MANOVA Summary Table (Relationship Status as IV).

21. Results of MANOVA with Independent Variables Bem Sex Role Inventory (BSRI) Categories and Biological Gender.

22. Comparison of Fit Statistics - Gay Male/Lesbian Female CFA. 138 


\section{LIST OF FIGURES}

FIGIJRE

PAGE

1. Illustration of the Formerly Popular Belief in the Unidimensionality and Bipolarity of Gender Roles................................ 16

2. Four Categories of the Bem Sex Role Inventory...................... 32

3. Intercorrelated Four-Factor Model for the GRCS - Gay Males.......... 139

4. Intercorrelated Four-Factor Model for the GRCS -- Lesbian Females....... 140 


\section{CHAPTER I}

\section{INTRODUCTION}

As corporate America and society at large have been challenged over the past few decades to become educated and tolerant of a diverse workforce and population, a better understanding of all types of people has become not only salient but crucial. It seems the trajectory for diversity, cultural inclusion, cnd equal rights in the United States began with the battles fought by African-Americans and women during the middle part of the $20^{\text {th }}$ century. Although those struggles continue to be faced today, the battlefield expanded to include other cultural minorities including sexual orientation minorities.

It was around the time that African-Americans and women began to gain equal rights in America that a renewed interest in psychological gender began to unfold. The common belief during that same time period regarding psychological gender was that the construct could be represented as a bipolar (M-F) and unidimensional construct (Bem, 1974, 1993; Spence, 1993). Because psychological gender was believed to be unidimensional, the relationship between masculinity and femininity was by default inverse. As people became less feminine, they were perceived to become more masculine (Spence, 1991). Conversely, as people became less masculine, they were believed to become more feminine. Scholars such as Bem, Corstantinople, and Spence theorized that perhaps this belief in unidimensionality and bipolarity did not truly capture the actual dynamics of the construct. Bem (1974) theorized about the potential for one individual to 
be androgynous, that is, to possess both masculine and feminine traits simultaneously. A female. for example, might possess leadership and assertive characteristics (e.g., masculine traits) in her job as a corporate executice while exhibiting nurturing and tendeness characteristics (e.g. feminine traits) in her role as a mother. Although belief in the unidimensionality of gender roles was axiomatic during the late 1960 s, empirical suppert for the multidimensionality of psychological gender roles proliferated the literature as researchers exammed the veracity of the unidimensionality assumption (Bem 1974: Constantinople. 1973).

Psychological gender is theoretically a function of both biological and sociological influences. The sociological influences are taught to most individuals from the earliest of ages. In North American culture, for example, female babies are dressed in pink while male babies wear blue. Females are taught to be nurturers and not to use harsh language while males are taught to be leaders and to never cry in public (Bem, 1974). Some individuals have these gender role expectations so deeply embedded within them that the individuals become sex-typed (Bem. 1974). A sex-typed male is one who exhibits primarily all masculine traits and litte to no feminine traits (Bem, 1974). A sextyped female. conversely, exhibits primarily all feminine traits and little to no masculine traits (Bem. 1974). A sex-typed individual often experiences great discomfort, stress and outright turmoil when gender incongruent behaviors become necessary (Bem \& Lenney, 1976; O’Neil, Helms. Gable, David, \& Wrightsman, 1986). The sex-typed male shedding tears at the funcral of a loved one, for example, would likely be uncomfortable with his public display of emotion. 
North American culture seems to value masculinity more highly than femininity (McCreary, 1994). Psychological gender characteristics that are stereotypically masculine have a higher degree of social desirability and status than characteristics that are stereotypically feminine (Long, 1989. 1993; Safir. Rosenmann, \& Kloner. 2003; Sandfort, 2005). Because masculinity is so highly valued, feminine traits exhibited by an otherwise masculine person are discouraged (MeCreary, 1994).

Although gender incongruent behaviors are discouraged in both sexes, society tends to be less forgiving of male transgressions into femininity than of female transgressions into masculinity (McCreary, 1994). An asymmetry cxists in the manner by which men and women are treated when they display psychological gender role behaviors deemed inappropriate by society. A "tomboy" girl is typically more acceptable than is a "sissy" boy (Long. 1989; Safir, Rosenmann, \& Kloner, 2003). When a female deviates in some way from the acceptable feminine role, the assumption is that she is altering her behavior in a way that is higher in social status, prestige, and desirability. A male displaying feminine behavior, however, is believed to be altering his actions in a statuslowering manner (McCreary, 1994). There are limitations, however, to the acceptability of "tomboyish" behavior in females. Females can be tomboys unt l their behaviors result in societal questions regarding sexual orientation. Gender incongruent behaviors are somerimes equated to deviations into socially unacceptable homosexuality; therefore, extreme deviations from assigned psychological gender roles are discouraged (McCreary, 1994).

One construct relevant to psychological gender theory is gender role conflict. This construct has received a great deal of attention since 1984 and occurs when psychological 
gender is incongruent with biological gender. It has sometimes been described, within men, as an actual fear of femininity $\left(0^{\circ}\right.$ Neil et al.. 1986). Several studies, which will be reported in the following chapter, examined the dimensionality of gender role conflict as operationally defined in the Gender Role Conflict Scale. Additionally, several studies reported four factors of the construct. These factors have been labeled (a) Success, Power, and Competition; (b) Restrictive Emotionality; (c) Restrictive Affectionate Behavior Between Men; and (d), Conflict Between Work and Family Relations. The factors and dimensionality of gender role conflict will also be discussed in greater detail in the following chapter.

Research has shown that there is significant mental health consequences associated with gender role conflict (Good \& Mintz, 1990). When a sex-typed, biological male s called upon to exhibit feminine characteristics or when a sex-typed, biological female is called upon to exhibit masculine characteristics, significant psychological distress can sometimes ensue. Psychological distress can result in negative mental health repercussions such as decreased self-esteem and increased loneliness in both males and females (Good \& Mintz. 1990). Significant gender differences have been found in the literature regarding gender role conflict and mental health variables such as self-esteem and loneliness. These differences will be elucidated in the following chapter of this dissertation.

Individuals within the gay and lesbian (GL) community could suffer from gender role conflict. As previously mentioned, gender role conflict occurs when there are differences between biological gender and psychological gender (O'Neil et al., 1986). Research has shown that gay males are often more psychologically androgynous or 
feminine than their heterosexual counterparts while lesbians are often more psychologically androgynous or masculine than their heterosexual counterparts (Hooherman. 1979). A feminine male or a masculine female is a clear violation of socially sanctioned gender roles. These findings, in conjunction with the fact that society disapproves of psychological gender role violations in general, might be partially responsible for the negative social attitudes toward homosexuality.

Social attitudes toward perceived sexual deviancy have been negative for many years. Although societal attitudes are slowly improving, the general consensus continues to be that sexual proclivities other than heterosexuality are socially unacceptable (Herek \& Berrill, 1992; McKee \& Hayes, 1994). These negative social attitudes toward homosexuality have resulted in verbal and physical attacks against gays and lesbians (Huebner, Rebchook, \& Kegeles, 2004). It is not surprising, given the fact that the majority of waking hours are typically spent within the workplace milicu, that antigay sentinents and discrimination have found their way into workplaces across the globe (Day \& Schoenrade, 2000: Ragins \& Comwell, 2001; Waldo, 1999). Workplace heterosexism. similar to racism and sexism, can naturally result in detrimental consequences for gay and lesbian (GL) employees. These negative consequences, however, can often extend beyond the GL victims. Negative repercussions, including mental health consequences. can often be felt by employers as well as heterosexual employees working in a heterosexist environment (Waldo. 1999).

Researchers have frequently examined the mental health consequences of living as a member of a minority group (Brewer \& Weber, 1994). Suffering the effects of prejudicial and discriminatory behaviors and actions can often result in mental health 
consequences including decreases to self-esteem and increases in loneliness and depression (Balsam, Beauchaine, Mickey, \& Rothblum, 2005: D'Augelli \& Grossman, 2001). Researchers have reported that minority group members can sometimes deflect the negative mental health effects of discriminatory victimization by attributing the belaviors and actions to discrimination against an entire group of people as opposed to internalizing the actions as directed exclusively toward the individual (Crocker \& Major, 1989). It has further been demonstrated that, if the discriminatory behavior was instigated by a person not deemed significant (e.g., a stranger), negative mental health effects may be minimal (Crocker \& Major, 1989; Rosenberg, 1979). An individual deemed significant, conversely, such as a parent or spouse, can sometimes cause significant damage to the mental health of the victim (Crocker \& Major, 1989).

\section{Statement of the Problem}

Given the number of empirical studies used to examine minority status discrimination such as racism and sexism on various mental health variables, it seems timely thatresearchers examine the effects of sexual orientation status on those same mental health variables. Although several studies, as will be summarized in the following chapter, have examined the relationships between (a)biological gender and mental health, (b) psychological gender and mental health, (c)gender role conflict and ment al health, and (d) the relationships among biological gender, psychological gender, gender role conflict, and mental health, few studies have simultaneously assessed the relationships between biological gender, psychological gender, gender role conflict, and mental health (e.g., self-esteem and loneliness) in a sample of gay and lesbian individuals. 
As will be reported in the following chapter of this dissertation, several studies have examined the self-esteem component of mental health concomitantly with the aforementioned variables. Few researchers, however, have examined loneliness simultaneously with biological gender, psychological gender, gender role conflict, and self-esteem in a sample of gay men and lesbian women. In fact, researchers have yet to examine these variables simultaneously in a lesbian sample. The lack of empirical research in loneliness is partially due to the relatively recent genesis of research interest in that particular construct. Loneliness is reportedly becoming a mental health issue for many demographic groups including males and females, young and old, and heterosexuals and homosexuals. In addition, research instruments with acceptable psychometric properties have recently been developed to measure the construct, helping to revive research interest in that area. A study designed to examine relationships among biological gender, psychological gender, gender role conflict, self-esteem, and loneliness in gay men and lesbian women would add significant and necessary research to the extant literature.

\section{Significance of the Study}

Myriad studies have demonstrated that psychological gender has significant relationships with sexual orientation and mental health constructs. Many of these studies are reported in the following chapter. Homosexuals, for example, have commonly been shown to exhibit higher levels of androgyny than have heterosexuals (Lippa \& Arad, 1997; Meycr, Blissett, \& Oldfield, 2001). In addition, many researchers have found little to no difference in levels of masculinity between male and female homosexuals and heterosexuals. Femininity has often been shown to have little or even a negative 
relationship to mental health variables such as self-esteem (Antill \& Cunningham, 1980). In addition, some researchers have shown that prejudice and discrimination related to sexual orientation status results in deleterious mental health consequences such as decreased self-esteem, increased loneliness, and increased depression for minority group members (D'Augelli \& Grossman, 2001; D'Augelli, Grossman, Hershberger, \& O'Connell, 2001; Feather, 1985). An understanding of the aforementioned variables is important and noteworthy. It is also important, however, to understand the relationship that gender role conflict has on each variable individually as well as to understand the dynamics of all variables simultaneously.

Although this study will not directly examine the effects of GL discrimination on gender role conflict, self-esteem, and loneliness, the potential significance of these mental health variables in GL individuals may be particularly pertinent to employers and mental health professionals alike. Employers and mental health professionals cognizant of the deleterious mental health effects of classification as a "sexual deviant" will be better equipped to meet the needs of individuals living within the GL community.

\section{Research Questions}

1. For homosexual individuals, is there a significant interaction between psychological gender and biological gender on gender role conflict?

2. Is there a significant main effect of psychological gender on gender role conflict?

3. Is there a significant main effect of biological gender on gender role conflict?

4. For homosexual individuals, is there a significant interaction between psychological gender and biological gender on self-esteem?

5. Is there a significant main effect of psychological gender on self-esteem? 
6. Is there a significant main effect of biological gender on self-esteem?

7. For homosexual individuals, is there a significant interaction between psychological gender and biological gender on loneliness?

8. Is there a significant main effect of psychological gender on loneliness?

9. Is there a significant main effect of biological gender on loneliness?

10. For homosexual individuals, what is the factor structure of the Gender Role Conflict Scale'?

11. For homosexual individuals, is there a significant difference in self-esteem based upon relationship status (i.e., single, in a non monogamous relationship, in a monogamous relationship, in a heterosexual marriage)?

12. For homosexual individuals, is there a significant difference in loneliness based upon relationship status (i.e., single, in a non monogamous relationship, in a monogamous relationship, in a heterosexual marriage)?

\section{Limitations}

This research study has limitations common to most field research. First, it is virtually impossible to find a truly random sample of GL individuals. Sampling techniques commonly used in GL research include finding participants from GL organizational mailing lists, placing advertisements in GL papers and in gay bars, identifying participants at social gatherings of GL individuals such as gay pride picnics, and utilizing snowball sampling techniques. All of these methods of finding research participants have limitations. The concern is that most people on a GL organizational mailing list could represent individuals who might be considered activists in the GL community. Individuals who attend GL functions or who frequent gay bars are probably 
more representative of those GL people who are more "open" and comfortable with their sexual orientation. In addition, those GL participants frequenting gay bars are typically younger in age. Finally, the problem with the snowball sampling technique is that the researcher typically finds participants similar to one another due to the fact that people tend to develop friendships with those who hold common interests. All of these reasons culminate in difficulties in finding a true sample that is generalizable to the greater GL population, especially those GL individuals who are more "closeted" with their sexual orientation and who choose to not socialize within the GL community.

A second limitation to the study relates to the use of a nonexperimental design. Because an experimental design was not used, it would be impossible to make causal inferences about the effects of one variable on another variable, especially when there are so many variables involved. A third limitation relates to the fact that self-report measures alone were used to gather data. Common method variance is typically a concern of the researcher when self-report measures alone are used to gather data. Because several constructs were measured in one study and self-reporting measures were used to gather data on all of them, the possibility of correlations resulting from one assessment method alone must be recognized.

\section{Delimitations}

The scope of this study is restricted by several delimitations. Most of these delimitations result from the fact that the sample is comprised of GL individuals. First, the sample is strictly comprised of GL persons "open" with others regarding their sexual orientations. These people are comfortable enough with their sexual orientations to live their lives partially, if not completely, as a person of a homosexual persuasion. Those 
persons who choose to keep their sexual orientations hidden from others could obviously not participate in this study. In addition, many closeted GL individuals live their lives quietly in heterosexual marriages. Identification of these individuals would be theoretically impossible. The study is further delimited by the fact that bisexual persons (i.e., persons sexually aroused by both sexes) are not included in study results. The number of participants who self-identified as bisexual, especially among male participants, was not large enough to make statistical inferences meaningful. This study also does not include transgender persons. Transgender individuals are defined as those persons who do not conform to societal expectations of gender norms associated with biological sex. This is an umbrella term that describes a biological male who feels like a female on the inside or a biological female who feels like a male internally (Marx \& Katz, 2006). It is believed that transgender individuals represent a unique population with very different life experiences than the general GL population. In addition, the mere fact that a person self-identifies as transgender does not necessarily mean that person is a member of the GL community.

This study is further delimited by the fact that levels of global self-esteem in GL participants were explored as opposed to levels of collective self-esteem. The term global self-esteem is used to refer to feelings of personal self-worth. The term collective selfesteem, however, is used to refer to the evaluation of the worthiness or value of a social group of which an individual is a member (Crocker \& Major, 1989). Collective selfesteem, although certainly worth examining, is beyond the scope of this dissertation. In addition, subdimensions of global self-esteem such as physical attractiveness and 
competency self-esteem among many others will not be examined. This study is strictly delimited to global levels of self-esteem.

\section{Definitions}

Psychological Gender has been defined as a set of beliefs and opinions about men and women and about supposed characteristics of masculinity and femininity (Deaux \& Kite, 1987; Whitley, Jr., 2001). Both men and women are socialized from an early age to behave in socially appropriate manners. Females, for example, are often taught to be nurturing and relatively submissive. Males, conversely, are often taught to be aggressive, to demonstrate leadership characteristics, and to refrain from showing excessive emotion.

Gender Role Conflict is defined as "a psychological state where gender roles have negative consequences or impact on a person or others" (O’Neil, Helms, Gable, David, \& Wrightsman, 1986, p. 336). A biological male who is psychologically feminine would likely suffer from gender role conflict. A biological female, conversely, who is psychologically masculine would likely suffer from gender role conflict.

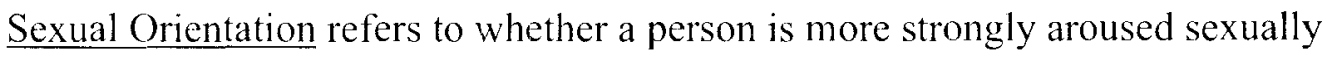
by members of his or her own sex (homosexual), the opposite sex (heterosexual), or both sexes (bisexual) (Bailey \& Zucker, 1995). For the purposes of this dissertation, the term "gay" will refer to homosexual men while the term "lesbian" will refer to homosexual women. Because sexual orientation is often a socially acrimonious topic, many GL individuals choose to live their lives "closeted." The term "closeted" refers to the decisions made by many GL individuals to hide their sexual orientations from others. GL participants involved in the current study were, at a minimum, partially open to others 
regarding sexual orientation status due to the fact that participants voluntarily completed an electronic survey.

Self-esteem is commonly defined as personal and global feelings of self-worth, self-regard, or self-acceptance (Rosenberg, 1979). High levels of self-esteem refer to highly positive global evaluations of the self. Low levels of self-esteem refer to negative evaluations of the self (Baumeister, Campbell, Krueger, \& Vohs, 2003).

Loneliness is "being without company" or "cut off from others"; "a sense of sadness from being alone" (Merriam-Websters Collegiate Dictionary, 2003, p. 798). Most definitions of loneliness focus on perceived social relationship deficits (Stokes \& Levin, 1986). Fromm-Reichmann (as cited in Solano, Batten, \& Parish, 1982) stated that the repercussions of loneliness are negative emotional consequences that range from mild discomfort to strong pain.

The following chapter will report the vast amount of extant literature examining varying combinations of biological gender, psychological gender, gender role conflict, self-esteem, and loneliness in both heterosexual and homosexual samples. The third chapter will present the methodology for a new study designed to examine the interrelationships among these variables while the fourth chapter will present the results of the study. Finally, the fifth chapter will present a discussion of the study and the relative implications. 


\section{CHAPTER II}

\section{LITERATURE REVIEW}

A review of psychological gender roles, gender role conflict, and certain mental health constructs such as self-esteem and loneliness will be presented. The major construct, psychological gender roles, will be presented first followed by a discussion of the extant literature surrounding self-esteem, loneliness, and gender role conflict. The purpose of this dissertation is to examine the interrelationship of biological gender, psychological gender, and gender role conflict on the mental health of gay and lesbian (GL) individuals.

\section{Psychological Gender Roles}

Psychological gender roles have been defined as a set of beliefs and opinions about men and women and about supposed characteristics of masculinity and femininity (Deaux \& Kite, 1987; Whitley, Jr., 2001). The term psychological gender role is used interchangeably with the term gender role throughout this dissertation. Psychological gender role refers to the degree to which individuals adopt traits traditionally associated with men and women ( $\mathrm{Lu} \& \mathrm{Wu}, 1998)$. O'Neil (as cited in Silva, 2002) defined gender roles as the non-physiological components of gender that are regarded as culturally appropriate. Because the empirical trajectory for understanding gender roles in addition to masculinity and femininity has been lengthy and even discordant at times, the section of this literature review dedicated to understanding the construct is presented in 
chronological order. It is believed this will foster the organization of the great deal of work completed by leading gender role scholars. It is first necessary to establish a general definition of the terms masculinity and femininity prior to discussing the theoretical development of psychological gender roles. Masculinity and femininity are well established terms used freely by scholars and laypersons alike. Because these terms are so commonly used, however, it is surprising when an educated adult is asked to define what he or she means when using these terms and little enlightenment is provided (Hoffman, Borders, \& Hattie, 2000; Spence \& Buckner, 1995). Masculinity and femininity (M-F), even with a lengthy history in psychological discourse have been among the most difficult concepts to define (Constantinople, 1973). Although M-F consists of component pieces, there does appear to be one component that is more significant than others. The one component that is common to many measurement instruments is reliance on an ability to differentiate male responses from female responses. As a result, masculinity and femininity is at least partially defined in terms of biological gender differences (Constantinople, 1973).

Bakan (as cited in Bem, Martyna, \& Watson, 1976) proffered that masculinity is connected with an agentic orientation, a concern for oneself. Conversely, femininity is associated with a communal orientation, a concern for relationships with others. Researchers believe that individuals acquire and internalize assigned psychological gender role characteristics; and, as a result, masculinity and femininity are tantamount to trait predispositions that correspond to the socially approved behavioral differences between men and women (Spence \& Helmreich, 1978). 


\section{Dimensions of Gender Roles}

Masculinity and femininity have been traditionally viewed as a unidimensional and bipolar construct (Bem, 1974; Spence, 1993). According to this model, the psychological traits and behaviors used to differentiate males from females contributed to a single M-F factor (Bem, 1974; Spence, 1993). It was believed that people could be equated to one point on a single, hypothetical, bipolar continuum (Spence, 1993). The gender role relationship was believed to be unidimensional in that highly feminine persons fell at one extreme and highly masculine persons fell at the other (Spence, 1991). Accordingly, a person could be masculine or feminine, but not both (Bem, 1974). This common belief is demonstrated in the Figure 1 :

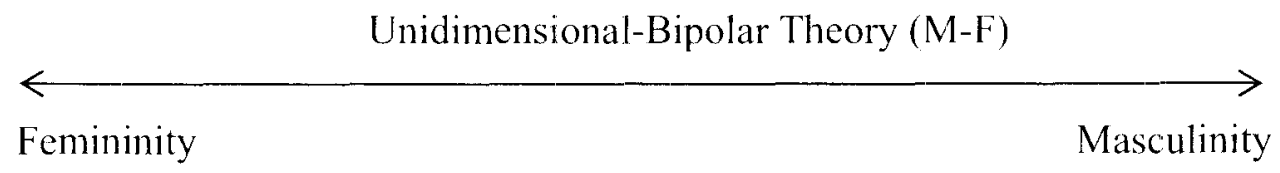

Figure 1. Illustration of the formerly popular belief in the unidimensionality and bipolarity of gender roles.

Constantinople (1973) proffered that the bipolarity assumption of M-F was evident in the existing measurement instruments in at least three ways: (a) the dependence on biological gender alone was used as the appropriate criterion for determining an item's M-F relevance. Items were constructed in a manner as to differentiate between a biological male and a biological female; (b) the assumption that the opposite of a masculine response was a ferninine response, especially when only two options were provided to participants; and (c) instruments utilized a single M-F score that was used to place individuals at one place on a single, bipolar continuum. Several 
existing studies and instruments were analyzed for evidence of validity of the bipolarity assumption. It was discovered, for example, that male and female participants sometimes scored high on both same-sex and opposite-sex scales, thus providing evidence that masculinity and femininity may not be a bipolar construct at all (Constantinople, 1973).

Although the measurement of $\mathrm{M}-\mathrm{F}$ as a unidimensional, bipolar construct was axiomatic in a historical sense, Constantinople posited that modicum evidence existed to support the assertion that extant scales measured a construct that served to undergird unidimensionality and bipolarity. Constantinople (1973) conducted a correlational analysis of the major existing M-F measurement scales. It was believed that, to support the unidimensionality theory, correlations between existing scales should be high. The results revealed medium to low correlations (i.e., males: .32 to .53 ; females: .20 to .55 ), serving to support the assertion of multidimensionality. A summary of factor analytic results further supported the possibility that masculinity and femininity were multidimensional in nature. Researchers repeatedly extracted multiple factors from data using both male and female participants (Constantinople, 1973).

A person furthermore would derive different estimates of relative levels of $\mathrm{M}-\mathrm{F}$ dependent upon the behaviors sampled at any given time. Constantinople began to proffer that perhaps, in addition to, or instead of, the unidimensional, bipolar (M-F) theory of masculinity and femininity, there could potentially exist two separate and measurable dimensions of masculinity and femininity. Assuming M-F were in reality a multidimensional construct, a single $\mathrm{M}-\mathrm{F}$ score that could ignore subtracts in masculinity and femininity would not be as appropriate as a profile of various measured subtract scores (Constantinople, 1973). 
Other theorists concurred with Constantinople and began to question the validity of the unidimensionality and bipolarity theories. Carlson (as cited in Constantinople, 1973 ) proposed that many dualities inherent in human nature might better be viewed as interactive forces working together in a complex manner toward integration. As a result of the increasing professional skepticism, an array of studies was completed in the hopes of further elucidating the dynamics of the construct. Research secmed to suggest that multidimensionality, as opposed to unidimensionality, was the relevant dimension in psychological gender studies.

Bem, along with Constantinople, was among the initial scholars in gender role studies to question the validity of the unidimensionality and bipolarity theory. Both in psychology and in society at large, masculinity and femininity have long been represented as bipolar ends of a single continuum. An individual, hence, had to be either masculine or feminine, but could not be both (Bem, 1974). Whereas earlier researchers focused on those individuals who fell at the extreme ends of the M-F distribution, Bem focused on those individuals who were in the middle of the distribution (Spence, 1993). Bem proffered that the dichotomous view of gender roles ignored two plausible hypotheses. The first hypothesis was that many individuals might actually be androgynous. People might possess characteristics that are concurrently masculine and feminine, assertive and yielding, or instrumental and expressive (Bem, 1974). Any of these behaviors could potentially surface, dependent upon the situational appropriateness of the given behavior. Persons exhibiting a relatively high degree of both masculinity and femininity are labeled androgynous (Spence \& Helmreich, 1978). Bem's second hypothesis regarding the unidimensionality and bipolarity theory was that strongly sex- 
typed individuals, as defined below, might be gravely limited in the range of behaviors made available to them as they move through different situations (Bem, 1974).

Kagan and Kohlberg (as cited in Bem, 1974) defined a sex-typed individual as one who is highly motivated to exhibit traits consistent with socially sanctioned and expected behaviors for his or her biological sex. A sex-typed male will make a calculated effort to suppress behaviors deemed inappropriate for his sex while a sex-typed female will suppress traits considered masculine by society (Bem, 1974). A male who exhibits high levels of masculinity would likely inhibit behaviors stereotyped as feminine while a female who exhibits high levels of femininity would likely inhibit behaviors stereotyped as masculine (Bem, 1974). Bem believed that the sex-typed male could be characterized as assertive, aggressive, and one who typically acts as a leader while the sex-typed female could be characterized as dependent, yielding, and cooperative (Bem, 1974).

The veracity of Bem's theory of androgyny would potentially nullify the validity of the unidimensionality and bipolarity theory. Bem created an instrument, the Bem Sex Role Inventory (BSRI), to foster the measurement of gender roles, including androgyny (Bem, 1974). The BSRI will be further discussed in a later section of this literature review. Bem administered the BSRI to a sample of 444 males and 279 females and correlated the results with participant scores from two commonly used gender role measurement instruments. The correlations were not significant which was indicative that the BSRI measured an aspect of gender roles not measured by the other scales. It was demonstrated that $34 \%$ of male participants and $27 \%$ of female participants were categorized as androgynous, indicating high levels of both masculine and feminine 
characteristics (Bem, 1974). This study provided support for the multidimensional assertion of psychological gender roles.

A number of researchers began to adopt the multifactorial approach to gender roles as a more realistic alternative to the traditional unifactorial model (Spence, 1993). With the mounting support from empirical studies, especially factor analytic studies, scholars began to hypothesize that masculine and feminine traits may indeed coexist in the same individual. Norland, James and Shover (1978) were among the early researchers to empirically test the assumptions of unidimensionality and bipolarity. The researchers believed that, for the bipolarity assumption to be supported, the relationship between scores on femininity and masculinity scales should have a negative correlation. Although the resulting relationship was indeed negative, it was not at all strong, $r=-.13, p<.05$. The researchers further stated that, to support the unidimensionality assumption, one would expect individual item correlations to be negative; however, 11 of 25 correlations were positive. The findings were further supported when factor analysis results extracted nine factors. If the unidimensionality assumption were truly valid, the researchers would logically have anticipated only one resulting factor. Study results did not support unidimensionality or bipolarity thus lending further support to multidimensionality.

\section{Gender Roles and Socialization}

Men, women, and children are expected to behave in socially sanctioned ways regarding gender roles. Children are taught appropriate gender roles at very early ages (Bem, 1974). To foster conformance to societal expectations, children learn appropriate behaviors from role models early in life. Many researchers wondered how the impact of individuals deemed "significant others" would influence the gender role socialization 
process. Myriad theories were used to attempt to clucidate the dynamics of the socialization process including the social learning theory which emphasized observational learning using venues such as general media and social presentations (Lucptow, 1980).

The relative influence of fathers and mothers on the gender role socialization process of children was examined by Lueptow (1980). It was shown that over one-third of male participants reported that both parents were influential while another one-third reported that neither parent was influential. Approximately $11 \%$ of the male participants, however, reported that only the mother was influential while approximately $20 \%$ reported that only the father was influential. Of the female participants, approximately $37 \%$ reported that both parents were influential. Approximately $23 \%$ of the female participants reported that only the mother was influential while approximately $8 \%$ reported that only the father was influential. These findings supported the assertion that, when only one parent was influential, it was more likely to be the parent of the same biological gender indicating that children were overall more heavily influenced by the parent who possessed similarly sanctioned gender role expectations.

Lueptow (1980) further addressed whether fathers played major roles in determining instrumental-expressive orientations of both males and females or whether same gender influences determined gender role orientations. Only one statistically significant item was found. Fathers were found to influence the expressive orientation of females $(p=.022)$. Female participants who were mostly influenced by fathers were shown to be more expressive than were the females influenced mostly by mothers. The finding that fathers were influential in the development of daughter expressive 
orientations was somewhat unexpected. This finding supports the assertion that, even though individuals often choose same-gendered role models, male role models may be more influential in determining gender role orientations than are female role models for both males and females.

As previously stated, children are socialized at the earliest of ages to conform to socially sanctioned gender roles. Researchers have examined the likelihood of children to conform to gender role societal expectations. Lynn (1976) completed a study to examine the tendencies of children to imitate certain adults. The purpose of the study was to determine if male children would choose to imitate male role models such as fathers or male strangers; or, if the same male children might choose to imitate mothers or female strangers. Statistical significance was found in the number of boys who chose to imitate male strangers $(\mathrm{n}=20)$ as opposed to female strangers $(\mathrm{n}=10), p={ }_{.02} 8$. The researchers, however, found that boy participants chose not to imitate the fathers any more than they chose to imitate male strangers. It was further reported that, overall, the boys chose to imitate masculine figures as opposed to feminine ones. Although the sample was small, this study demonstrated that males are socialized to imitate stereotypically male traits.

Further evidence that individuals are socialized to conform to stereotypically defined gender roles was provided by Bem and Lenney (1976). The researchers desired to specifically examine the likelihood that participants would avoid cross-sexed behaviors. Cross-sexed behavior occurs when a biological male exhibits stereotypically feminine traits or when a biological female exhibits stereotypically masculine traits. The researchers further examined if a decrease in self-esteem would result from a sex-typed 
participant's involvement in a cross-sexed activity. Study results revealed a significant main effect of sex, $F(1,132)=104.65, p<.001$ and demonstrated male participants were more likely to choose certain activities when no gender role conflict was involved.

When gender role conflict was introduced, females became more likely to choose the conflicting activities. The analysis of variance further identified a significant main effect of gender role, $F(2,132)=6.42, p<.005$. Female participants were more comfortable in gender-reversed roles than were the male participants. This makes sense as the literature shows that it is more socially acceptable for females to deviate from assigned gender roles than it is for males to commit the same social transgression (Bem \& Lenney, 1976). Study results further revealed a significant gender role effect in negativity scores, $F(2,132)=7.57, p<.001$. Negativity scores were used to analyze how poorly participants felt about themselves (e.g., self-esteem) when performing cross-sexed activities. It was shown that sex-typed participants felt much worse about themselves after performing a cross-sexed activity than did other participants, $t(141)=3.87, p<.001$. This study demonstrated that cross-sexed behavior is often avoided by sex-typed individuals. In addition, cross-sexed behaviors can result in negative mental health outcomes for sexed-typed individuals.

O'Heron and Orlofsky (1990) suggested that people who deviate from assigned gender role stereotypes by failing to develop normative levels of sex-typed personality characteristics have a weaker sense of gender identity, as defined below, than those individuals who succumb and adhere more closely to assigned gender role stereotypes. The researchers defined gender identity as a person's sense of self as a woman or a man in addition to a global sense of femininity and masculinity. For men, gender identity was 
related to stereotypical traits of masculinity. Those males with high M traits (masculinetyped and androgynous) scored higher than low M males in gender identity. Masculinetyped women, however, scored lower than other groups in gender identity. The researchers suggested that the results revealed that women high in self-assertive traits and low in expressive traits perceived themselves as less feminine. Such deviations from socially assigned gender roles are more common among members of the GL community than among the heterosexual population (Lippa \& Arad, 1997).

\section{Gender Roles and GL Socialization}

Myriad studies have revealed that members of the GL community often deviate from socially assigned gender roles (Lippa \& Arad, 1997; Sandfort, 2005). Partially as a result of these deviations, prejudice against the GL community continues to exist in American and, indeed, other cultures (Leets \& Giles, 1997; Van Der Meer, 2003). Although progress has been made in understanding the gay and lesbian lifestyle, perhaps one of the more divisive debates in North American culture continues to center on sexual orientation. The vast majority of Americans continue to believe that homosexuality is socially unacceptable. There is a cultural stigma attached to the GL community that is taught early in childhood along with the concomitant privileging of heterosexuality. Children are taught to scream the word faggot as a pejorative before they know what the word means (Frable, Wortman, \& Joseph, 1997). Individuals categorized as GL are often subjected to negative social repercussions (Waldo, 1999). These negative social attitudes are sometimes manifested in the form of prejudicial behaviors.

Researchers have reported on social attitudes based upon empirical findings. For instance, Herek (1984) conducted a factor analytic study to examine the components of 
attitudes toward GL people and reported a two-factor structure of attitudes. The first factor, labeled the Belief Factor, loaded statements such as "Male homosexuals tend to be very feminine," "Most lesbians are generally afraid of men," and "Male homosexuals are more likely to seduce young people than are heterosexuals," This factor tended to measure beliefs about GL people as opposed to actual attitudes. The second factor, labeled the Condemnation-Tolerance Factor, was a measure of attitudes toward GL individuals. Items that loaded on this factor included statements that characterized the gay lifestyle as disgusting, unnatural, sinful, and perverse (Herek, 1984).

Although attitudes toward the GL community have become less hostile in recent years, the majority of Americans continue to view homosexuality as morally unacceptable (Whitley, Jr., 2001). Much of this prejudice is manifested in the form of verbal and physical attacks. It has been reported that $50 \%$ of GL students surveyed for a particular study reported overhearing disparaging comments about the GL community, $26 \%$ experienced verbal insults, $26 \%$ reported personal threats of physical assault, and $23 \%$ reported being the victirns of assault (Kite \& Deaux, 1986). Hunter (1990) reported that $46 \%$ of participants experienced violent physical assaults related to sexual orientation. In addition, $61 \%$ of the violent assaults occurred within the family. Research suggests familial reactions are still overall quite negative. Difficulties with family members can range from feelings of isolation and alienation to actual violence and even expulsion from the family home (Martin \& Hetrick, 1988).

D'Augelli (1989) examined patterns of victimization of gay men and lesbian women. Some of the interesting findings included the fact that $26 \%$ of the participants had been verbally insulted once and $26 \%$ had been physically threatened. Objects had 
been thrown at $12 \%$ of the participants, while $5 \%$ had been spat upon and $4 \%$ had been punched. It was reported that gay male participants were victims of more verbal insults, $\chi^{2}(2)=9.45, p<.05$ than fernale participants. It was further shown that only $8 \%$ of the lesbian women received threats of violence as opposed to $35 \%$ of the gay men, $\chi^{2}(2)=$ $9.22, p<.01$

The results of these multiple studies demonstrate very clearly that societal attitudes remain negative and often result in GL discrimination, harassment, violence, and victimization. These acts of victimization frequently result in harmful physical and mental health consequences to the victims including decreased self-esteem, increased loneliness, and increased suicidal ideation (Balsam, Beauchaine, Mickey, \& Rothblum, 2005; Savin-Williams \& Ream, 2003).

Workplace Heterosexism.

Heterosexism is defined as "an ideological system that denies, denigrates, and stigmatizes any nonheterosexual form of behavior, identity, relationship, or community" (Herek \& Berrill, 1992, p. 150). A second definition of heterosexism is that heterosexuality is in all manners superior to other sexual orientations or proclivities. Like racism, sexism, and ageism, heterosexism awards power to those persons of the dominant status and discriminates against those persons without power (McKee \& Hayes, 1994).

The workplace is not exempt from negative social attitudes toward mernbers of the GL community. Even though the majority of the population is surely aware that workplace discrimination is ethically and sometimes legally unacceptable in most any form, it is a well-known fact that discriminatory practices continue to exist within many milieus. Because most people spend the majority of their waking hours in the workplace 
environment, researchers realize that understanding the effects of workplace heterosexism is a necessity. Ragins and Cornwell (2001) tested a model of perceived workplace sexual orientation discrimination to determine which antecedent factors (e.g., supportive policies and practices, and the presence of GL coworkers and supervisors) had the greatest impact on perceptions of workplace discrimination.

It was reported that GL employees perceived significantly less workplace discrimination when supervisors were also GL, $r=-.16, p<.001$. This was a weak and negative correlation which indicated that as the number of gay supervisors increased, perceived discrimination decreased. GL employees further reported less perceived workplace discrimination when a higher proportion of GL coworkers were in their work groups, $r=-.27, p<.001$. This correlation, however, was also found to be rather weak and negative. Another weak and negative correlation was found between the degree of supportive workplace policies and practices and reported workplace discrimination, $r=-.28, p<.001$. The workplace practice that resulted in the greatest impact on perceived discrimination was whether same-sex partners were welcomed at company social events, $r=-.60, p<.001$. This correlation was found to be moderate to strong and negative which indicated that, as same-sex partners were welcomed at social events, perceptions of heterosexism decreased. Other factors resulting in significant, although weak and negative, relationships to perceived workplace discrimination included whether antidiscrimination policies included sexual orientation, $r=-.22, p<.001$, and whether same-sex domestic partner benefits were offered by the organization, $r=-.21, p<.001$.

The researchers were not surprised to discover that the level of perceived workplace discrimination significantly correlated with the degree of sexual orientation 
disclosure in the workplace. A moderate and negative correlation was found between perceived discrimination and organization-based self-esteem $(r=-.41, p<.001)$. Overall, the researchers demonstrated that the perception alone of a discriminatory workplace environment can have deleterious consequences for both the employer and the employee.

A second workplace study was completed by Day and Schoenrade (2000). The purpose of this study was to investigate myriad GL workplace issues including the effects of sexual orientation disclosure and the impact of antidiscrimination policies and top management support on employee organizational commitment. The level of sexual orientation disclosure was found to be significantly related to employee commitment to the organization. It was reported that disclosure of sexual orientation accounted for $4 \%$ of the overall variance in commitment. It was further reported that GL employees more open about their sexual orientation were more likely to be psychologically committed to their organizations.

Commitment was shown to have a significant, positive relationship to the presence of an organizational antidiscrimination policy. Employee commitment was greater when organizations had an antidiscrimination policy. Commitment was further shown to be significantly related to levels of top management support for antidiscrimination policies. As perceived top management support for antidiscrimination policies increased, GL employee commitment increased. It was suggested that perhaps organizations with policies that prohibit discrimination based upon sexual orientation tend to be typically more progressive and concerned about overall employee welfare. It appeared that, in general, supportive organizations led to more committed employees. 
Unlike the Day and Schoenrade (2000) study, Smith and Ingram (2004) examined the effects of unsupportive social interactions and heterosexism within the workplace on mental health. The measurement instrument of workplace heterosexism and unsupportive social interactions included two subscales, the "Minimizing" and the "Blaming" subscales. It was reported that the "Minimizing" subscale measured items intended to downplay an event or to even force optimism about the event. An example would be "Someone believed I was overreacting to the perceived heterosexist occurrence." The "Blaming" subscale measured faultfinding such as "Comments were made which were intended to make me feel the blame for sensing heterosexism."

Bivariate correlations demonstrated that heterosexism had statistically significant positive correlations with unsupportive social interactions (i.e., minimizing $r=.64, p<$ .001 ; blaming $r=.73, p<.001)$ and mental health symptoms $(r=.36, p<.001)$. These moderate to strong correlations indicated that, as heterosexism increased, unsupportive social interactions increased, and symptoms of mental health issues increased.

Minimizing unsupportive social interactions had significant and moderate positive correlations with mental health symptoms $(r=.36, p<.001)$. Blaming unsupportive social interactions, however, were not significantly correlated to any of the outcome variables.

Waldo (1999) was also interested in examining the mental health effects of workplace heterosexism. The researcher assessed the impact of workplace heterosexism on minority stress levels. It was proffered that, when heterosexism occurs, GL employees would experience minority stress and would be more likely to exhibit negative mental health outcomes. The researcher further hypothesized that relatively more "out" 
employees and those who were relatively more "closeted" would experience greater amounts of minority stress. Those employees who were less "out" were hypothesized to experience greater levels of indirect (covert) workplace heterosexism (e.g., stress from others assuming they are heterosexual) while those employees who were more "out" were hypothesized to experience greater levels of direct (overt) heterosexism (e.g., stress related to being a target of minority discrimination).

Structural equation models were used to analyze participant data. Paths reported to be statistically significant included a path from organizational context to heterosexism (.54) which was indicative that the perceptions of organizational tolerance of heterosexism were positively correlated with actual experiences of heterosexism. The path from heterosexism to psychological distress (.33) was also found to be significant which was indicative that increased workplace heterosexism resulted in increased mental health distress. It was further shown that increased levels of "outness" resulted in fewer instances of indirect heterosexism (path $=-.17$ ). The path linking job gender context (i.e., ratio of females to males within the workplace) to direct heterosexism was found to be statistically significant (path $=-.25$ ), suggesting that working with a larger ratio of females would result in decreased direct heterosexism. The hypothesis that greater "outness" would be positively correlated with increased direct heterosexism was supported $($ path $=.21)$.

It seems that workplace heterosexism often results in harmful consequences for GL employees including increases in negative mental health symptoms. Indirect heterosexism was shown to be just as harmful as direct forms of heterosexism. In this age of supposed political correctness, it may be that employers attempt to be inclusive and 
accepting of GL employees while the sincerity of their actions may be dubious at best. This possible insincerity could potentially result in an increase in indirect heterosexism that is easily identifiable by GL employees. In addition, coworkers may not necessarily agree with employer's perceived attitudes toward workplace heterosexism, whether positive or negative. This could potentially result in negative repercussions for all parties involved including heterosexual coworkers. It seems clear that workplace heterosexism, whether direct or indirect, negatively impacts a variety of mental heath variables in GL employees and could potentially impact the mental health of heterosexual coworkers as well.

\section{Gender Role Measurement}

As society began to realize the magnitude of diversity among individuals, including GL individuals, the need to properly measure psychological gender roles became more of a necessity. In addition, the previously mentioned shift in gender role beliefs to multidimensionality necessitated the development of more appropriate construct measurement scales such as the Bem Sex Role Inventory (BSRI). Although greater detail will be provided about this scale in a later chapter, a laconic presentation of the BSRI development is presented here simply because the instrument served as a catalyst for much of the verbiage used by researchers in studies included in this literature review.

\section{Bem Sex Role Inventory}

The BSRI is comprised of several features that make it unique from other instruments used to measure levels of masculinity and femininity (Bem, 1974). Bem differentiated her instrument from others by first including Masculinity and Femininity 
Scales that were comprised of 20 stereotypically masculine and feminine traits, respectively. Bem further theoretically distinguished the BSRI by designing it in such a manner as to measure levels of androgyny as well as characteristics of sex-typed individuals. In addition, Bem included a Social Desirability Scale that was completely neutral with respect to biological gender and included an additional 20 items. The Social Desirability Scale served primarily to provide a neutral context for the other two scales. It was originally utilized to ensure that the instrument would not simply capture participant tendencies to endorse socially desirable traits (Bern, 1974).

Gender Role Categories.

The BSRI initially classified people into three gender role categories using a median-split: feminine, masculine, and androgynous (Choi \& Fuqua, 2003). An additional category was later added and labeled "undifferentiated." This category was added to account for people with both low masculine and low feminine characteristics. The summarization of potential BSRI results is captured in Figure 2.

Potential Results of the BSRI

\begin{tabular}{|c|c|c|c|}
\hline \multirow{4}{*}{ Femininity } & & \multicolumn{2}{|c|}{ Masculinity } \\
\hline & & Low & High \\
\hline & Low & Undifferentiated & Masculine \\
\hline & High & Feminine & Androgynous \\
\hline
\end{tabular}

Figure 2. Four categories of the Bem Sex Role Inventory

These four assigned categories have been used by researchers on numerous occasions in attempting to gain a better understanding of psychological gender roles. Because empirical support for the multidimensionality assumption compounded, it made theoretical sense that exhibited traits would differ based upon specific milieus. For 
example, a male could exhibit stereotypically masculine traits at a sporting event while permitting himself to shed tears, a stereotypically feminine trait, on a sad occasion.

Whether or not a man is comfortable shedding tears is sometimes a function of immediate location. Social expectations of appropriate gender roles differ based upon the part of the globe in which an individual happens to find him or herself in at any given moment. Research has shown that there are likely two applicable components in the study of gender roles. In addition to the biological component, gender roles are partially a socially developed phenomenon. Assigned male and female gender roles have been shown to differ by culture and environment (Kohlberg, 1966).

Utilizing the gender role categorization assigned by the BSRI, the following is an overview of several studies conducted by researchers to further elucidate the dynamics of gender role orientation. As the majority of study findings result in participant attained levels of masculinity, femininity, and androgyny, the section dedicated to the undifferentiated category is relatively short.

Masculine. A person who completes the BSRI and scores low on the femininity scale and high on the masculinity scale is categorized as masculine. As this scale is a measurement instrument of psychological masculinity, it is possible for either a biological male or a biological female to fall into the masculine category. A person who scores high on the masculinity scale possesses stereotypically masculine traits such as independence, assertiveness, forcefulness, and athleticism (Bem, 1974).

Multiple studies have been utilized to examine gender role differences between heterosexuals and homosexuals. Heilbrun, Jr. and Thompson, Jr. (1977) compared GL participants to heterosexual participants. The researchers reported that homosexual 
female participants differed significantly in psychological gender from heterosexual females, $\chi^{2}=12.32, d f=3, p<.01$. There was a high occurrence of masculinity and low rates of femininity and undifferentiated gender roles found in the homosexual females. There was no significance found in the male heterosexual and homosexual participants $\left(\chi^{2}=3.63, d f=3, p>.30\right)$. It was reported that the minimal variance found in male participants occurred in the lower incidence of masculinity and higher levels of femininity in the homosexual males. This lack of significance is rather incongruent with the literature due to the fact that many researchers, as will be demonstrated, have found higher levels of femininity in male homosexuals than in male heterosexuals.

The researchers further explored degrees of homosexuality. The results revealed two significant effects for the males. It was found that males with higher levels of masculinity were likely to be heterosexual, $F=15.08, d f=(1,118), p<.001$. The males, however, with higher levels of femininity were also found to be higher in heterosexuality compared to the low feminine males, $F=5.14, d f=(1,118), p<.05$. This was an unexpected finding. The females exhibited only one significant effect. Female participants with higher levels of femininity were more likely heterosexual than females with lower femininity levels, $F=4.96, d f(1,88), p<.05$. The researchers summarized by stating that greater levels of conformity to prescribed gender roles were associated with higher scores on the heterosexuality scale.

Because research findings were not always consistent, Lippa and Arad (1997) conducted a study to examine possible links between sexual orientation and masculine instrumentality, and feminine expressiveness. The researchers examined correlational differences between psychological gender and sexual orientation. Every item included on 
the questionnaire showed statistically significant gender differences at the $p<.001$ level of significance. It was demonstrated that $9 \%$ of the male participants had some level of same-sex attraction while $10 \%$ of the females declared some degree of same-sex attraction. Masculinity scores exhibited significant, moderate correlations with male sexual orientation. Male participants who scored high on $\mathrm{M}(r=-.28, p<.01)$ were less likely to report same-sex attractions. It was reported that the correlations between the female gender-related traits and the sexual behavior factors were weak.

The overall results of the literature seem to indicate that males with higher levels of masculinity are more likely to be heterosexual. Conversely, males with higher levels of femininity are more likely to be homosexual. Heterosexual men have been shown to be more frequently masculine, whereas heterosexual women were shown to be more frequently feminine or undifferentiated (Sandfort, 2005). It was further reported that females with higher levels of femininity were more likely to be heterosexual (Heilbrun, Jr. \& Thompson, Jr., 1977).

Feminine. A person who scores high on the femininity scale and low on the masculinity scale is categorized as psychologically feminine. Once again, in addition to a biological female, it is also possible for a biological male to score high on the femininity scale and low on the masculinity scale. A person who scores high on the femininity scale possesses stereotypically feminine traits such as yielding, loyal, and compassionate (Bem, 1974).

Some researchers have found higher levels of femininity in gay males as compared to their heterosexual counterparts (Heilbrun, Jr. \& Thompson, Jr., 1977; Lippa \& Arad, 1997). To better understand this relationship, researchers have sometimes 
examined males only, comparing gay men to heterosexual men on various masculinityfemininity measures. Gay men typically reported possessing more feminine traits on measures, as well as described less masculine interests and attitudes from childhood forward (Heilbrun Jr. \& Thompson Jr., 1977; Mallen, 1983). Similarly, Hooberman (as cited in Mallen, 1983) stated male heterosexuals reported higher masculinity scores on the BSRI while gay men reported higher femininity scores on the same instrument. More gay men were categorized as feminine and androgynous while more heterosexual men were sex-typed as masculine.

Bernard and Epstein (1978) examined gender role differences between male homosexuals and male heterosexuals. The researchers factor analyzed participant responses from several instruments. Homosexual participant data was analyzed independently of heterosexual participant data. The first factor was identified as Feminine Openness and accounted for $31 \%$ of the total common variance. This indicated that Feminine Openness accounted for $31 \%$ of the variance in femininity levels of both homosexuals and heterosexuals. Feminine Openness related to traits such as feminine role characteristics, androgyny, and aesthetic sensitivity. The second factor was labeled Masculine Boldness and accounted for $23 \%$ of the total common variance. This second factor finding indicated that Masculine Boldness accounted for $23 \%$ of the variance in levels of masculinity of both homosexuals and heterosexuals. Traits included in Masculine Boldness included self-confidence and outgoingness.

The results suggested that male homosexual participants identified significantly more with Feminine Openness than did heterosexual participants, $t=3.70, d f=p<.001$. The researchers reported that homiosexual participants tended to conform more closely to 
particular aspects of the feminine role (e.g., sensitive and open to feelings). No other significant differences were found between the homosexual and heterosexual participants. It was reported that the Masculine Boldness scores were virtually the same for both heterosexual and homosexual participants. The researchers believed that, although the homosexuals appeared to conform more to certain aspects of the feminine role, the homosexual and heterosexual participants tended to conform equally to the masculine role (Bernard \& Epstein, 1978). Similar to other studies, male homosexuals exhibited higher levels of femininity than did heterosexual males. Unlike the previously reported studies, however, there were no significant differences found between homosexual and heterosexual men in levels of masculinity.

The previously reported gender role studies were used to assess levels of selfreported gender roles. Other researchers have examined gender role perceptions of GL individuals by both heterosexual and homosexual participants. Taylor (1983) examined stereotypes of homosexuals and gender roles. Participants were asked to rate groups of people based upon traits believed applicable to members of predetermined groups (i.e., gay men, lesbian women, heterosexual men, and heterosexual women). Male homosexuals were viewed significantly different from female homosexuals on 41 of the $55 \mathrm{PAQ}$ items. The first supported stereotype was that male homosexuals were "needful of others approval." Gay men were shown not to be "runners of the show," and were found to be "helpful to others," and "expressive of tender feelings." The second supported stereotype was that lesbian women were described as stereotypically "not needful of other's approval," "runners of the show," "unhelpful," and "not expressive of tender feelings." It was reported that on 48 of the 55 PAQ items, male homosexuals were 
rated as more feminine than were lesbian women. Conversely, lesbian women were rated as more masculine than were gay men.

It was further found that gay men were rated significantly different from heteroscxual men (i.e., 47 PAQ items revealed significant differences). Gay men were believed to be more feminine than were heterosexual males. It was further found that lesbian women were rated significantly different from heterosexual women (i.e., 45 PAQ items revealed significant differences). Lesbian women were believed to be more masculine than were heterosexual women. These differences were reported to be evidence that homosexuals were perceived as gender role deviants.

Undifferentiated. It is possible for an individual to score low on both the masculinity and the femininity scales. When this situation occurs, the individual is categorized as undifferentiated (Choi \& Fuqua, 2003). An undifferentiated individual possesses low levels of both stereotypically masculine and feminine traits. Being classified as undifferentiated occurs less frequently than classification into one of the other categories. There have been studies, however, that resulted in significant findings relating to the undifferentiated category. One study reported that lesbian women gravitated toward androgynous extremes as well as undifferentiation (LaTorre \& Wendenburg, 1983). Because the majority of gender role categorization findings relate to categories other than undifferentiated, the undifferentiated findings, although typically non significant, are being reported in sections dedicated to the other gender role categories.

Androgynous. A person who scores high on both the masculinity and femininity scales is categorized as androgynous (Choi \& Fuqua, 2003). An individual categorized as 
androgynous possesses high levels of traits stereotypically categorized as both masculine and feminine. These traits may include acting as a leader (masculine), does not use harsh language (feminine), analytical (masculine), sympathetic (feminine), and individualistic (masculine).

It has often been the general consensus that a non-androgynous gender role could seriously restrict the range of behaviors available to a person as he or she moves from one situation to another (Bem, 1975). An androgynous person should be able to remain sensitive to the evolving constraints of a situation and engage in behavior that seems most effective and logical at the moment, regardless of societal stereotypes deemed appropriate for one gender or the other (Bem, 1975). Bem argued that an androgynous self-concept encourages an individual to engage openly in both masculine and feminine behaviors. Androgynous people do not merely survive in our changing society, they actually thrive (Kaplan \& Bean, 1976). It has been argued that for effective and healthy human functioning, both masculinity and femininity must be tempered by the other, and the two traits must be synthesized into a more balanced and truly androgynous personality (Bem, 1976).

Bem (1975) conducted one of the classic androgyny experiments to date. The study was conducted to demonstrate the behavioral adaptability of the androgynous person. It was hypothesized that sex-typed participants would do well only when the behavior in question was congruent with personal definitions of masculinity or femininity. The study was designed to evoke feminine behaviors by having participants interact with a kitten. As anticipated, androgynous and masculine male participants conformed less than feminine participants, $t=2.62, p<.02$. In addition, as predicted, 
there was no statistical difference in the responses between masculine and androgynous participants. The researcher showed that masculine and androgynous individuals were more independent and conformed less to societal pressures than did their feminine counterparts.

Bem, Martyna, and Watson (1976) further examined the concept of androgyny. The researchers wanted to see if comparable findings would result if a human baby were used as opposed to a kitten. Specifically, the researchers were interested in determining if androgynous and feminine subjects would be significantly more nurturing, a stereotypically feminine trait, than the masculine participants were to the babies. The analysis revealed a significant main effect of the participant psychological gender role, $F(3,68)=2.67, p=.05$. The planned comparisons showed that the feminine and androgynous male and female participants were significantly more nurturing toward the baby than were the masculine participants, $t(68)=2.12, p<.05$. The planned comparisons also revealed that the ferminine and androgynous participants did not differ significantly from each other. Based upon the findings, Bem et al. (1976) asserted that androgynous participants, unlike their masculine counterparts, were able to exhibit stereotypically feminine behaviors.

The Bem (1975) and the Bem, Martyna, and Watson (1976) studies were important in that they demonstrated the ability of feminine and androgynous participants to exhibit stereotypically feminine behavior (i.e., nurturance) while interacting with a kitten or a human baby. The studies were further seminal in that they demonstrated the difficulties of stereotypically masculine participants to exhibit gender incongruent behaviors. The results of studies, however, have sometimes been ambivalent (Bernard \& 
Epstein, 1978). Some studies have found that, when examining levels of masculinity and femininity, results contradict existing stereotypes of gay men as feminine renegades and gay women as mannish deviants (Bailey \& Zucker, 1995; Sandfort, 2005). Other researchers, however, have reported gay men and women to be frequently more androgynous than their heterosexual counterparts. Researchers have further found no significant differences in levels of masculinity between gay and heterosexual males while levels of lesbian masculinity have been greater than masculinity in heterosexual females.

There were recurring themes in the studies reported in this literature review. Even though several studies report little or no differences in masculinity levels between gay men and heterosexual men, the overall trend seems to be that heterosexual males have higher masculinity scores than gay males. In addition, members of the GL community appear to have higher androgyny scores than their heterosexual counterparts. Gay men, in general, seem to have lower masculinity scores and higher femininity scores than heterosexual men while lesbian women, in general, seem to have lower femininity scores and higher masculinity scores than heterosexual women.

\section{Gender Roles and Mental Health}

North American society has for years considered masculinity to be the trademark of the psychologically healthy male while femininity has been deemed the trademark of the psychologically healthy female. In recent years, however, the female liberation movement argued current beliefs regarding gender role differentiation have outlived their usefulness (Bem, 1993). Some believe the system now serves to prohibit men and women from devcloping as complete human beings. Proponents of androgyny maintain that 
androgynous people, those who combine high levels of masculinity and femininity, are better mentally adjusted individuals than sex-typed persons (Bassoff \& Glass, 1982).

Researchers have long been interested in understanding the effects of psychological gender on mental health variables such as self-esteem and loneliness. In addition, researchers have examined the effects of stigmatized group membership (e.g., sexual orientation) on levels of self-esteem and loneliness. There is a significant amount of extant empirical research that examined these relationships. Self-esteem, loneliness, and gender role conflict were added to this literature review, not only to assess the relationship of biological gender and psychological gender on these variables, but also to better understand the interrelationship of all constructs simultaneously.

\section{Mental Health and Self-Esteem}

Self-esteem is commonly defined as personal and global feelings of self-worth, self-regard, or self-acceptance (Rosenberg, 1979). It is a central aspect of psychological well-being and colors the affective tone of one's daily experience (Taylor \& Brown, 1988). High levels of self-esteem refer to highly positive global evaluations of the self. Low levels of self-esteem refer to negative evaluations of the self (Baumeister, Campbell, Krueger, \& Vohs, 2003). Other researchers have added unique perspectives to the definition. High levels of self-esteem may refer to an accurate, justifiable, and balanced appreciation of an individual's worth as a person and one's successes and competencies. It can also, however, refer to an overly inflated, arrogant, grandiose, and unwarranted sense of conceited superiority and power over others (Baumeister et al., 2003). By the same token, low levels of self-esteem can be either an accurate, well-founded understanding of one's shortcomings as an individual or perhaps a distorted and even 
pathological sense of insecurity and inferiority. In summation, self-esteem is perception rather than reality (Baumeister et al., 2003).

Rosenberg was one of the leading psychologists in self-esteem studies. He was noted for creating the Rosenberg Self-Esteem Scale which is arguably the most ubiquitous measurement instrument of self-esteem. Rosenberg had his own definition of self-esteem, defining the construct as a negative or positive attitude toward the self (Rosenberg, 1965). The person with positive self-esteem may be characterized by having feelings of self-respect and maintains the belief that he or she is a person of worth (Rosenberg, 1979). The person with positive feelings is capable of realizing his or her merits; however, he or she is also quite capable of recognizing inadequacies. Rosenberg stated that the person with low self-esteem is lacking in self-respect and considers him or herself unworthy or deficient as a person (Rosenberg, 1979).

North American culture in particular has come to embrace the ideology that high levels of self-esteem are not only desirable, but are also the central psychological source from which positive behaviors and outcomes spring (Baumeister et al., 2003). The individual unconcerned with feelings of worthiness and value, or with avoiding feelings of worthlessness, is certainly a rarity in North American culture (Crocker \& Park, 2004). It has been noted that the search for high levels of self-esteem is not a universal human motive, but a cultural or ideological phenomenon (Baumeister et al., 2003). Dimensions of Self-Esteem.

It is generally believed that self-esteem is derived and influenced by several sources including work, school, parents, children, life-partners, peers, coworkers, ctc. (Hills, Francis, \& Jennings, 2006). It is partially due to these multiple influences that self- 
esteem is a construct that has received much empirical debate relating to dimensionality. The consensus seems to be that self-esteem is both unidimensional and multidimensional (Swaim \& Wayman, 2004). Global (i.e., overall) self-esteem is apparently best represented as a unidimensional construct. The Rosenberg Self-esteem Scale is an example of a measure of global self-esteem. Researchers have shown, however, that selfesteem is a multidimensional construct in that it is influenced by myriad subdimensions (Crocker, 1998; Pelham \& Swann, Jr., 1989). Physical appearance and intelligence, for example, may influence self-esteem levels - and do so in differing ways. Individuals may have high levels of self-esteem relative to physical appearance while academic competency self-esteem levels may be relatively low.

The specific subdimensions identified by researchers have not been consistent. One identified subdimension of self-esteem is an "affective" component (Pelham \& Swann, Jr., 1989). The affective component refers to those factors that evoke feelings or emotions within an individual. For example, the treatment of a child by a caregiver will influence the child's level of self-esteem. It has been reported that even infants become aware of either acceptance or rejection from others. Rosenberg (as cited in Pelham \& Swann, Jr., 1989) proffered that these early affective experiences could influence the selfesteem levels of adults many years later. Affective components are often ignited in specific situations or environments.

Another subdimension of self-esteem is a "cognitive" component, a culmination of specific self-views. The cognitive component is influenced by specific self-views developed by individuals as they move from preverbal years into adulthood while developing belief systems along the way (Pelham \& Swann, Jr., 1989). Self-views are 
often influenced by perceptions of how others might view the self. This other perceived self-view has been reported to heavily influence global levels of self-esteem. The cognitive component and specific self-views have been identified as the building blocks of self-esteem. It was noted that the component dimensions can be heavily influenced and changed based upon the level of importance attachedo specific ideas or situation $\mathrm{s}$, in addition to the environment one finds him or herself in at a particular moment (Crocker \& Major, 1989; Pelham \& Swann, Jr., 1989).

Specific methods by which people frame self-views can influence levels of selfesteem. Self-views, for example, that are strongly connected to an individual's values or goals will more heavily influence a person's sense of self-esteem than would self-views with a weaker connection to values and goals. It is the importance of the self-view that influences the possibility to impact self-esteem (Pelham \& Swann, Jr., 1989). It has been shown that, dependent upon the importance of a situation to an individual, the environment in which the situation occurs may or may not influence levels of self-esteem (Crocker, 1998).

Swaim and Wayman (2004) identified three subdimensions of self-esteem: (a) self-confidence; (b) competence; and, (c) social acceptance. It may be that these subdimensions could be components of the affective and cognitive components identified by other researchers. Self-confidence and social acceptance, for example, could be considered components of the affective dimension (i.e., evoking feelings or emotions within the individual) while competence may be considered a factor in the cognitive dimension (i.e., culmination of specific self-views). Whether or not the subdimensions identified by Swaim and Wayman (2004) could be considered components of the 
dimensions identified by other researchers does not change the fact that self-esteem clearly appears to be a multidimensional construct consisting of at least two dimensions and multiple subdimensions.

Researchers have long been interested in clarifying the composition of selfesteem. Pelham and Swann (1989) conducted a study to examine the contribution of three individual factors to global self-esteem. Components examined included both negative and positive affective states and experiences, specific self-views (i.e., conceptions of individual strengths and weaknesses), and the manner in which self-views were framed in terms of importance and certainty. Using simultaneous multiple regression analysis, all of the predictor variables were shown to account for a unique portion of the variance in selfesteem. Negative affectivity $(\beta=-.29, p<.001)$, which is part of the affective dimension of self-esteem, was shown to account for the most uniqueness in self-esteem variability followed by composite self-views $(\beta=.26, p<.001)$ which is part of the cognitive dimension of self-esteem. Positive affectivity $(\beta=.22, p<.001)$, part of the affective dimension of self-esteem, accounted for the third largest variance in self-esteem. Selfesteem appeared to be related to, not only individual specific self-views, but to more rudimentary affective factors too.

Still other researchers have provided additional support for the multidimensionality of self-esteem. For example, it has been demonstrated in the literature that those individuals who are members of concealable minority groups (e.g., closeted sexual minorities) can suffer negative mental health consequences of prejudice and discrimination, dependent upon the environment and severity of the discrimination. These types of scenarios support both the cognitive and the affective dimensions of self- 
esteem. Frable, Hoey, and Platt (1998) conducted a study to examine the effect of cultural stigmatization on people with hidden (e.g., sexual orientation) versus conspicuous (e.g., race) characteristics. It was hypothesized that people with concealable stigmas such as sexual orientation would be more prone to negative self-views because of difficulties in finding similar others. It was shown that participants with concealable stigmas felt less good about themselves, $F(1,81)=4.87, p<.05$ and felt more depressed than members of other minority groups, $F(1,81)=6.55, p<.025$. Participants with concealable stigmas had lower self-esteem than the other participants, $F(1,80)=9.88, p<.005$. It was further noted that concealable stigmatized group members tended to be alone, $F(1,81)=3.21, p$ $=.07$. This study served to support the assertion that, dependent upon the environment, including those with whom an individual happens to be with at a particular moment, both affective and cognitive self-esteem levels can be influenced both positively and negatively. In addition, the individual components of self-esteem are clearly multidimensional in nature.

Gender Roles and Self-Esteem.

Social scientists have examined the effects of gender role conditioning on mental health. Much attention has been given to the potentially restrictive effects of gender roles and their impact on specific components of mental health (Long, 1989). Androgyny, for example, is believed to have beneficial consequences such as increases in self-esteem (Allgood-Merten \& Stockard, 1991; Feather, 1985; Lu \& Wu, 1998; Spence \& Helmreich, 1980). Several theorists and researchers have claimed that androgynous individuals are superior in many ways to sex-typed individuals (Lundy \& Rosenberg, 1987). Historical data suggested that psychological androgyny may lead to the most 
socially desirable and acceptable consequences, the absolute strengths of both components of masculinity and femininity, influencing attitudinal and behavioral individual results (O'Connor, Mann, \& Bardwick, 1978; Orlofsky, 1977; Spence, Helmreich, \& Stapp, 1975).

Historically speaking, androgynous people were believed to be more adaptive in their daily interactions and thus able to display higher levels of self-esteem than were sex-typed persons (Antill \& Cunningham, 1980; Orlofsky, 1977). Individuals less vested in traditional gender norms have significantly better psychological outcomes because they are less likely to permit the opinions, judgments, and performances of others determine their levels of self-esteem (Sanchez \& Crocker, 2005). Persons categorized as undifferentiated or feminine have been shown to have lower levels of self-esteem as compared to androgynous individuals. High levels of femininity in females have been positively correlated with high anxiety and low self-esteem (Bassoff \& Glass, 1982).

Although some continue to believe that androgyny is strongly correlated with high levels of self-esteem, it unequivocally appears that masculinity rather than androgyny is an important element of mental health for both males and females (Bassoff \& Glass, 1982; Burnett, Anderson, \& Heppner, 1995; Long, 1989). In addition, some studies have reported that men who have low levels of masculine characteristics (feminine-typed and undifferentiated orientations) seem less well-adjusted than their counterparts who are sex-typed (Orlofsky, 1977). These findings are not surprising since masculine traits have traditionally been viewed in American society as more valued than female traits (Bem, 1974). Feelings of being valued would likely result in increases in self-esteem levels. 
Some findings that are relevant to the current study were reported by Hooberman (1979) who compared male homosexuals and heterosexuals on psychological gender and self-esteem. The researcher reported that homosexuals had significantly higher femininity $(t=5.28, p<.001)$ and androgyny $(t=6.22, p<.001)$ scores than heterosexual participants. The homosexual participants also reported significantly lower masculinity $(t$ $=2.69, p<.001)$ scores than the heterosexual participants. No statistical significance was found, however, between self-esteem scores between homosexual and heterosexual males, $t(85)=.97, p>.05$. Correlations were analyzed between self-esteem scores and levels of masculinity and femininity. The results revealed a significant correlation between levels of self-esteem and masculinity between homosexuals and heterosexuals combined, $r=.44, p=.01$, a medium correlational level. The results further revealed significant, medium-sized, correlations between levels of self-esteem and masculinity for heterosexuals, $r=.35, p=.05$ and for homosexuals, $r=.53, p=.05$. No significant correlation was found in femininity scores and self-esteem. The overall findings of this study showed that male homosexuals were higher in androgyny and femininity than heterosexual males and lower in masculinity than heterosexual males. No significant differences were found in self-esteem between homosexuals and heterosexuals.

Other researchers examined the relation of self-esteem with gender-related variables such as psychological gender roles, gender role conflict, self-esteem, loneliness, or some combination of the constructs. Carlson and Baxter (1984) conducted a study to examine the interaction of androgyny and self-esteem on Irish homosexual and heterosexual males and females. It was reported that gay males were more frequently categorized as androgynous $(36.7 \%)$ than were heterosexual males $(4.3 \%)$. Conversely, 
lesbian females were more frequently categorized as androgynous $(21.7 \%)$ than were heterosexual females $(11.8 \%)$.

Multiple regression analysis was used to examine levels of masculinity and femininity in predicting levels of self-esteem in both heterosexuals and homosexuals. The researchers reported that heterosexual masculinity and femininity scores did not significantly predict levels of self-esteem $\left(R^{2}=.08 ; F(2,33)=1.34\right)$. The multiple regression analysis, however, showed that the gay and lesbian masculinity and femininity scores were significant predictors of self-esteem $\left(R^{2}=.28, F(2,67)=12.97 ; p<.001\right)$. These findings indicated that $28 \%$ of the changes in self-esteem for GL participants were accounted for by changes in masculinity and femininity scores.

It was further reported that perceived levels of masculinity were more powerful predictors of self-esteem $(\beta=.52 ; F(2,67)=24.86 ; p<.001)$ than were perceived levels of femininity $(\beta=-.14 ; F(2,67)=1.92 ; \mathrm{ns})$. It was demonstrated that the self-esteem levels of gay men and lesbian women increased as the perceived levels of masculinity increased. Although it is not possible to say without equivocating that, in a society that devalues homosexuality, high self-perceived levels of femininity cause lower levels of self-esteem, the sample in this particular study did indeed exhibit lower levels of selfesteem as femininity scores increased.

Multiple researchers have examined the relationship between psychological gender roles and self-esteem. The overriding theme appears to be that masculinity is positively related to self-esteem in both males and females (Allgood-Merten \& Stockard, 1991; Antill \& Cunningham, 1980; Feather, 1985; Long, 1990, 1993; Lundy \& Rosenberg, 1987; Orlofsky, 1977; Stericker \& Johnson, 1977). Conversely, femininity is 
often found to have either no relationship or even a slightly negative relationship with self-esteem (Allgood-Merten \& Stockard, 1991; Antill \& Cunningham, 1980; Feather, 1985; Long, 1990, 1993; Orlofsky, 1977; Stericker \& Johnson, 1977). Undifferentiated individuals have sometimes been found to report lower levels of self-esteem (Orlofsky, 1977). Males are often found to have higher levels of self-esteem than do females (Allgood-Merten \& Stockard, 1991; Feather, 1985). Other researchers, however, have reported no gender differences in self-esteem (Stericker \& Johnson, 1977).

The literature tends to indicate that masculinity has a more significant relationship with self-esteem in both males and females than do other psychological gender role categories. Androgyny, however, is also frequently associated with positive correlations in self-esteem. Conversely, femininity is typically shown to have a minimal relationship with self-esteem levels. The minimal relationship between femininity and self-esteem is sometimes negative, indicating that as femininity increases, self-esteem levels actually decrease. Undifferentiated status, like femininity, was shown to have a minimal relationship with self-esteem.

\section{Mental Health and Loneliness}

Most definitions of loneliness focus on perceived social relationship deficits (Stokes \& Levin, 1986). Social relationships typically provide individuals with opportunities for companionship and emotional intimacy. The lexicological definition of loneliness is "being without company" or "cut off from others"; "a sense of sadness from being alone" (Merriam-Websters Collegiate Dictionary, 2003). Fromm-Reichmann (as cited in Solano, Batten, \& Parish, 1982) stated that the repercussions of loneliness are negative emotional consequences that range from mild discomfort to strong pain. 
Dimensions of Loneliness.

Ellison (as cited in Solano, Batten, \& Parish, 1982) posited that loneliness was comprised of four distinct dimensions including cognitive, emotional, behavioral, and motivational. Most research has focused on the cognitive and emotional dimensions. The cognitive dimension is enacted when an individual concludes that he or she has fewer social relationships than desired (Solano, Batten, \& Parish, 1982). Although the dimensionality of loneliness has received a fair amount of scholarly debate over recent years, the general consensus seems to be that loneliness is in reality a unidimensional construct that can be represented on a bipolar continuum (Russell, 1996). It has been argued by Russell (1996) that the multidimensionality proffered by other researchers more accurately reflected assessments of other relationships or constructs that may lead to loneliness.

Multiple exploratory and confirmatory factor analytic studies have supported the assertion of unidimensionality by reporting one single factor (Oshagen \& Allen, 1992; Russell, 1996). The overall consensus from several factor analytic studies revealed that all items on the UCLA Loneliness Scale significantly loaded on one bipolar global loneliness factor (i.e., positive and negative loneliness) supporting the assertion of unidimensionality (Russell, 1996). This finding buttressed Russell's theory that other researchers may have mistakenly identified various constructs (i.e., cognitive, emotional, behavioral, and motivational) that merely resulted in loneliness as loneliness itself. Russell (1996) concluded that multidimensional measures of the loneliness construct merely reflect either assessments of deficits that may lead to loneliness, or assessments of consequences that follow becoming lonely. 
Gender Roles and Loneliness.

A renewed interest in loneliness has been evident in the mental health literature. The recent surge in interest is partially due to the fact that more reliable measurement instruments have been developed (Russell, Peplau, \& Cutrona, 1980). Revised measurement instruments such as the UCLA Loneliness Scale have been successful in gathering loneliness information in a more surreptitious or clandestine manner than previous scales (Russell, Peplau, \& Cutrona, 1980; Stokes \& Levin, 1986). This is important due to the fact that many participants are reportedly uncomfortable with the admission of feelings of loneliness (Cramer \& Neyedley, 1998). This has been particularly evident in sex-typed males. Renewed interest in the construct is also due to necessity. Weiss (as cited in Solano, Batten, \& Parish, 1982) stated that loneliness is becoming a serious and widespread problem in the United States for several reasons including the fact that the population is aging and living longer. Spouses are sometimes passing away and leaving partners behind and lonely for several years. One does not need to be older, however, to experience loneliness. Loneliness is unfortunately all too common among individuals of all ages (Cramer \& Neyedley, 1998; Joiner, Jr. \& Rudd, 1996; Solano, Batten, \& Parish, 1982; \& Stokes \& Levin, 1986).

Using the BSRI and the UCLA Loneliness Scale, Cramer and Neyedley (1998) assessed the relationship between psychological gender and loneliness. The researchers discovered that, for the sample as a whole, loneliness was negatively related to masculinity, but not to femininity, $t(254)=1.97, p=.0499$. This same finding was also reported when analyzing only the female participants $(r=-.30, p<.05)$. Although the relationship was negative, the reported correlation was relatively weak. When analyzing 
just the male participants, however, both masculinity $(r=-.35, p<.05)$ and femininity $(r=-.20, p<.05)$ were shown to be negatively related to loneliness. Once again, however, the correlations were relatively weak. Using masculinity and femininity as covariates, the researchers reported significant gender differences, $F(1,250)=6.08$, $p=.014$ whereby the male participants reported more loneliness than female participants $(M=41.23$ vs. 38.37). It was further reported that a significant amount of the variance in loneliness was explained by masculinity scores, $F(1,250)=29.99, p<.001, \omega^{2}=10 \%$. The researchers summarized by stating that, irrespective of the existing relationship between participant psychological gender and biological gender, biological gender differences in levels of loneliness emerged only after accounting for masculinity (Cramer \& Neyedley, 1998).

Patterns between loneliness and self-disclosure of feelings of loneliness to significant others were assessed by Solano, Batten, and Parish (1982). It was reported that male participants were lonelier than female participants, $t(73)=1.81, p<.07$. An analysis of variance (ANOVA) was further used to assess deficiencies in levels of self-disclosure as perceived by participants. The researchers found no significant biological gender main effect, $F(1,219)<1$. It was reported, however, that the interaction approached significance, $F(3,219)=2.40, p<.07$. The degree of intimacy differed significantly by role-relationship type, $F(3,219)=4.54, p<.01$. An examination of the mean scores revealed that the highest level of self-perceived disclosure was to mothers $(M=79.2)$ followed by same-sex friends $(M=73.4)$, fathers $(M=71.9)$, and finally opposite-sex friends $(M=68.4)$. The researchers summarized by stating that high correlations were more likely to exist between male perceived self-disclosure to an opposite-sexed person 
and levels of loneliness. The less a male self-disclosed, the more likely he would have feelings of loneliness. Females reportedly related the need to self-disclose to both males and females.

The ability of social networks to predict loneliness by biological gender was examined by Stokes and Levin (1986). All significance was found in the male participants. A significant, negative correlation was found in loneliness and size of social networks $(r=-.21, p<.05)$, number of confidants $(r=-.25, p<.05)$, and number of socially supportive behaviors $(r=-.28, p<.01)$. The reported correlations, although negative and significant, were somewhat weak. As the size of social networks, the number of confidants, and the number of socially supportive behaviors increased, loneliness levels decreased. There was no statistical significance found in loneliness and the other variables among female participants.

Although other researchers such as Meredith and Woodward (as cited in Cramer \& Neyedley, 1998) reported no significant gender differences in levels of loneliness, the overall theme appears to be that males are significantly lonelier than females (Russell, Peplau, \& Cutrona, 1980). This theme has intrigued researchers based upon gender role beliefs due to the fact that biological males are typically higher in masculinity than are females (Bem, 1974). Masculinity, however, is negatively related to loneliness. One would logically deduce that males would exhibit lower levels of loneliness due to having higher levels of masculinity. Scholars have proposed potential reasons for this discrepancy. First, males tend to interact in larger groups based upon shared interests and activities while females tend to form dyadic relationships in which they are able to place an emphasis on emotional intimacy and sharing (Stokes \& Levin, 1986). Males do not 
typically have the intimacy in friendships that is often displayed by females (Stokes \& Levin, 1986).

Second, because males realize that the admission of feelings of loneliness is inconsistent with stereotypically masculine characteristics (Cramer \& Neyedley, 1998), minimal effort may have been put into responding to measurement instruments in an appropriate manner. As a result of this inconsistency, males are believed to sometimes conceal feelings of loneliness (Cramer \& Neyedley, 1998). In addition, scales may have been interpreted differently by males than by females (Cramer $\&$ Neyedley, 1998).

Assuming researchers are correct in stating that the overall theme suggests a higher level of loneliness among males than among females, and that males sometimes attempt to conceal feelings of loneliness, the true level of loneliness among males may be significantly higher than levels reported in the literature. It is clear, however, that further research needs to be completed in studies of loneliness.

Loneliness and the GL Population.

It would likely be difficult to experience physical and emotional harassment and victimization without experiencing concomitant negative mental health effects such as decreases to self-esteem and increased loneliness. Loneliness can sometimes be the result of gender role conflict and societal rejection. D'Augelli and Grossman (2001) conducted a study to examine the impact of a lifetime of GL victimization on mental health using a sample of older GL adults. Mental health was inclusive of self-esteem and loneliness. Approximately two-thirds of the participants $(63 \%)$ experienced some form of verbal abuse, $29 \%$ had been threatened with some form of physical violence, $11 \%$ had objects thrown at them, $12 \%$ had been threatened with weapons, and $16 \%$ had been physically 
attacked. Significant differences were found between the varying levels of victimization groups and mental health indicators. Men reported significantly more internalized homophobia related to sexual orientation than did women. Participants who had been physically attacked reported significantly lower levels of self-esteem $(F=5.75, p<.01)$ and lower overall mental health $(F=5.34, p<.01)$ and higher levels of loneliness $(F=5.87, p<.01)$ than those who experienced verbal victimization only.

D'Augelli, Grossman, Hershberger, and O'Connell (2001) investigated significant predictors of mental health in older GL adults. This study was important because older GL individuals lived a significant portion of their lives when it was much more socially unacceptable to be homosexual. The researchers hoped to examine how the attitudes of older GL adults regarding their sexual orientation affected their mental health as measured by self-esteem, internalized homophobia, and loneliness. The majority of the participants $(M=34.85, S D=4.5)$ reported having high levels of self-esteem. It was further demonstrated that most participants had low levels of internalized homophobia $(M=23.66, S D=6.2)$ and high levels of loneliness $(M=14.1, S D=4.3)$. The authors reported that participants who lived alone had lower levels of self-esteem than did participants with partners $(t=3.84, p<.01)$. Those participants with partners reported having higher overall mental health $(t=3.19, p<.01)$. Overall the researchers found that current mental health was predicted by higher levels of self-esteem and lower levels of loneliness.

A qualitative study designed to examine the experiences and views of gay men regarding self-perceptions and mental health needs was conducted by Robertson (1998). Anxiety and levels of depression represented the mental health variables. Feelings of 
isolation and misery were commonly reported. Due to a fear of discovery, many of the respondents actively avoided social gatherings - leading to more isolation and loneliness. In addition, many respondents reported low feelings of self-esteem. The researcher reported that the internalization of prejudice led to great feelings of isolation. In addition, over 25 percent of the respondents experienced medical contact related to anxiety or depression while the majority of participants reported mental distress related to sexuality. The researcher reported findings that exhibited a deep internalization of homophobia as a result of social stigma and gender role conflict.

It appears that GL individuals sometimes experience elcvated levels of loneliness. This finding may be a result, however, of the relatively small number of studies that have analyzed this construct in GL participants. It seems that perhaps older GL individuals and those who are without partners experience greater levels of loneliness than do younger, and perhaps more social, GL individuals and those with partners. The fact that homosexuality is more socially acceptable today has likely resulted in increased networking and decreased levels of loneliness.

Researchers have determined that males exhibit higher levels of loneliness than do females (Cramer \& Neyedley, 1998). In addition, masculinity appears to have a significant negative relationship to loneliness in both male and female samples. Femininity, conversely, often has no relationship with loneliness or only a relatively small and negative correlation in male samples. There has been no significant correlation found between loneliness and femininity in female samples. 


\section{Gender Role Conflict}

A relatively new construct identified and examined in the literature over recent years has been labeled "gender role conflict." The common definition of gender role conflict is "a psychological state where gender roles have negative consequences or impact on a person or others" (O’Neil, Helms, Gable, David, \& Wrightsman, 1986, p. 336). Researchers reported that the resulting outcome of gender role conflict is often the restriction of a person's ability to maximize full human potential or sometimes the restriction of the potential of others (O'Neil et al., 1986). Because society is less forgiving of male transgressions into femininity than of female transgressions into masculinity (Long, 1989, 1993; McCreary, 1994; Safir, Rosenmann, \& Kloner, 2003; Sandfort, 2005), empirical work assessing gender role conflict has focused primarily on male gender role conflict. There has been, however, modicum female gender role conflict studies conducted over recent years.

O’Neil, 1990 (as cited in Good et al., 1995) reported that masculine gender role conflict occurred when male conformity to rigid, sexist, or restrictive societal expectations of the male gender role result in personal restrictions, devaluation and occasional violations of the self or others. Males were reported to actively avoid behaviors or actions considered feminine. Boys are reportedly taught behaviors deemed gender role appropriate at a very early age through positive and negative reinforcements (Mahalik, Cournoyer, DeFranc, Cherry, \& Napolitano, 1998). An incongruence of assigned gender role traits with those actually possessed results in conflict. Shepard (2001) reported that gender role conflict is most likely to occur when a person experiences differences in the actual gender role self and the ideal concept of the gender 
role self as defined by society. Those individuals who have learned and acquired the most rigid gender role stereotypes are the most likely to suffer from gender role conflict (Shepard, 2001).

\section{Dimensions of Gender Role Conflict}

O’Neil, Helms, Gable, David, and Wrightsman (1986) postulated that gender role conflict could be conceptualized as four interrelated and complex dimensions. The four proposed dimensions included cognitions, affective experiences, behaviors, and unconscious experiences. Cognitions, according to the researchers, referred to the individual's belief about his or her own gender roles as related to societal beliefs regarding assigned gender roles. Affective experiences referred to feelings about societal and individual beliefs regarding gender role expectations and conflicts. Behaviors referred to situational responses and interactions with others as a result of gender role expectations and conflict. Finally, O'Neil et al. (1986) referred to the unconscious experiences as repressed intrapsychic processes regarding gender roles that were not part of the conscious awareness.

Researchers began to proffer that gender role conflict might result in harmful mental health consequences such as decreases in self-esteem and increases in loneliness (Good \& Mintz, 1990). Because it was suggested that gender role conflict might result in negative mental health ramifications, the importance of creating a scale to effectively measure the construct became apparent. The Gender-Role Conflict Scale (GRCS) was created by O'Neil et al. (1986) to measure personal gender role attitudes, conflicts, and behaviors of men. As reported later, Zamarripa, Wampold and Gregory (2003) reported 
that the Gender Role Conflict Scale was valid for use in female samples as well as male samples. The GRCS will be discussed at length in the following chapter.

Using a variety of statistical techniques and analyses including confirmatory factor analysis it was suggested that there were four relevant factors of gender role conflict, supporting the assertion that gender role conflict is multidimensional in nature. The first factor identified by O'Neil et al. (1986) was titled "Success, Power, and Competition." The Success, Power, and Competition factor represented the need of a male to be successful and powerful (Mahalik et al., 1998). The factor could further be defined by a persistent worry in gaining wealth, upward mobility, carcer success, and achievement (Silva, 2002). A sex-typed male who loses his job or becomes a stay-athome dad would likely experience some degree of Success, Power, and Competition gender role conflict. Although the four determined factors overlap the four dimensions of gender role conflict, Success, Power, and Competition clearly supports the cognition dimension due to the fact that perceived gender roles often impact ultimate goals and objectives. For example, a psychologically feminine male, because of gender role socialization, may not believe he has the ability to be a corporate $\mathrm{CEO}$.

The second resulting factor was titled "Restrictive Emotionality" and referred to uneasiness experienced by a male in expressing emotions either to the self or to others. Those who experience Restrictive Emotionality are reportedly fearful of feelings that seem womanly (Mahalik et al, 1998). More expressive traits are feminine in nature (Bem, 1974). When a situation requires the expression of feminine traits such as nurturance, the result is gender role conflict for the sex-typed male (O’Neil et al., 1986). This factor could easily support the affective and unconscious dimensions of gender role conflict. As 
affective experiences reflect emotive feelings surrounding gender role issues, it is easy to see how one's desire to restrict his or her emotionality would correlate with the affective dimension of gender role conflict. Restrictive emotionality further supports the unconscious dimension of gender role conflict simply because gender roles are taught from the earliest of ages. Individuals may behave or react in certain ways without even being fully cognizant of their actions.

The third factor extracted by O'Neil et al. (1986) was labeled "Restrictive Affectionate Behavior Between Men." This factor represented the male discomfort with, and often outright avoidance of, any confirmation of affection or caring between men. This factor supports the behavioral dimension of gender role conflict. As the behavioral dimension represents how individuals act, respond, and interact with others regarding gender role issues, it is easy to see how Restrictive Affectionate Behavior Between Men would undergird the behavioral dimension of gender role conflict. Examples of this type of behavior include wariness of overly friendly male overtures (Mahalik et al., 1998). Excessive affection displayed by one male to another male might create discomfort for the sex-typed, heterosexual male. Such behaviors would likely be associated with homosexuality and avoided if possible (Mahalik et al., 1998).

The fourth and final significant factor extracted was labeled "Conflict Between Work and Family Relations." This factor was used to assess distress felt by those trying to balance work obligations with family obligations. Home and family responsibilities could result in gender role conflict for the sex-typed male as those duties may be perceived as more feminine in nature. As the dimensions were reportedly overlapping, it 
is proffered that Conflict Between Work and Family Relations likely supports all four dimensions of gender role conflict to some degree.

Other researchers conducted factor analytic studies to support the assertion of gender role conflict multidimensionality. Simonsen, Blazina, and Watkins, Jr. (2000) examined the effects of gender role conflict on the mental health of gay men. The researchers wanted to specifically see how gender role conflict would impact the willingness of gay men to seek professional help. In addition, the researchers wanted to understand the relationship between gender role conflict and mental health outcomes. Because the Gender Role Conflict Scale (GRCS) had not been utilized in a study of gay men, the researchers examined the factorial validity of the scores obtained from a gay sample. Using a principal-components analysis with Promax rotation, it was determined that 32 out of 37 items loaded on the same factors as those identified by O'Neil et al. (1986). The consensus was that the factor analysis approximated and confirmed the fourfactor model of the GRCS indicating that the factor structure of the GRCS scores obtained from a gay sample was quite similar to the ones obtained from heterosexuals.

It was hypothesized that gender role conflict would have a positive and significant correlation with mental health as measured by anger, anxiety, and depression. It was further hypothesized that gender role conflict would be negatively correlated with attitudes toward seeking professional help. Canonical correlation analysis was used to analyze the data. Root 1 was comprised of the four gender role conflict factors (i.e., Success, Power, and Competition, Restrictive Emotionality, Restrictive Affectionate Behavior Between Men, and Conflict between Work and Family Relations) while Root 2 consisted of the four mental health variables (i.e., Attitudes toward seeking professional 
help, anger, anxiety, and depression). A canonical correlation root of $563, F(5,107)=$ $3.68, p<.01$ was reported to be an indicator that gay men who had fewer experiences of conflict regarding expressing emotion and giving affection typically had better mental health outcomes. In addition these men were typically more open to seeking psychological help. The second canonical root of $.359, F(5,107)=2.38, p<.01$ was reported to be an indicator that gay men who experienced higher levels of Conflict between Work and Family Relations or Success, Power, and Competition conflicts typically exhibited increased levels of anger, anxiety, and depression. This study was important because it gave empirical evidence to support the belief that gender role conflict results in negative mental health consequences in gay men.

Good et al. (1995) provided additional evidence supporting the factorial validity and multidimensionality of the GRCS by taking a confirmatory factor analytic approach. The sample consisted of 1,043 male undergraduate students. It was found that data from this sample supported the four-factor model reported by the developers of the GRCS. In addition, it was reported that oblique rotation indicated all items, with one exception, supported the same factors specified by the developers. The reported coefficient alpha was .89 which is comparable to reliabilities reported in other studies. It was demonstrated that masculinity was significantly and positively correlated with the GRCS with the exception of the Conflict Between Work and Family Relations subscale. Reported correlations for the overall GRCS and the Success, Power, and Competition, Restrictive Emotionality, and Restrictive Affectionate Behavior Between Men subscales were $r=$ $.60, p<.001 ; r=.62, p<.001 ; r=.29, p<.01$, and $r=.51, p<.001$, respectively. All correlations were relatively moderate to high. It was reported that the overall four factor 
structure model of the GRCS was strongly supported, providing support for the factorial validity of the instrument and the multidimensionality of the construct.

Additionally, Good et al. (1985) examined the relationship between gender role conflict and mental health as measured by psychological distress. The positive and moderate correlation between gender role conflict and mental health outcomes was determined to be significant $(r=.38, p<.001)$ which indicated that gender role conflict can result in negative mental health outcomes (e.g., psychological distress). It was reported that all of the GRCS subscales had significant weak to moderate correlations with mental health. The correlations between mental health and the overall GRCS and the Success, Power, and Competition, Restrictive Emotionality, Restrictive Affectionate Behavior Between Men, and Conflict Between Work and Family Relations subscales were $.38, .25, .37, .19$, and .35 , respectively. The researchers used simultaneous multiple regression analysis to predict mental health and found significant results, $F(4,123)=7.50, p<.001$. The study results supported previous research findings that gender role conflict has a significant detrimental impact on mental health outcomes.

As several studies have been completed to examine the psychometric properties and factor structure of the GRCS, it seems relatively clear that gender role conflict and the GRCS have resulted in significant research interest. Factor analytic results appear to confirm the four-factor structure of the GRCS and support the assertion that gender role conflict is indeed multidimensional in nature. In addition, it appears that it is the Success, Power, and Competition, Restrictive Emotionality, and Restrictive Affectionate Behavior Between Men factors of gender role conflict that have the most significant relationship with mental health. 


\section{Gender Role Conflict and the GL Population}

Numerous studies have revealed that members of the GL community often deviate from socially assigned gender roles (Lippa \& Arad, 1997; Sandfort, 2005). Individuals who place high values on traditional gender roles devalue homosexuals simply because homosexuals are perceived to be gender role deviants (Taylor, 1983). For several years, evidence has been accumulated to suggest gender role evaluations are major predictors of attitudes toward homosexuals (Whitely, Jr., 2001). Some research findings have supported the view that the heterosexual dislike of GL people is at least partially provoked by an often clandestine and sometimes overt desire to maintain traditional gender roles (Whitley, Jr., 2001). As GL individuals are well aware of socially assigned gender roles, inherent deviations in actual and expected gender roles would seemingly result in gender role conflict.

Gender role incongruent males are often assumed to be sexual deviants or homosexuals while gender role incongruent females are sometimes simply believed to be strong, assertive women (McCreary, 1994). Researchers have examined this very phenomenon. McCreary (1994) reported that participants attributed personality characteristics and behaviors of males to be a significantly greater indication of sexual orientation than those of females, $F(1,142)=6.48, p=.012$. Males presented in a female-valued manner resulted in significantly stronger perceptions of homosexuality ( 3.83 vs. $1.78, p<.01$ ). Research examining the perceptions of men and women behaving in ways that were deemed gender congruent and gender incongruent showed that males of all ages were viewed more negatively than females for gender role transgressions 
(McCreary, 1994). As society seems to be typically more accepting of female homosexuality as opposed to male homosexuality, these findings make theoretical sense.

Irrespective of the cultural aspect of gender role orientation or reported social transgressions, many researchers continue to strive for a greater understanding of the relationship between gender roles and sexual orientation. Researchers of gender roles who studied gay male and lesbian female individuals attempted to demonstrate that, on several psychometric measures, both groups (gay males versus lesbian females) produced responses that were atypical to those of their own gender and more typical of the opposite gender (Heilbrun Jr. \& Thompson Jr., 1977; Mallen, 1983; \& Meyer, Blissett, \& Oldfield, 2001). It has been reported that GL individuals were more likely than were heterosexuals to demonstrate "cross-gender" patterns of responses. Gay men tend to be more feminine than heterosexual males and gay women tend to be more masculine than heterosexual females (Lippa \& Arad, 1997; Meyer, Blissett, \& Oldfield, 2001).

Although empirical work examining the effects of gender role conflict on gay participants has been limited, these types of studies are rapidly gaining in popularity. Jones (1998) conducted a study to examine the effects of gender role conflict on the mental health of gay men. Mental health measures were anxiety and depression. Utilizing correlational analysis, it was reported that anxiety was positively and significantly correlated with Success, Power, and Competition $(r=.26, p<.01)$, Restrictive Emotionality $(r=.34, p<.01)$, and Restrictive Affectionate Behavior Between Men $(r=.25, p<.01)$. As these components of gender role conflict increased, anxiety significantly increased as well. As is often reported in the literature, no significant correlation was found between anxiety and Conflict Between Work and Family 
Relations, implying that as Conflict Between Work and Family Relations increased, there was little to no impact on anxiety levels. It may be possible that, although many GL individuals are increasingly making choices to become parents, the majority of gay men and lesbian women remain childless, decreasing the potential for Conflicts Between Work and Family Relations.

Jones (1998) further reported that depression was found to positively and significantly correlate with Restrictive Emotionality $(r=.43, p<.01)$ and Restrictive Affectionate Behavior Between Men $(r=.25, p<.01)$. Both of these weak to moderate relationships were indicative that, as Restrictive Emotionality and Restrictive Affectionate Behavior Between Men increased, depression increased significantly as well. There was no statistical significance found between Success, Power, and Competition, Conflict Between Work and Family Relations, and depression.

The effects of gender role conflict on the mental health of gay men were also assessed by Shepard (2001). Mental health was measured by examining anger, anxiety, depression, self-esteem, and attitudes toward seeking professional help. The researcher used canonical correlation analysis to examine gender role conflict in 102 gay men due to the fact that there were multiple independent and dependent variables. The researcher examined the canonical correlational results of the sample and reported that only two of the four produced significant canonical correlations. The first canonical variable set included the four gender role conflict factors. The second canonical variable set was comprised of the mental health variables. The first canonical root produced a strong and positive correlation of $.88, F(5,96)=17.53, p<.001$. It was reported that $78.6 \%$ of the variance in the first root (i.e., gender role conflict) could be predicted by the paired 
variate (i.e., mental health variables), indicating that almost $79 \%$ of the change in gender role conflict could be explained by changes in mental health variables. The second significant canonical root resulted in another strong and positive correlation of .75, $F(5,96)=9.19, p<.001$. It was reported that $57.3 \%$ of the variance in the second variate (i.e., mental health variables) could be predicted by the paired variate (i.e., gender role conflict). This was indicative that $57.3 \%$ of the change in mental health could be explained by changes in gender role conflict.

Gay men with lower Restrictive Affectionate Behavior Between Men and Success, Power, and Competition had better overall mental health including higher selfesteem. The researcher stated that those participants who were less concerned about exhibiting affectionate behavior toward other men or who were less concerned with being successful and competitive reported having better overall mental health. It was further reported that gay men with higher Restrictive Affectionate Behavior Between Men and Restrictive Emotionality had lower mental health such as decreased self-esteem. These reported correlations were overall relatively strong and significant.

The effects of gender role conflict and internalized homonegativity on the mental health of gay men were examined by Ervin (2004). Mayfield (as cited in Ervin, 2004) defined internalized homonegativity as negative attitudes toward homosexuality often adopted and internalized by gay men and lesbian women as a result of growing up in a society that is heterosexist and antigay. The researcher's sample included 277 gay men ranging in age from 18 to 76 . Ervin (2004) utilized hierarchical multiple regressions to assess the impact of gender role conflict and internalized homonegativity on mental health. Mental health was comprised of six dimensions of psychological well-being 
including (a) autonomy, (b) environmental mastery, (c) personal growth, (d) positive relations with others, (e) purpose in life, and (f) self-acceptance.

The first block of variables entered into the hierarchical regression equation was comprised of the demographic variables including age, education, ethnicity, gender, and socio-economic status. It was reported that these variables accounted for $14.7 \%$ of the variance in overall mental health, $F(4,272)=11.68, p<.001$. It was further reported that, when gender role conflict and internalized homonegativity were entered into the equation, an $\mathrm{R}^{2}$ of .318 was produced. These findings indicated that gender role conflict and internalized homonegativity accounted for almost $32 \%$ of the variance in mental health after controlling for the demographic variables. Ervin (2004) reported that the only gender role conflict subscales resulting in significant mental health outcomes were Restrictive Emotionality $(t=-5.34, p<.001)$ and Conflict Between Work and Family Relations $(t=-3.58, p<.001)$. These findings indicated that as the Restrictive Emotionality and Conflict Between Work and Family Relations components of gender role conflict increased, overall mental health decreased.

\section{Gender Role Conflict and Women}

Gender role conflict has primarily been examined in male samples. There have, however, been a handful of studies that assessed gender role conflict in women. According to O'Neil (as cited in Silva, 2002), studies examining gender role conflict in women have become a necessity due to the fact that more women are challenging stereotypical characteristics assigned to femininity such as weak, dependent and submissive. Accordingly, the pronouns used in the GRCS were modified to be applicable 
to women with the result being the GRCS-W. There have been approximately eight studies to date that have examined gender role conflict in women.

Ethnicity, gender, and gender role conflict were assessed by Silva (2002) by examining differences in gender role conflict between a 56 person Latino sample and a 118 person Latina sample. The researcher found significant differences between the male and female participants. Male participants had higher overall gender role conflict, $t=-36$, $p=.0004$. In addition, male participants were reportedly higher than female participants in Success, Power, and Competition $(t=-2.98, p=.0033)$, Restrictive Emotionality $(t=-2.26, p=.0249)$ and Restrictive Affectionate Behavior Between Men/Women $(t=-5.88, p=.0000)$. No significant gender difference was found in Conflict Between Work and Family Relations. This was purportedly due to the fact that both males and females experience comparable stress relating to conflicts between work and home.

Zamarripa, Wampold, and Gregory (2003) were also among the first researchers to examine gender role conflict in both males and females. The researchers assessed if the results repeatedly found in male samples could be replicated in a sample that included both males and females. Male participants in this study were found to exhibit higher Restrictive Emotionality as was anticipated, $t=2.65, p<.009$. An examination of the means further revealed that men exhibited higher levels of Restrictive Affectionate Behavior Between Men/Women than did the women. The highest degree of restrictive affection was from men toward other men, followed by men toward women, and women toward women. Based upon socialized gender role theories, these findings were also anticipated by the researchers. There were no significant differences found between the sexes in Conflict Between Work and Family Relations or in levels of depression. 
Regression analysis was used to examine the relationship between the conflict variables and the mental health variables (i.e., depression and anxiety). Restrictive Emotionality was found to be a statistically significant predictor of depression for both men $(\beta=.29, p=.026)$ and women $(\beta=.17, p=.05)$. Conflict Between Work and Family Relations was found to be a significant predictor of depression for men $(\beta=.23, p=.018)$ and for women $(\beta=.19, p=.026)$. In addition, Conflict Between Work and Family Relations significantly predicted anxiety in both men $(t=3.43, p=.001)$ and women $(t=3.36, p=.001)$. Both Conflict Between Work and Family Relations and Restrictive Emotionality, as predicted, resulted in decreased mental health for both male and female participants. This study added further empirical support for findings found by other researchers in gender role conflict studies. Additional researchers, however, continued to examine the effects of gender role conflict on mental health outcomes.

\section{Gender Role Conflict and Mental Health}

The most explicit source of stress-induced mental health issues for minorities such as GL individuals, include societal rejection and discrimination that are experienced because of membership in a stigmatized group (Meyer, 1995). Deviation from approved societal gender roles can often be the catalyst for becoming a member of a stigmatized group. An otherwise minor occurrence, such as a slur directed at a homosexual, may evoke feelings of hurt and rejection disproportionate to the occurrence that precipitated them (Meyer, 1995). Individuals aware that they do not necessarily conform to societal expectations of appropriate gender roles often experience significant amounts of gender role conflict (O’Neil et al., 1986). 
Prejudicial events and discriminatory actions or behaviors are sometimes a catalyst for much of the gender role conflict and subsequent mental health issues suffered by GL individuals. As previously noted, researchers have examined the correlations between gender role conflict and the mental health of men and women (Carter, Williams, Juby, \& Buckley, 2005; Good \& Mintz, 1990; Good et al.. 1995; Sharpe \& Heppner, 1991; Simonsen, Blazina, \& Watkins, Jr., 2000). The empirical results have been fairly consistent in reporting negative mental health consequences associated with gender role conflict. Mental health constructs analyzed by researchers have included depression, anger, anxiety, shame, self-esteem and loneliness among others (Carter, Williams, Juby, \& Buckley, 2005).

\section{Gender Role Conflict and Self-Esteem}

Gender role conflict has been shown to result in harmful mental health outcomes including decreases in self-esteem (Good \& Mintz, 1990). Sharpe and Heppner (1991) examined the relationship of gender role, gender role conflict, and mental health (i.e., self-esteem, anxiety, depression, social intimacy, and contentment/distress) of male college students. Using correlational analyses, it was reported that masculinity was strongly and positively correlated with self-esteem, $r=.60, p<.01$ and moderately and negatively correlated with depression, $r=-.39, p<.01$. These findings seemed to duplicate those found by other researchers. It was further shown that masculinity did not significantly correlate with the GRCS as a whole. Masculinity, however, did significantly correlate moderately and positively with Success, Power, and Competition, $r=.29, p<$ .0001 . 
Femininity was shown to moderately and negatively correlate with Success, Power, and Competition, $r=-.26, p<.0002$ and Restrictive Emotionality, $r=-.26, p<.0001$. As masculinity increased, the drive for Success, Power, and Competition increased, however, as femininity increased, the drive for Success, Power, and Competition decreased. In addition, as femininity increased, Restrictive Emotionality decreased. This finding makes theoretical sense as it is typically masculine, sex-typed individuals who experience greater levels of Restrictive Emotionality. The researchers also used canonical analysis to analyze the data. The first canonical root was comprised of the four gender role conflict factors. The second canonical root consisted of the mental health variables. The first canonical root accounted for $56 \%$ of the variance in mental health variables. This indicated that $56 \%$ of the change in mental health levels could be explained by changes in gender role conflict. Conversely, the second canonical root revealed that $26 \%$ of the variance in gender role conflict was explained by changes in the mental health variables. Supporting the overall theme in the literature, the study revealed strong, positive correlations between masculinity and self-esteem. The researchers further reported that increases in gender role conflict appeared to be related to decreases in overall mental health. Sharpe and Heppner (1991) reported that their study replicated previous findings in that masculinity scores were positively related to self-esteem and negatively related to mental health.

In summary, a review of the literature indicates that gender role conflict tends to result in detrimental mental health repercussions including increased levels of depression for male and female participants and decreased levels of self-esteem in male participants. 
It appeared that, although gender role conflict seemingly resulted in deleterious mental health outcomes, the outcomes were not in general significantly different by gender. Gender Role Conflict and Loneliness

No studies were located that assessd gender role conflict simultaneously with loneliness. As both constructs have only recently gained researcher interest, it is not surprising that no empirical studies have been conducted to date that analyzed the interrelationship of the constructs. Several studies have been conducted that examined gender role conflict with variables other than loneliness; however, this will be the first known study to analyze gender role conflict and loneliness concomitantly. 


\section{Literature Review Summary}

Because there were multiple constructs analyzed in this literature review, it is believed that a list is the most succinct method of presenting a summary of the important findings. Significant findings pertinent to this dissertation follow.

1. Psychological gender, gender role conflict, and self-esteem are believed to be multidimensional in nature (Bem, 1974; Constantinople, 1973; Crocker, 1998; O’Neil, Helms, Gable, David, \& Wrightsman, 1986; Pelham \& Swann, Jr., 1989; Simonsen, Blazina, \& Watkins, Jr., 2000; Spence, 1993). Loneliness is believed to be unidimensional (Russell, 1996).

2. Sex-typed individuals prefer to perform activities congruent with their own gender role orientations (Bem \& Lenney, 1976).

3. Androgynous people are more adaptable to functioning in either masculine or feminine activities (Bem, 1975; Bem, Martyna, \& Watson, 1976).

4. Cross-sexed activities may result in negative mental health outcomes for sextyped persons (Bem \& Lenney, 1976).

5. Gay men experience more discrimination than lesbian women (D'Augelli, 1989).

6. GL individuals are typically more androgynous than are heterosexuals (Carlson \& Baxter, 1984; Hooberman, 1979).

7. Gay men are typically more feminine than are heterosexual men while lesbian women are typically more masculine than are heterosexual women (Bernard \& Epstein, 1978; Heilbrun, Jr., \& Thompson, Jr., 1977; Hooberman, 1979; Lippa \& Arad, 1997; Mallen, 1983). 
8. Masculinity has the strongest correlation with self-esteem, followed by androgyny (Allgood-Merten \& Stockard, 1991; Antill \& Cunningham, 1980; Burnett, Anderson, \& Heppner, 1995; Carlson \& Baxter, 1984; Feather, 1985; Hooberman, 1979; Long, 1990, 1993; Lu \& Wu, 1998; Lundy \& Rosenberg, 1987; Orlofsky, 1977; Spence \& Helmreich, 1980; Stericker \& Johnson, 1977).

9. Femininity and undifferentiated have little or even slightly negative correlations with self-esteem (Allgood-Merten \& Stockard, 1991; Antill \& Cunningham, 1980; Bassoff \& Glass, 1982; Carlson \& Baxter, 1984; Feather, 1985; Long, 1990, 1993; Orlofsky, 1977; Stericker \& Johnson, 1977).

10. Males typically have higher levels of self-esteem than females (Allgood-Merten \& Stockard, 1991; Bassoff \& Glass, 1982; Feather, 1985).

11. Males are lonelier than females (Cramer \& Neyedley, 1998; Russell, Peplau, \& Cutrona, 1980; Solano, Batten \& Parish, 1982; Stokes \& Levin, 1986).

12. Loneliness is negatively related to masculinity in both males and females (Cramer \& Neyedley, 1998).

13. In males, femininity is negatively related to loneliness. In females, femininity is not related to loneliness (Cramer \& Neyedley, 1998).

14. Gender role conflict is positively correlated with loneliness (D'Augelli \& Grossman, 2001; D’Augelli, Grossman, Hershberger, \& O'Connell, 2001).

15. Gender role conflict is negatively related to self-esteem (Ervin, 2004; Good \& Mintz, 1990; Good et al., 1985; Jones, 1998; Simonsen, Blazina, \& Watkins, Jr., 2000; Sharpe \& Heppner, 1991; Shepard, 2001). 
16. Masculinity is positively correlated with gender role conflict in general (Good et al., 1995; Silva, 2002; Simonsen, Blazina, \& Watkins, Jr., 2000).

17. Femininity is negatively correlated with Success, Power, and Competition and Restrictive Emotionality (Sharpe \& Heppner, 1991).

18. Males tend to exhibit more overall gender role conflict than do females (Silva, 2002). In addition, Restrictive Emotionality, Restrictive Affectionate Behavior Between Men/Women, and Success, Power, and Competition are slightly higher among men (Zamarripa, Wampold, \& Gregory, 2003).

Based upon the summarized empirical evidence reported by other researchers, it is possible to develop realistic hypotheses for a new study that will beused to examine the interrelationship of biological gender, psychological gender, gender role conflict, selfesteem, and loneliness in a gay and lesbian sample. The following chapter will delineate the design of the current study. 


\section{CHAPTER III}

\section{METHODS}

This chapter presents a detailed description of study participants and design followed by a thorough discussion of all instruments used. The final section of this chapter is dedicated to discourse surrounding the statistical analyses that will be utilized to answer determined research questions.

Participants

The population of interest in this study included gay and lesbian (GL) persons in locations all across the United States. Approximately 100 to 200 college and university GL groups who had listed contact information on http://www.glbtstudentpride.com were asked to forward study information to individuals on their respective Listservs. A Listserv is defined as "Used for software for managing email transmission to and from a list of subscribers" (Merriam-Websters Collegiate Dictionary, 2003). It is impossible to know exactly how many potential participants received the study information due to the fact that the number of subscribers on each Listserv was unknown. Participants on many, if not all, of the Listservs included students, faculty, and alumni. In addition, snowball sampling, arguably the most commonly used method of gathering a GL sample, was employed as a secondary method of gathering sample participants. Snowball sampling occurs when data are gathered from a friend who identifies another friend and so forth (Rossman \& Rallis, 2003). When attempting to use the snowball sampling technique, 
potential GL participants were asked to forward the electronic survey link to other known GL individuals.

An advertisement was placed in a Louisville, Kentucky coffee shop known to be frequented by GL customers. In addition, an advertisement was placed in a liberal newspaper published in Louisville, Kentucky. Although a small number of participants were recruited using advertisements, the response rate was minimal compared to the other recruitment techniques employed.

Although recruiting participants via GL chatrooms was the least effective of all techniques used, a minimal number of participants were recruited in this manner. A small number of male participants were located using Gay.com, a website used by gay men to chat with other gay males around the world. A profile that included study information was created. Males interested in participating in the study responded accordingly. Potential lesbian participants were recruited using America Online chatrooms, and sites such as Butch-femme.com, and technodyke.com. Once again, profiles were creating that included study information. Lesbians interested in participating in the study responded accordingly.

This study included a total of 692 responding participants. The participant base was comprised of $400(57.8 \%$ ) gay males and $292(42.2 \%)$ lesbian females. Participants were United States residents representing forty-three states and Washington, D.C. A large percentage of the total "combined gender" participants resided in California $(11.3 \%)$, New York (9.8\%), Ohio (9.7\%), Virginia (8.4\%), and Washington $(6.8 \%)$. The largest percentage of male participants resided in California (15.5\%), New York (9.8\%), Virginia (9.5\%), and Ohio (7.5\%). The largest percentage of female participants resided 
in Ohio (12.7\%), New York (9.9\%), Washington (8.6\%), Michigan (7.2\%), and Pennsylvania $(7.2 \%)$

Although participant age varied widely, the largest percentage of both male $(42.2 \%)$ and female $(52.1 \%)$ participants was between the ages of 21 and $30 . \mathrm{A}$ substantial number of participants, both male (31.0\%) and female $(25.0 \%)$, however, was between 31 and 50 years of age. Table 1 provides greater detail of participant age demographics. The majority of both male $(64.2 \%)$ and female $(62.7 \%)$ participants had earned a minimum of a college degree with $17 \%$ of the males and $14.1 \%$ of the females having earned professional degrees. Table 2 provides greater detail of participant education demographics.

Table 1 .

Participant Age

\begin{tabular}{lcccccc}
\hline Variable & \multicolumn{2}{c}{ Males } & \multicolumn{2}{c}{ Females } & Total Sample \\
\hline Age & Frequency & $\%$ & Frequency & $\%$ & Frequency & $\%$ \\
\hline $10-20$ & 62 & $15.5 \%$ & 45 & $15.4 \%$ & 107 & $15.5 \%$ \\
$21-30$ & 169 & $42.2 \%$ & 152 & $52.1 \%$ & 321 & $46.4 \%$ \\
$31-40$ & 67 & $16.7 \%$ & 45 & $15.4 \%$ & 112 & $16.2 \%$ \\
$41-50$ & 57 & $14.3 \%$ & 28 & $9.6 \%$ & 85 & $12.3 \%$ \\
$51-60$ & 37 & $9.3 \%$ & 16 & $5.5 \%$ & 53 & $7.7 \%$ \\
$61+$ & 8 & $2.0 \%$ & 5 & $1.7 \%$ & 13 & $1.9 \%$ \\
Missing & - & - & 1 & $.3 \%$ & 1 & $0.0 \%$ \\
Total & 400 & $100 \%$ & 292 & $100 \%$ & 692 & $100 \%$ \\
\hline
\end{tabular}


Table 2.

Participant Education

\begin{tabular}{|c|c|c|c|c|c|c|}
\hline \multirow{2}{*}{$\begin{array}{l}\text { Variable } \\
\text { Education }\end{array}$} & \multicolumn{2}{|c|}{ Males } & \multicolumn{2}{|c|}{ Females } & \multicolumn{2}{|c|}{ Total Sample } \\
\hline & Frequency & $\%$ & Frequency & $\%$ & Frequency & $\%$ \\
\hline High School & 2 & $.5 \%$ & 9 & $3.1 \%$ & 11 & $1.6 \%$ \\
\hline Some College & 138 & $34.5 \%$ & 93 & $31.8 \%$ & 231 & $33.6 \%$ \\
\hline College Graduate & 110 & $27.5 \%$ & 78 & $26.7 \%$ & 188 & $27.3 \%$ \\
\hline Masters Degree & 79 & $19.7 \%$ & 64 & $21.9 \%$ & 143 & $20.8 \%$ \\
\hline Professional Degree & 68 & $17.0 \%$ & 41 & $14.1 \%$ & 109 & $15.8 \%$ \\
\hline Other & 3 & $.8 \%$ & 3 & $1.0 \%$ & 6 & $.9 \%$ \\
\hline Missing & - & - & 4 & $1.4 \%$ & 4 & $.0 \%$ \\
\hline Total & 400 & $100 \%$ & 292 & $100 \%$ & 692 & $100 \%$ \\
\hline
\end{tabular}

Relationship status was examined because the researcher proffered levels of loneliness and self-esteem may be influenced by partnership status (D'Augelli, Grossman, Hershberger, \& O'Connell, 2001). The majority of total participants reported single status $(47.4 \%)$ or monogamous relationship status $(44.8 \%)$. Of the male participants, $56.7 \%$ reported single status and $34.5 \%$ reported monogamous relationship status. Of the female participants, $34.6 \%$ were single and $58.9 \%$ were in monogamous relationships. Table 3 provides the complete details of participant relationship status.

Most participants earned $\$ 25,000$ or less annually. This may have been due to the fact that participants were primarily recruited from college and university gay and lesbian Listservs. A total of $169(42.2 \%)$ male participants and $169(57.9 \%)$ female participants reported income levels of $\$ 25,000$ or less. Those participants reporting income levels in 
excess of $\$ 100,000$ included $43(10.8 \%)$ males and $10(3.4 \%)$ females. Complete

participant demographic information relative to income status is reported in Table 4.

Table 3 .

Relationship Status

\begin{tabular}{lcccccc}
\hline Variable & \multicolumn{2}{c}{ Males } & \multicolumn{2}{c}{ Females } & \multicolumn{2}{c}{ Total Sample } \\
\hline Relationship Status & Frequency & $\%$ & Frequency & $\%$ & Frequency & $\%$ \\
\hline Single & 227 & $56.7 \%$ & 101 & $34.6 \%$ & 328 & $47.4 \%$ \\
Non Monogamous & 30 & $7.5 \%$ & 16 & $5.5 \%$ & 46 & $6.6 \%$ \\
Monogamous & 138 & $34.5 \%$ & 172 & $58.9 \%$ & 310 & $44.8 \%$ \\
Heterosexual Marriage & 3 & $.8 \%$ & 1 & $.3 \%$ & 4 & $.6 \%$ \\
Missing & 2 & $.5 \%$ & 2 & $.7 \%$ & 4 & $.6 \%$ \\
Total & 400 & $100 \%$ & 292 & $100 \%$ & 692 & $100 \%$ \\
\hline
\end{tabular}

Table 4.

Income Level

\begin{tabular}{llll} 
Variable & Males & Females & Total Sample \\
\hline
\end{tabular}

\begin{tabular}{lcccccc} 
Income Level & Frequency & $\%$ & Frequency & $\%$ & Frequency & $\%$ \\
\hline$\$ 25,000$ or less & 169 & $42.2 \%$ & 169 & $57.9 \%$ & 338 & $48.8 \%$ \\
$\$ 25,001$ to $\$ 50,000$ & 91 & $22.7 \%$ & 64 & $21.9 \%$ & 155 & $22.4 \%$ \\
$\$ 50,001$ to $\$ 75,000$ & 62 & $15.5 \%$ & 32 & $11.0 \%$ & 94 & $13.6 \%$ \\
$\$ 75,001$ to $\$ 100,000$ & 24 & $6.0 \%$ & 8 & $2.7 \%$ & 32 & $4.6 \%$ \\
$\$ 100,001$ or higher & 43 & $10.8 \%$ & 10 & $3.4 \%$ & 53 & $7.7 \%$ \\
Missing & 11 & $2.8 \%$ & 9 & $3.1 \%$ & 20 & $2.9 \%$ \\
Total & 400 & $100 \%$ & 292 & $100 \%$ & 692 & $100 \%$ \\
& & & & & &
\end{tabular}

\section{Design}

Biological gender (i.e., male and female) of a homosexual sample and psychological gender (i.e., masculinity, femininity, androgyny, and undifferentiated) 
served as the independent variables in this study. Psychological gender was measured using the Bem Sex Role Inventory (BSRI). Overall gender role conflict, self-esteem, and loneliness functioned as dependent variables. Gender role conflict was measured using the Gender Role Conflict Scale (GRCS). In order to limit the number of dependent variables to a manageable number, the overall GRCS score was used as the dependent variable as opposed to using the four GRCS subscale scores. Self-esteem was measured using the Rosenberg Self-esteem Scale, and loneliness was measured using the Revised UCLA Loneliness Scale.

A non-experimental design was used in conducting this study. All data other than demographic data were collected with an electronic survey using Likert-type scaled responses. The survey packet included demographic questions, the psychological gender scale (BSRI), the Gender Role Conflict Scale (GRCS), the Rosenberg Self-esteem Scale (RSES), and the Revised UCLA Loneliness Scale (UCLA). Collected demographic information included age, biological gender, sexual orientation status, level of education, relationship status, and income level. Surveymonkey.com was used to create the electronic survey distributed to interested participants. Surveymonkey.com accumulated participant responses and exported collected data into an Excel spreadsheet that was, in turn, easily imported into statistical software, SPSS 15.0.

\section{Procedure}

The researcher used a variety of procedures in attempting to collect participant data. Some of the procedures attempted were more effective than others. The GL college and university Listservs provided the majority of study participants. This population appeared eager to participate in the study. Snowball sampling, although certainly useful, 
provided modicum results compared to the college and university Listservs. In addition, advertisements were placed in liberal newspapers and coffee houses commonly frequented by GL customers. Although a few participants responded to these advertisements, the number of participants relative to the GL Listservs was minimal. The researcher attended a GL gay pride picnic in Louisville, KY hoping to find willing participants. Most individuals at the picnic, however, were not interested in discussing a survey while they were attending a picnic. Finally, a minimal number of participants were recruited using gay and lesbian internet chatrooms. Chatrooms were the least effective of all procedures attempted.

It would likely be remiss to not discuss in greater detail the electronic survey used for this study. The original intent was to use paper copies of the survey in collecting research data. After careful consideration, however, an electronic version of the instrument seemed preferable for several reasons. First, the increase in efficiencies and reduction in paper, postage, mailing, and data entry costs were significant (Dillman, 2000). This was especially true given the number of participants and the fact that participants were located all over the United States. Second, the time spent in survey implementation was decreased from weeks or months to days (Dillman, 2000).

Most importantly, according to Dillman, the potential for reducing the close correspondence between survey costs and sample size could not be ignored. Once the electronic survey was developed, the cost of adding each additional participant was significantly less compared to traditional mailing techniques. The need for pre-survey notices and follow-up letters was eliminated altogether. A third reason to choose the electronic version was that many participants were more likely to complete an easy-to- 
use, electronic survey over flipping through pages of a paper copy. In addition, participants could complete the survey at their own convenience and not have to worry about making a trip to the post office to return the completed survey. Fourth, participants would likely consider the electronic version to be more anonymous than a paper copy. The only person who had access to the electronic results was the researcher. In addition, there was no way to tell who completed a particular survey. The surveys were completely anonymous. Surveymonkey.com also tracked survey responses by computer. Only one response per computer was permitted. This option eliminated the possibility of an individual completing the survey more than once. One caveat issued by Dillman, however, was the fact that there continues to be individuals who either do not have internet access, who do not have the internet skills necessary to access the survey, or who simply have an aversion to computer technology. After considering the options, the internet survey seemed to clearly be the option most likely to generate the best participant response rate at the lowest researcher cost.

\section{Instruments}

Five commonly used instruments were used to gather study data. Participants were asked to respond to a total of 103 survey items. Estimated time for participants to complete the survey packet was approximately 15-20 minutes.

\section{The Bem Sex Role Inventory-Short Form (BSRI)}

The BSRI was published in 1974 as a measurement instrument of psychological gender, and is arguably the most commonly used tool to measure the construct. The instrument includes a Femininity scale, a Masculinity Scale, and a Neutral Social Desirability Scale. The Femininity Scale is comprised of 20 traits considered socially 
desirable for a female. The central characteristic of the Femininity Scale is an affective concern for the welfare of others (Parsons \& Bales, 1955). The Masculinity Scale contains 20 traits deemed socially desirable for a male. The central characteristic of the Masculinity Scale is a cognitive focus on completing the job (Bem, 1974). The Neutral Social Desirability Scale contains 20 traits that are neutral regarding biological sex. The Neutral Scale was included on the instrument in an attempt to discourage participants from responding in a manner deemed socially desirable. Utilizing a 7-point, Likert-type scale $(1=$ never or almost never true, $7=$ always or almost always true $)$, participants respond to the $60 \mathrm{BSRI}$ items as an indication of how well each descriptor applies to them personally. Based upon responses, respondents receive two scores, a masculinity score and a femininity score. Respondents may be further categorized into one of four categories based upon their scores: masculine, feminine, androgynous, or undifferentiated.

Validity of the Bem Sex Role Inventory

Although the BSRI is arguably the most commonly used instrument to measure psychological gender, it has not been exempt from its share of controversy. The debate stems from the fact that many believe the BSRI may measure constructs other than masculinity and femininity. Some researchers posit that masculinity has been associated with an "instrumental" orientation, a cognitive focus on getting the job done, whereas femininity has been associated with an "expressive" orientation, an affective concern for the welfare of others (Parsons \& Bales, 1955).

As a result of the tremendous empirical interest in the BSRI, myriad factor analytic studies have been completed. Choi and Fuqua (2003) comprised a summary 
report of 23 exploratory factor analytic studies completed since the development of the BSRI. The majority of the researchers reported one F factor. Items loading on the F factor included expressive and/or communal traits such as affectionate and compassionate. Only 10 of the 20 feminine traits included on the BSRI, however, loaded on the factor. It was reported that this finding, along with other multidimensional suggestions in the literature, implied an under representation of dimensions of femininity.

Bem reported one $\mathrm{M}$ factor on which 17 of the 20 masculine traits loaded significantly (Bem, 1981). Masculine traits that loaded significantly included assertive, independent, competitive, and strong personality. Some of the studies reviewed revealed similar findings to Bem's (1981) study. The M factors reported in many of the studies, however, appeared to be much more complex. Many of the researchers reported two to three factors. Collins, Waters, and Waters (as cited in Choi \& Fuqua, 2003) suggested that perhaps the BSRIM items reflected two very distinct masculine traits (i.e., agentic and instrumental). The $\mathrm{F}$ items, on the other hand, perhaps reflected a singular trait, expressiveness. Considering the fact that the unidimensionality of the $\mathrm{M}$ subscale was not supported in the majority of the 23 studies, the resulting factor that Bem described as "masculine" might be more appropriately described as a construct with two components: agentic and instrumental (Choi \& Fuquà, 2003). The Choi and Fuqua study provided support for the assumption of multidimensionality.

Despite a lack of sufficient evidence supporting its construct validity, the BSRI remains the most common measure of masculinity and femininity in the general population. The validity of BSRI inventory scores in the GL population, however, is even less clear. Chung (1995) completed a study designed to address that particular issue. 
Using correlational and factor analytic techniques, the BSRI was reported to be equally valid for both heterosexuals and homosexuals. There were very few differences noted on the 40 items included on the masculinity and femininity scales. This finding was especially true for the Short Form of the BSRI which includes only the first 10 items from both scales. Reported coefficient alphas on the BSRI Short Form Femininity Scale were .84 and .80 for heterosexual and gay respondents, respectively. The reported coefficient alphas on the BSRI Short Form Masculinity Scale were .89 and .86 for heterosexual and gay respondents, respectively.

Regardless of the empirical debate concerning the validity of the BSRI, it continues to be the measurement instrument of choice for many researchers. Furthermore, the instrument appears to be equally valid for both heterosexuals and homosexuals. Whether or not the instrument actually measures masculinity and femininity or subcategories of masculinity and femininity has not discouraged researchers from using the BSRI. Although some posit that the BSRI may actually measure subcategories of masculinity and femininity such as instrumental and expressive traits (Spence, 1991), the concurrence seems to be that the instrument continues to be an overall valid measure of psychological gender role orientation and continues to be widely used despite criticisms based upon theoretical and methodological concerns (Hoffman, Borders, \& Hattie, 2000). Reliability of the Bem Sex Role Inventory

Bem (1974) calculated coefficient alpha separately for cach scale in an attempt to establish internal consistency using two different samples. The reliability coefficients for the first sample for the three respective scales were high (i.e., Masculinity, .86; Femininity, .80; Social Desirability, .75). Similarly, Bem (1974) reported that the 
coefficient alphas for the second sample were also high (i.e., Masculinity, .86 , Femininity, .82, Social Desirability, .70).

To further establish the stability of the BSRI scores, Bem used the test-retest technique. The BSRI was administered to the same sample approximately four weeks following the initial administration of the instrument. Bem computed product-moment correlations between the two sets of scores and the test-retest results on all four scales (i.e., Masculinity $r=.90$; Femininity $r=.90$; Androgyny $r=.93$; Social Desirability $r=.89)$ indicated that the scales were highly reliable.

The psychometric properties of the instrument have been examined by multiple researchers. Bem, in response to reliability concerns, created a short form BSRI. The short form, as previously reported, includes the first 10 items from each scale, resulting in a 30-item instrument. The short form has been reported to be statistically reliable by many researchers (Bem, 1981). Bem reported that, even with the elimination of those items with poor item-total correlations, the short-form correlates highly with the longform (approximately .90).

Chung (1995) tested the reliability of the BSRI on a sample of heterosexual and homosexual participants. The resulting coefficient alphas indicated that the instrument was reliable for both heterosexual and homosexual samples. The reported coefficient alphas on the Femininity Scale were .73 for heterosexuals and .74 for homosexuals using the long form while the coefficient alphas on the short form were .84 for heterosexuals and .80 for homosexuals. The reported alpha coefficients on the Masculinity Scale were .90 for heterosexuals and .86 for homosexuals using the long form and .89 for heterosexuals and .86 for homosexuals on the short form (Chung, 1995). As previously 
mentioned, the short form version of the BSRI will be used in the current study. A 7-point, Likert-type scale ( 1 = never true of self, $7=$ always true of self $)$ will be used to determine overall Masculinity and Femininity Scale scores. The mean score from each scale will represent the final Masculinity and Femininity Scores per participant.

\section{Gender Role Conflict Scale (GRCS)}

The GRCS is a 37-item measurement instrument of gender role conflict among men. As described in a previous chapter, the scale is adaptable to females and will be modified appropriately with developer permission to fit the needs of the current study. The GRCS was developed in 1986 due to the fact that there was a lack of psychometric instruments available to accurately measure gender role conflict. Participants are asked to rate the degree to which they either agree or disagree about personal gender role attitudes, conflicts, and behaviors using a 6 -point, Likert-type scale $(1=$ Strongly agree to $6=$ Strongly disagree) (O'Neil et al., 1986). The GRCS is comprised of four factors or categories: (a) 13-item Success, Power, and Competition factor (i.e., Strong drive to move up the corporate ladder and to be smarter and physically stronger than others), (b) 10-item Restrictive Emotionality (i.e., Difficulty expressing feelings or denying others the right to express emotive feelings), (c) 8-item Restrictive Affectionate Behavior Between Men (i.e., Index of a man's avoidance and discomfort of affection between men), and (d) 6-item Conflicts Between Work and Family Relations (i.e., Measures the level of distress experienced due to work and school obligations on family and life commitments).

Examples of items from the GRCS are "Competing with others is the best way to succeed" which is part of the Success, Power, and Competition factor and "I have 
difficulty telling others I care about them" which is part of the Restrictive Emotionality factor (O'Neil et al., 1986). Also included are "Verbally expressing my love to another man is difficult for me" which is representative of the Restrictive Affectionate Behavior Between Men factor and "I feel torn between my hectic work schedule and caring for my health" which is representative of the Conflicts Between Work and Family Relations factor.

\section{Validity of the Gender Role Conflict Scale}

O'Neil et al. (1986) originally included 85 items on the GRCS. The researchers proffered the possibility that the GRCS measured six factors that included Restrictive Emotionality, Homophobia, Control, Restricted Sexual and Affectionate Behavior, Obsession with Achievement and Success, and Health Care Problems. The validity of the GRCS was established in several ways including item-reduction procedures, reliability data analysis and factor analysis (O’Neil et al.). First, using a 5-point, Likert-type scale, raters assessed (a) which items definitely related to the male gender role to (b) which items definitely did not relate to the male gender role. Using 3.5 as the median, all items that were rated as not relating to the male gender role were excluded from the instrument.

Second, principal components and common factor model factor analyses, with both orthogonal and oblique rotations, were completed. All items that loaded less than .35 , or any item that loaded more than .30 on more than one scale, were eliminated from the GRCS. The result of the factor analysis and item-reduction was the four-factor structure previously described. In addition, multiple researchers have been successful in confirming the four factor structure proposed by O'Neil et al. (Good et al., 1995; Simonsen, Blazina, \& Watkins, Jr., 2000). 


\section{Reliability of the Gender Role Conflict Scale}

The reliability of the GRCS was established using a four-week test-retest analysis. Reliability coefficients were reported to be .84 on the Success, Power, and Competition factor, .76 on the Restrictive Emotionality factor, .86 on the Restrictive Affectionate Behavior Between Men factor, and .72 on the Conflicts Between Work and Family Relations factor (O'Neil et al, 1986). Good et al. reported coefficient alphas of .92 on the GRCS as a whole and $.88, .89, .93$, and .79 on the Success, Power, and Competition, Restrictive Emotionality, Restrictive Affectionate Behavior Between Men, and Conflicts Between Work and Family Relations factors, respectively. Zamarripa, Wampold, and Gregory (2003) found that, when analyzing the gender effects on certain mental health variables, the GRCS was as reliable for the women in their sample as it was for the men. Certain scale items were rewritten to make the instrument applicable to female respondents. The resulting coefficient alphas were comparable to those reported in the literature.

\section{Rosenberg Self-Esteem Scale (RSES)}

The 10-item Rosenberg-Self Esteem Scale is arguably the most ubiquitous measurement instrument of global self-esteem. The instrument was designed to measure levels of self-acceptance and self-worth (Balsam, Beauchaine, Mickey, \& Rothblum, 2005). Participants respond to statements such as "On the whole, I am satisfied with myself" using either a 4-point or a 5-point, Likert type scale $(1=$ strongly agree to $5=$ strongly disagree). It was noted in the literature that some researchers used a 4-point, Likert type scale while others used a 5-point scale. The scales that used a 5-point, Likert type scale assigned a neutral position to response number 3, "Neither agree nor disagree." 
In addition, sometimes the results were recoded from 1 to 5 to 0 to 4 , or from 1 to 4 to 0 to 3. This made the comparison and interpretation of means somewhat arduous. Responses are summed, however, yielding a possible score from 10 to 50 or 10 to 40 , dependent upon the scale used, with higher scores indicating higher levels of self-esteem (D'Augelli, Grossman, Hershberger, \& O'Connell, 2001). Developed in 1965, it has proven validity and reliability in numerous studies. Reported coefficient alphas range from the high .80s to the low .90s (Balsam, Beauchaine, Mickey, \& Rothblum, 2005; D'Augelli \& Grossman, 2001; D'Augelli, Grossman, Hershberger, \& O'Connell, 2001; Vincke \& Van Heeringen, 2002).

\section{Revised UCLA Loneliness Scale (UCLA)}

The 20-item, Revised UCLA Loneliness Scale, a commonly used measurement instrument of loneliness, will be used to measure levels of loneliness. Ten positively worded items and ten negatively worded items are scored using a 4-point, Likert-type scale $(1=$ Never to $4=$ Often $)$. Possible scores range from 20 to 80 with higher scores being indicative of higher levels of loneliness (Cramer \& Neyedley, 1998). The instrument developers reported that, in college student samples, the reported coefficient alpha was .96 . Test-retest correlations were reported to be .70 and .60 after two month and seven month intervals (Cramer \& Neyedley, 1998). Other researchers reported coefficient alphas ranging from .86 to .90 (D'Augelli, Grossman, Hershberger, \& O'Connell, 2001; Stokes \& Levin, 1986). It was further reported that the developers reported strong validity due to a high correlation $(r=.91)$ between two different samples (Stokes \& Levin, 1986). Discriminant validity was examined by comparing the instrument to other instruments used to measure mood and personality. The highest 
correlation was with the Self-Labeling Loneliness Index. The correlation between the two instruments was .71, indicating that the two measured similar constructs. It further seems that, because researchers are commonly using the Revised UCLA Loneliness Scale, they appear to have accepted that the instrument has adequate validity.

\section{Statistical Analysis}

Stevens (2002) was referred to in the determination of an adequate sample size. It was decided that, for the current study, power would equal .90 and $\alpha$ would equal .05 . Since a two-way factorial MANOVA was used in the statistical analysis, to have a moderate effect size, the recommended sample size was approximately, $n=350$. A minimum of 175 males plus 175 females needed to be recruited in order to meet the base number of participants. As was evident in the participant section of this chapter, the minimum participant requirements were exceeded for both male and female participants. SPSS 15.0 was used for all statistical analyses with the exception of the GRCS factor analysis. EQS was used as the statistical software for factor analytic purposes. Descriptive statistics and intercorrelation coefficients among all major variables are reported in Chapter IV. In addition, the internal consistency of each scale used was obtained and reported.

There were in essence 5 major research questions. Three of these questions inquired about the interrelationship of two independent variables (i.e., biological gender and psychological gender) on a set of dependent variables (i.e., gender role conflict, selfesteem, and loneliness). The broad research questions were as follows: 
1. For homosexual individuals, is there a significant interaction between psychological gender and biological gender on gender role conflict, self-esteem, and loneliness?

2. Is there a significant main effect of psychological gender on gender role conflict, self-esteem, and loneliness?

3. Is there a significant main effect of biological gender on gender role conflict, self-esteem, and loneliness?

4. For homosexual individuals, what is the factor structure of the Gender Role Conflict Scale?

5. For homosexual individuals, is there a significant difference in self-esteem and loneliness based upon relationship status (i.e., single, in a non monogamous relationship, in a monogamous relationship, in a heterosexual marriage)?

In order to foster an analysis and reporting structure that was not overly complex, however, each of the dependent variables was assigned to an individual research question as reported in Chapter I of this dissertation.

As previously reported, there were two independent variables (i.e., psychological gender and biological gender) used in this study. Psychological gender had four levels: (a) masculine, (b) feminine, (c) androgynous, and (d) undifferentiated as determined by the BSRI. Biological gender had two levels: (a) male, and (b) female. The dependent variables were gender role conflict, self-esteem, and loneliness. A two-way, multivariate analysis of variance (MANOVA) was used as the primary method of statistical analysis. Since the MANOVA was statistically significant at $p=.05$, a univariate analysis of variance (ANOVA) was performed on each dependent variable. In addition, a 
confirmatory factor analysis was used to answer the research question inquiring about the factor structure of the Gender Role Conflict Scale (GRCS). The intent of the factor analysis was to evaluate if the four GRCS factors extracted in the literature fit the current data sample.

The final research questions regarding the effects of relationship status on selfesteem and loneliness were analyzed using a MANOVA. Relationship status with four levels (i.e, single, in a non monogamous relationship, in a monogamous relationship, in a heterosexual marriage) served as the independent variable while self-esteem and loneliness served as the dependent variables. Table 5 summarizes the key facts regarding the analysis for research questions one through nine and 11 through 12 . Table 5-A summarizes the analyses for research question 10 . The results of the statistical analyses for all research questions are reported in Chapter IV of this dissertation. 


\section{Table 5}

For Research Questions I through 9 and 11 through 12: Dependent Variables, Effects Tested, Statistical Procedures, and Measurement of the Indepndent Variable Psychological Gender

\begin{tabular}{|c|c|c|c|}
\hline $\begin{array}{l}\text { Research } \\
\text { Question }\end{array}$ & $\begin{array}{l}\text { Dependent } \\
\text { Variable }\end{array}$ & $\begin{array}{l}\text { Effect } \\
\text { Tested }\end{array}$ & $\begin{array}{l}\text { Statistical Procedure } \\
\text { and Measurement for } \\
\text { Independent Variable } \\
\text { Gender Role }\end{array}$ \\
\hline 1 & $\begin{array}{l}\text { Gender Role Conflict } \\
\text { (GRCS) }\end{array}$ & $\begin{array}{l}\text { Gender x Gender Role } \\
\text { interaction }\end{array}$ & Two-way MANOVA \\
\hline 2 & $\begin{array}{l}\text { Gender Role Conflict } \\
\text { (GRCS) }\end{array}$ & $\begin{array}{l}\text { Main effect of Gender } \\
\text { Role }\end{array}$ & Two-way MANOVA \\
\hline 3 & $\begin{array}{l}\text { Gender Role Conflict } \\
\text { (GRCS) }\end{array}$ & Main effect of Gender & Two-way MANOVA \\
\hline 4 & $\begin{array}{l}\text { Self-esteem } \\
\text { (Rosenberg Scale) }\end{array}$ & $\begin{array}{l}\text { Gender x Gender Role } \\
\text { interaction }\end{array}$ & Two-way MANOVA \\
\hline 5 & $\begin{array}{l}\text { Self-esteem } \\
\text { (Rsenberg Scale) }\end{array}$ & $\begin{array}{l}\text { Main effect of Gender } \\
\text { Role }\end{array}$ & Two-way MANOVA \\
\hline 6 & $\begin{array}{l}\text { Self-esteem } \\
\text { (Rosenberg Scale) }\end{array}$ & Main effect of Gender & Two-way MANOVA \\
\hline 7 & $\begin{array}{l}\text { Loneliness } \\
\text { (UCLA Loneliness } \\
\text { Scale) }\end{array}$ & $\begin{array}{l}\text { Gender x Gender Role } \\
\text { interaction }\end{array}$ & Two-way MANOVA \\
\hline 8 & $\begin{array}{l}\text { Loneliness } \\
\text { (UCLA Loneliness } \\
\text { Scale) }\end{array}$ & $\begin{array}{l}\text { Main effect of Gender } \\
\text { Role }\end{array}$ & Two-way MANOVA \\
\hline 9 & $\begin{array}{l}\text { Loneliness } \\
\text { (UCLA Loneliness } \\
\text { Scale) }\end{array}$ & Main effect of Gender & Two-way MANOVA \\
\hline 11 & $\begin{array}{l}\text { Self-Esteem } \\
\text { (Rosenberg Scale) }\end{array}$ & $\begin{array}{l}\text { Main effect of } \\
\text { Relationship Status }\end{array}$ & One-Way MANOVA \\
\hline 12 & $\begin{array}{l}\text { Loneliness (UCLA } \\
\text { Loneliness Scale) }\end{array}$ & $\begin{array}{l}\text { Main effect of } \\
\text { Relationship Status }\end{array}$ & One-Way MANOVA \\
\hline
\end{tabular}

a If the MANOVA has a significant effect, follow-up ANOVA will be performed on each dependent variable.

Note. GRCS $=$ Gender Role Conflict Scale, BSRI = Bem Sex Role Inventory 
Table 5-A

Analyses for Research Question 10

\begin{tabular}{|l|l|l|}
\hline Instrument & Statistical Procedure & Hypothesis \\
\hline $\begin{array}{l}\text { Gender Role } \\
\text { Conflict Scale } \\
\text { (GRCS) }\end{array}$ & $\begin{array}{l}\text { Confirmatory Factor } \\
\text { Analysis }\end{array}$ & $\begin{array}{l}\text { Factor structure of GRCS for } \\
\text { sample of homosexual persons } \\
\text { will be comparable to factor } \\
\text { structure obtained from a sample } \\
\text { of heterosexual persons }\end{array}$ \\
\hline
\end{tabular}




\section{CHAPTER IV}

\section{RESULTS}

This chapter presents all preliminary analyses including the statistical assumptions, reliability analysis, descriptive statistics, and correlational analyses. In addition, the statistical results from the analyses involving the twelve research questions are presented. Statistical analyses are presented throughout the chapter while the findings relative to the research questions are summarized at the end of the chapter. All statistical analyses were completed using SPSS 15.0 with the exception of the confirmatory factor analysis. EQS (Bentler, 1995) was used to complete the confirmatory factor analysis.

\section{Assumptions}

An analysis of the major multivariate assumptions was completed prior to other multivariate procedures. Assumptions assessed included independence, normality, and equality of covariance of matrices.

\section{Independence}

Independence was addressed prior to data collection. The survey design facilitated the ability of participants to complete the electronic instrument at their own convenience. Participants were scattered across the United States and were unable to influence the responses of others. It is believed that the assumption of independence was sufficiently met in this study. 


\section{Normality}

Because there is no direct test for multivariate normality, univariate normality was assessed on each of the dependent variables. Histograms with a bell-shaped curve were used to determine that the dependent variable approximated a normal distribution. In addition, the Shapiro-Wilk statistic was generated for each of the dependent variables. The resulting Shapiro-Wilk statistic for the Gender Role Conflict Scale (GRCS), Rosenberg Self-Esteem Scale (RSES), and UCLA Loneliness Scale (UCLA) was 1.0, .95, and .99 , respectively, indicating that the assumption of normality was sufficiently met due to the fact that all values were in excess of the assigned alpha value of .01 .

\section{Equality of Covariance of Matrices}

Box's test of equality of covariance matrices was run as a test of this assumption. Using the results from the Bem Sex Role Inventory - Masculine Scale (BSRIM), the Bem Sex Role Inventory - Feminine Scale (BSRIF) (i.e., psychological gender group), and group (i.e., gay male or lesbian female) as independent variables, statistical significance was found, $F(42,411327.1)=1.58, p=.01$. It is believed that the statistical significance in Box's $M$ was a result of the disparity in the number of female participants versus the number of male participants. Tabachnick and Fidell (2007) reported that a MANOVA is robust enough to overcome the violation of this assumption assuming that the significance value is not too extreme, for example, less than .001 . Based upon the sample size and the significance value of Box's $M$ for this study, violation of this assumption is not believed to have impacted statistical results in a significant manner. 


\section{Reliability Analysis}

Table 6 was used to report the resultingcoefficient alpha estimates. The resultin $g$ Cronbach alphas were comparable to those found in the literature on each respective scale (Bem, 1974; D’Augelli \& Grossman, 2001; O’Neil, et al., 1986; Russell, 1996; Spence, 1986). All reliability coefficients were relatively strong. In addition, the reliability coefficients reported for the GRCS for the current study were very similar to those reported by Rogers and Abbey-Hines (1997).

Table 6.

Comparison of Reliability Coefficients on the BSRI, RSES, UCLA Loneliness Scale, and the GRCS

\begin{tabular}{lccc} 
Variable & Number of Items & Cocfficient of Internal Consistency \\
\hline & & Current Study & Literature \\
\cline { 2 - 3 } BSRI & 20 & .84 & .84 \\
RSES & 10 & .90 & .90 \\
UCLA & 20 & .94 & .96 \\
GRCS & 37 & .93 & .92 \\
GRCSSPC & 13 & .93 & .87 \\
GRCSRE & 10 & .90 & .88 \\
GRCSRAB & 8 & .84 & .96 \\
GRCSCBWFR & 6 & .88 & .79 \\
\hline
\end{tabular}

\section{Psychological Gender Categories}

Psychological gender category was determined using the Bem Sex Role Inventory (BSRI). The BSRI categorizes participants into one of four psychological gender categories. These categories include masculine, feminine, androgynous, and undifferentiated orientations. In this study, the median BSRIM $(M=5.0)$ and BSRIF 
$(M=5.6)$ scores were used to determine participant psychological gender. If both scores were above the median score, the participant was categorized as androgynous. If the masculine score was above the median and the feminine score was below the median, the participant was deemed masculine. Conversely, if the feminine score was above the median score and the masculine score was below the median score, the participant was categorized as feminine. In the event that both scores were below the median score, the participant was deemed undifferentiated.

Although the median-split methodology is commonly used in behavioral science research, Pedhazur (1997) warned that the continuous variable categorization practice is problematic and should be avoided. Based upon the sample in question, an individual could potentially be categorized differently dependent upon sample median values. In other words, an individual could be categorized as androgynous in one sample and masculine in a second sample. Psychological gender categorization, nevertheless, was determined in this study based upon the commonly used median-split methodology in order to facilitate the examination of the effects of psychological gender group on the dependent variables (i.e., gender role conflict, self-esteem, and loneliness).

Table 7 provides the delineation of participant psychological gender categorization based upon the BSRI results. The largest percentage of male participants was categorized as either undifferentiated $(27 \%)$ or feminine (26.5\%). Most female participants were categorized as either androgynous (28.2\%) or feminine (29.2\%). Other researchers, such as Bem (1977), reported more masculine and undifferentiated male participants than the remaining two categories (i.e., feminine and androgynous). The fact that male participants were primarily feminine and undifferentiated is likely due to the 
fact that the males in the current study were gay; and, as reported earlier, gay males are more feminine than are heterosexual males while heterosexual males are more masculine than are homosexual males (Bernard \& Epstein, 1978; Heilbrun, Jr., \& Thompson, Jr., 1977; Hooberman, 1979; Lippa \& Arad, 1997; Mallen, 1983).

Table 7.

BSRI Psychological Gender Categorizations

\begin{tabular}{lcccccc}
\hline Variable & \multicolumn{2}{c}{ Males } & \multicolumn{2}{c}{ Females } & \multicolumn{2}{c}{ Total Sample } \\
\hline BSRI & Frequency & $\%$ & Frequency & $\%$ & Frequency & $\%$ \\
\hline Androgynous & 94 & $23.5 \%$ & 82 & $28.2 \%$ & 176 & $25.4 \%$ \\
Masculine & 92 & $23.0 \%$ & 61 & $20.9 \%$ & 153 & $22.1 \%$ \\
Feminine & 106 & $26.5 \%$ & 85 & $29.2 \%$ & 191 & $27.6 \%$ \\
Undifferentiated & 108 & $27.0 \%$ & 63 & $21.7 \%$ & 171 & $24.9 \%$ \\
Missing & - & - & 1 & $0.0 \%$ & 1 & $0.0 \%$ \\
Total & 400 & $100 \%$ & 292 & $100 \%$ & 692 & $100 \%$ \\
\hline
\end{tabular}

Hooberman (1977) compared male homosexuals to male heterosexuals and found that, although there was significant psychological gender differences, the majority of both the homosexual and heterosexual male groups were categorized as masculine and feminine. A large percentage of both male groups, however, were also categorized as androgynous and undifferentiated. Hooberman provided an example of Pedhazur's concern. The resulting categorization is a function of those persons included in each sample. Although the literature reports that homosexual males are typically more feminine or androgynous than are heterosexual males (Bernard \& Epstein, 1978; Heilbrun, Jr., \& Thompson, Jr., 1977; Hooberman, 1979; Lippa \& Arad, 1997; Mallen, 1983), in actuality, psychological gender differs bysample. The Hooberman results 
demonstrated that both heterosexual and homosexual males could fall into any one of the psychological gender categories based upon the characteristics of the particular sample in question.

\section{Means, Medians, and Standard Deviations by Variable}

It was noted that several of the score frequency distributions were negatively skewed. The only exceptions were the UCLA Loneliness Scale, the overall Gender Role Conflict Scale, the Restrictive Emotionality subcategory of the GRCS, and the Restrictive Affectionate Behavior subcategory of the GRCS. Because the median is less sensitive to extreme scores, it may be a more appropriate measure of central tendency than is the mean of highly skewed distributions. Both means and medians, however, are reported in this study. Table 8 is used to juxtapose the gay male means, medians, and standard deviations of each major variable used in this study. Table 9 juxtaposes the lesbian female means, medians, and standard deviations on the same variables. The following discussion regarding resulting scale means contains the researcher's impressions of the data after inspecting the means of various groups on the scales. Statistical significance testing, presented later in this chapter, constitutes the definitive data analysis.

\section{UCLA Loneliness Scale - Descriptive Statistics}

Because higher scores on the UCLA Loneliness Scale indicated higher levels of loneliness, this sample seemed to have an overall average level of loneliness $(M=2.22$, $S D=.53)$. The mean scores on the UCLA Loneliness Scale were $M=2.23, S D=.53$ and $M=2.20, S D=.51$ for males and females, respectively. This indicated that males were slightly lonelier than were females. The highest possible rating on a UCLA Loneliness Scale question is four, indicating that the mean would be somewhere in between 2 and 3 
on a 4-point scale. Russell, Peplau, and Cutrona (1980) reported overall male and female mean scores of 1.85 and 1.80, respectively. Although the Russell, Peplau, and Cutrona mean scores were somewhat lower than those found in the current study, males were once again reported to be lonelier than females.

Table 8.

Descriptive Statistics by Major Variable - Gay Males

\begin{tabular}{lllll}
\hline Scale & $\mathrm{N}$ & $\mathrm{M}$ & $\mathrm{Mdn}$ & $\mathrm{SD}$ \\
\hline BSRI & 400 & 5.20 & 5.24 & .57 \\
UCLA & 386 & 2.23 & 2.20 & .53 \\
RSES & 400 & 2.96 & 3.10 & .73 \\
GRCS & 361 & 3.31 & 3.24 & .79 \\
SPC & 361 & 3.71 & 3.69 & .93 \\
RE & 362 & 3.10 & 3.05 & 1.07 \\
RAB & 361 & 2.57 & 2.38 & 1.02 \\
CBWFR & 361 & 3.81 & 3.98 & 1.20 \\
\hline
\end{tabular}

Table 9.

Descriptive Statistics by Major Variable - Lesbian Females

\begin{tabular}{lllll}
\hline Scale & $\mathrm{N}$ & $\mathrm{M}$ & $\mathrm{Mdn}$ & $\mathrm{SD}$ \\
\hline BSRI & 291 & 5.28 & 5.30 & .65 \\
UCLA & 270 & 2.20 & 2.20 & .51 \\
RSES & 280 & 2.93 & 3.00 & .76 \\
GRCS & 247 & 3.14 & 3.11 & .80 \\
$\quad$ SPC & 248 & 3.56 & 3.62 & .98 \\
RE & 248 & 2.91 & 2.90 & 1.17 \\
RAB & 248 & 2.26 & 2.13 & .92 \\
CBWFR & 247 & 3.77 & 4.00 & 1.22 \\
\hline
\end{tabular}




\section{Rosenberg Self-Esteem Scale - Descriptive Statistics}

Because participants responded to the Rosenberg Self-Esteem Scale (RSES) using a 5-point, Likert type scale that ranged from zero to four, the overall mean score on the RSES indicated that the participants as a whole had average levels of self-esteem ( $M=$ 2.95, $S D=.74$ ). The male and female means on the RSES were $M=2.96, S D=.73$ and $M=2.93, S D=.76$, respectively. The RSES mean scores, although very similar, indicated that male self-esteem was slightly higher than female levels of self-esteem. This finding was congruent with the literature (Allgood-Merten \& Stockard, 1991; Bassoff \& Glass, 1982; Feather, 1985). Using a 5-point, Likert type scale that ranged from one to five, Feather (1985) reported a male self-esteem mean of 2.99 and a female self-esteem mean of 2.81; and, Zeigler-Hill (2006) reported an overall mean self-esteem score of 3.31 .

Although the self-esteem means reported in the current study appear to be comparable to those scores reported by other researchers, a true comparison of RSES was difficult as some researchers used a 1 to 5 point scale while others used a 1 to 4 point scale. In addition, some researchers recoded the scales in accordance with Rosenberg's directive from a 1 to 5 point scale to a 0 to 4 point scale while others recoded from a 1 to 4 point scale to a 0 to 3 point scale. Other researchers chose not to recode scores at all. Furthermore, some researchers chose not to disclose whether they had utilized a 4 point scale or a 5 point scale.

\section{Gender Role Conflict Scale - Descriptive Statistics}

The scores on the Gender Role Conflict Scale and the Success, Power and Competition (SPC), Restrictive Emotionality (RE), and Conflict Between Work and 
Family Relations (CBWFR) subcategories of the GRCS indicated average levels of gender role conflict. All of the means approximated three on a maximum scale of six. Higher scores indicated higher levels of gender role conflict. Restrictive Affectionate Behavior (RAB), however, was the lowest gender role conflict subcategory reported by this sample $(M=2.44, S D=.99)$. The relatively low mean score on RAB is not surprising given the fact that the sample was comprised of gay men and lesbian women. One would logically anticipate lower levels of restrictive affectionate behavior toward a member of the same sex when the participants are gay or lesbian.

The current study overall GRCS mean was equal to 3.24 with aSD of .80 . The male mean $(M=3.31 ; S D=.79)$ on the overall GRCS was higher than the female mean $(M=3.14 ; S D=.80)$ indicating that males had higher gender role conflict than females. This finding was also congruent with the literature (Silva, 2002). In addition, the male means on all of the subcategories of gender role conflict were higher than the female means. The male means for SPC, RE, Restrictive Affectionate Behavior Between Men (RABBM), and CBWFR were $3.71,3.10,2.57$, and 3.81 , respectively. The female means for SPC, RE, Restrictive Affectionate Behavior Between Women (RABBW), and CBWFR were $3.56,2.91,2.26$, and 3.77 , respectively. These biological gender differences in subscale means were also congruent with the literature (Zamarripa, Wampold, \& Gregory, 2003).

The means reported for the current study were higher than those reported by Silva (2002). Female means reported by Silva were $2.36,2.99,2.14,1.70$, and 2.81 for overall gender role conflict, SPC, RE, RABBW, and CBWFR, respectively. Male means reported by Silva were $2.80,3.41,2.55,2.66$, and 2.88 , for overall gender roll conflict, 
SPC, RE, RABBM, and CBWFR, respectively. Jones (1998) examined gender role conflict in men alone and reported mean values of $3.59,3.02,2.50$, and 3.78 on $\mathrm{SPC}, \mathrm{RE}$, RABBM, and CBWFR, respectively. It appears that the means reported in the current study were more similar to those reported by Jones (1998). Silva's study participants were exclusively Latino/Latina. One might speculate that cultural differences may have been partially responsible for GRCS mean differences between that study and the current study.

\section{Psychological Gender-Descriptive Statistics}

The mean BSRIF score $(M=5.51, S D=.79)$ was higher than the mean BSRIM score $(M=4.96, S D=.82)$. In addition, the male and female BSRI means were very similar (Male $M=5.20$; Female $M=5.28$ ). The slight differences in the masculinity and femininity means indicated that participants were slightly higher in psychological femininity than they were in psychological masculinity. Bem (1977) reported the normative means and medians for the short-form BSRI $N=816$ ) femininity scale at 5.38 and 5.50, respectively. Bem's reported means and medians on the short-form BSRI masculinity scale were 4.83 and 4.80 , respectively. The reported BSRI means and medians found in this study were similar to those reported by Bem.

\section{Loneliness, Biological Gender, and Psychological Gender-Descriptive Statistics}

Table 10 was used to analyze the means, medians, and standard deviations from the UCLA Loneliness Scale by biological gender and psychological gender. Of particular interest from this table is the fact that, although there was not a lot of variance between the mean scores, the androgynous participants, both male and female, had lower levels of loneliness than did theother psychological gender category participants. In addition, the 
male and female participants categorized as undifferentiated (Male $M=2.38$; Female $M$ $=2.35$ ) had overall higher levels of loneliness than did the other psychological gender categorized participants. Loneliness means in masculine males and females were also relatively high (Male $M=2.26$; Female $M=2.23$ ), second only tparticipants categorized as undifferentiated. These findings were consistent with those found in the literature (Cramer \& Neyedley, 1998).

Table 10.

UCLA Loneliness ScaleMeans, Medians, and Sta ndard Deviations by Psychological Gender Category

\begin{tabular}{llllllllll}
\hline & \multicolumn{1}{c}{ Bem Sex Role Inventory } \\
\cline { 2 - 10 } Variable & $M$ & $M d n$ & $S D$ & $M$ & $M d n$ & $S D$ & $M$ & $M d n$ & $S D$ \\
Androgynous & 2.07 & 2.00 & .52 & 2.10 & 2.10 & .47 & 2.09 & 2.00 & .50 \\
Masculine & 2.26 & 2.15 & .62 & 2.23 & 2.20 & .49 & 2.26 & 2.20 & .57 \\
Feminine & 2.18 & 2.20 & .48 & 2.18 & 2.15 & .52 & 2.18 & 2.18 & .50 \\
Undifferentiated & 2.38 & 2.38 & .49 & 2.35 & 2.35 & .55 & 2.37 & 2.35 & .51 \\
Total & 2.23 & 2.20 & .53 & 2.21 & 2.20 & .51 & 2.22 & 2.20 & .53 \\
\hline
\end{tabular}

Self-Esteem, Biological Gender, and Psychological Gender-Descriptive

\section{Statistics}

Table 11 displays the means, medians, and standard deviations from the Rosenberg Self-Esteem Scale (RSES) by biological gender and psychological gender. The BSRI categorized androgynous males had the highest self-esteem $M=3.23)$ and the undifferentiated males had the lowest self-esteem $(M=2.71)$. Similar results were found in the female participants with the androgynous females having the highest self-esteem $(M=3.14)$ and the undifferentiated females having the lowest self-esteem $(M=2.62)$. The reported feminine means were also relatively low for both male and female participants, $M=2.87$ and $M=2.86$, respectively. These findings are very consistent with 
findings reported by other researchers (Allgood-Merten \& Stockard, 1991; Antill \& Cunningham, 1980; Bassoff \& Glass, 1982; Carlson \& Baxter, 1984; Feather, 1985; Long, 1990, 1993; Orlofsky, 1977; Stericker \& Johnson, 1977).

Table 11 .

Rosenberg Self-Esteem Scale Means, Medians, and Standard Deviations by Psychological Gender Category

\begin{tabular}{lllllllllll}
\hline & \multicolumn{1}{c}{ Bem Sex Role Inventory } \\
\cline { 2 - 11 } Variable & $M$ & $M d n$ & $S D$ & $M$ & $M d n$ & $S D$ & $M$ & $M d n$ & $S D$ \\
Androgynous & 3.23 & 3.43 & .64 & 3.14 & 3.20 & .67 & 3.19 & 3.40 & .66 \\
Masculine & 3.09 & 3.20 & .66 & 3.08 & 3.15 & .66 & 3.08 & 3.20 & .66 \\
Feminine & 2.87 & 2.90 & .72 & 2.86 & 2.90 & .74 & 2.87 & 2.90 & .73 \\
Undifferentiated & 2.71 & 2.80 & .76 & 2.62 & 2.70 & .87 & 2.68 & 2.70 & .80 \\
Total & 2.96 & 3.10 & .73 & 2.93 & 3.00 & .76 & 2.95 & 3.00 & .74 \\
\hline
\end{tabular}

Gender Role Conflict, Biological Gender, and Psychological Gender-Descriptive Statistics

Table 12 is used to report the means, medians, and standard deviations from the Gender Role Conflict Scale by biological gender and psychological gender. The mean gender role conflict scores were highest for masculine male $(M=3.50)$ and female $(M=$ 3.42) participants. Other researchers have reported similar findings (Good et al., 1995; Silva, 2002; Simonsen, Blazina, \& Watkins, Jr., 2000). The lowest mean gender role conflict scores were attributable to the feminine participants (Male $M=3.17$; Female $M=$ 2.99) followed by androgynous and undifferentiated participants.

As reported in Table 13, the mean "Success, Power, and Competition" (SPC) scores demonstrated that masculine males and females had higher SPC gender role conflict than the other categories. This observation is also congruent with those reported by other researchers (Sharpe \& Heppner, 1991). The BSRI masculine male and female 
mean scores were $M=4.02$ and $M=3.94$, respectively. The remaining gender role categories had relatively similar mean scores. Table 14 reports the means, medians, and standard deviations from the Gender Role Conflict Scale "Restrictive Emotionality" (RE) subcategory by biological gender and psychological gender. The undifferentiated categorization for both males and females had the highest reported RE gender role conflict (Male $M=3.32$; Female $M=3.27$ ). Androgynous participants reported the lowest RE conflict (Male $M=2.83$; Female $M=2.61$ ).

Table 12.

Gender Role Conflict Scale Means, Medians, and Standard Deviations by Psychological Gender Category

\begin{tabular}{lllllllllll}
\hline & \multicolumn{8}{c}{ Bem Sex Role Inventory } \\
\cline { 2 - 11 } Variable & $M$ & $M d n$ & $S D$ & $M$ & $M d n$ & $S D$ & $M$ & $M d n$ & $S D$ \\
Androgynous & 3.26 & 3.24 & .80 & 3.03 & 3.01 & .88 & 3.16 & 3.18 & .84 \\
Masculine & 3.50 & 3.38 & .94 & 3.42 & 3.38 & .65 & 3.47 & 3.38 & .83 \\
Feminine & 3.17 & 3.16 & .69 & 2.99 & 2.95 & .78 & 3.09 & 3.01 & .74 \\
Undifferentiated & 3.36 & 3.30 & .70 & 3.24 & 3.26 & .79 & 3.31 & 3.28 & .73 \\
Total & 3.31 & 3.24 & .79 & 3.14 & 3.11 & .80 & 3.24 & 3.19 & .80 \\
\hline
\end{tabular}

Table 13.

Gender Role Conflict Scale (SPC) Means, Medians, and Standard Deviations by Psychological Gender Category

\begin{tabular}{lllrlllllll}
\hline \multicolumn{1}{c}{ Males } & \multicolumn{7}{c}{ Females } & \multicolumn{3}{c}{ Total } \\
\hline Variable & $M$ & $M d n$ & $S D$ & $M$ & $M d n$ & $S D$ & $M$ & $M d n$ & $S D$ \\
Androgynous & 3.81 & 3.73 & .92 & 3.64 & 3.77 & 1.07 & 3.74 & 3.77 & .99 \\
Masculine & 4.02 & 4.08 & 1.04 & 3.94 & 4.04 & .89 & 3.99 & 4.08 & .98 \\
Feminine & 3.47 & 3.54 & .84 & 3.25 & 3.38 & .91 & 3.37 & 3.46 & .88 \\
Undifferentiated & 3.60 & 3.67 & .86 & 3.53 & 3.46 & .89 & 3.58 & 3.62 & .87 \\
Total & 3.71 & 3.69 & .93 & 3.56 & 3.62 & .98 & 3.02 & 3.00 & 1.11 \\
& & & & & & & & & \\
\hline
\end{tabular}


Table 14.

Gender Role Conflict Scale (RE) Means, Medians, and Standard Deviations by Psychological Gender Category

\begin{tabular}{|c|c|c|c|c|c|c|c|c|c|}
\hline \multirow[b]{3}{*}{ Variable } & \multicolumn{9}{|c|}{ Bem Sex Role Inventory } \\
\hline & \multicolumn{2}{|c|}{ Males } & \multicolumn{4}{|c|}{ Females } & \multicolumn{3}{|c|}{ Total } \\
\hline & $M$ & $M d n$ & $S D$ & $M$ & $M d n$ & $S D$ & $M$ & $M d n$ & $S D$ \\
\hline Androgynous & 2.83 & 2.65 & 1.07 & 2.61 & 2.40 & 1.20 & 2.74 & 2.50 & 1.13 \\
\hline Masculine & 3.25 & 3.10 & 1.19 & 3.17 & 3.10 & 1.02 & 3.22 & 3.10 & 1.12 \\
\hline Feminine & 2.99 & 3.10 & .95 & 2.76 & 2.60 & 1.11 & 2.89 & 2.90 & 1.02 \\
\hline Undifferentiated & 3.32 & 3.10 & 1.01 & 3.27 & 3.25 & 1.23 & 3.30 & 3.20 & 1.09 \\
\hline Total & 3.10 & 3.05 & 1.07 & 2.91 & 2.90 & 1.17 & 3.02 & 3.00 & 1.11 \\
\hline
\end{tabular}

The means, medians, and standard deviations from the Gender Role Conflict Scale "Restrictive Affectionate Behavior" (RAB) subcategory by biological gender and psychological gender are reported in Table 15. The undifferentiated categorization for both males and females had the highest reported RAB conflict (Male $M=2.77$; Female $M$ $=2.44$ ). Androgynous participants reported the lowest RAB conflict (Male $M=2.36$;

Female $M=2.08$ ). Table 16 is used to report the means, medians, and standard deviations from the Gender Role Conflict Scale "Conflict Between Work and Family Relations" (CBWFR) subcategory by biological gender and psychological gender. The BSRI categorized psychological gender revealed that androgynous males $(M=3.97)$ and masculine females $(M=4.08)$ reported the highest CBWFR conflict; and, undifferentiated males and females reported the lowest CBWFR conflict (Male $M=3.68$; Female $M=3.60$ ). 


\section{Table 15.}

Gender Role Conflict Scale (RAB) Means, Medians, and Standard Deviations by Psychological Gender Category

\begin{tabular}{lrrrrrrrrrr}
\hline & \multicolumn{1}{c}{ Bem Sex Role Inventory } \\
\hline Variable & \multicolumn{3}{c}{ Males } & \multicolumn{3}{c}{ Females } & \multicolumn{4}{c}{ Total } \\
\cline { 2 - 11 } Androgynous & 2.36 & 2.13 & .88 & 2.08 & 1.88 & .85 & 2.24 & 2.06 & .88 \\
Masculine & 2.65 & 2.31 & 1.26 & 2.40 & 2.25 & .93 & 2.55 & 2.25 & 1.14 \\
Feminine & 2.48 & 2.13 & .96 & 2.22 & 2.13 & .91 & 2.36 & 2.13 & .94 \\
Undifferentiated & 2.77 & 2.69 & .93 & 2.44 & 2.19 & 1.01 & 2.65 & 2.50 & .97 \\
Total & 2.57 & 2.38 & 1.02 & 2.27 & 2.13 & .93 & 2.44 & 2.25 & .99 \\
& & & & & & & & & \\
\end{tabular}

Table 16.

Gender Role Conflict Scale (CBWFR) Means, Medians, and Standard Deviations by Psychological Gender Category

\begin{tabular}{lcccccccccc}
\hline & \multicolumn{8}{c}{ Bem Sex Role Inventory } \\
\hline Variable & $M$ & $M d n$ & $S D$ & $M$ & $M d n$ & $S D$ & $M$ & $M d n$ & $S D$ \\
Androgynous & 3.97 & 4.08 & 1.16 & 3.63 & 3.91 & 1.34 & 3.82 & 4.00 & 1.25 \\
Masculine & 3.92 & 4.00 & 1.27 & 4.08 & 4.17 & 1.08 & 3.98 & 4.00 & 1.20 \\
Feminine & 3.73 & 3.98 & 1.18 & 3.83 & 4.00 & 1.20 & 3.78 & 4.00 & 1.19 \\
Undifferentiated & 3.68 & 3.58 & 1.18 & 3.60 & 3.67 & 1.14 & 3.65 & 3.67 & 1.17 \\
Total & 3.81 & 3.98 & 1.20 & 3.78 & 4.00 & 1.21 & 3.80 & 4.00 & 1.20 \\
& & & & & & & & & & \\
\hline
\end{tabular}




\section{Correlation Analysis}

Table 17 provides a detailed reporting of all male and female interval-scaled correlations. Some of the correlations deemed salient are reported in text. Both of the psychological gender scales (i.e., BSRIM, BSRIF) were negatively and significantly correlated with the UCLA Loneliness Scale. Correlations between psychological gender and loneliness were $r=-.18, p<.01$ on the BSRIM and $r=-.26, p<.01$ on the BSRIF. This indicated that those participants who had low loneliness scores also had high masculinity or femininity scores. As both masculinity and femininity increased, loneliness levels decreased. This is an interesting finding that is incongruent with the literature. Masculinity and femininity are negatively correlated with loneliness in males; however, only masculinity is negatively correlated with loneliness in females. Femininity has no relationship with loneliness in females (Cramer \& Neyedley, 1998). The fact that there were so many more males in the current study may have had something to do with the fact that both masculinity and femininity correlated with loneliness in biological genders combined.

Both of the psychological gender scales were significantly correlated with selfesteem. The resulting correlations between psychological gender and self-esteem were positive. The strongest correlation was between self-esteem and the BSRIM, $r=.33, p<$ .01 . Although the correlation between femininity and self-esteem was relatively weak (BSRIF, $r=.19, p<.01$ ), it was revealed that, as levels of either masculinity or femininity increased, self-esteem increased accordingly. This particular finding is incongruent with the literature due to the fact that femininityis typically reported to either have no relationship with self-esteem or is typically reported to have a slightly 


\section{Table 17.}

Correlation Analysis (Combined Gay Male/Lesbian Female)

\begin{tabular}{llllllllll}
\hline & BSRIM & BSRIF & UCLA & RSES & GRCS & SPC & RE & RAB & CBWFR \\
\hline BSRIM & - & & & & & & & & \\
BSRIF & $.13^{* *}$ & - & & & & & & & \\
UCLA & $-.18^{* *}$ & $-.26^{* *}$ & - & & & & & & \\
RSES & $.33^{* *}$ & $.19^{* *}$ & $-.59^{* *}$ & - & & & & & \\
GRCS & .05 & $-.27^{* *}$ & $.50^{* *}$ & $-.40^{* *}$ & - & & & & \\
SPC & $.22^{* *}$ & $-.17^{* *}$ & $.29^{* *}$ & $-.23^{* *}$ & $.79^{* *}$ & - & & \\
RE & $-.09^{*}$ & $-.31^{* *}$ & $.48^{* *}$ & $-.38^{* *}$ & $.80^{* *}$ & $.37 * *$ & - & \\
RAB & $-.11^{* *}$ & $-.28^{* *}$ & $.47^{* *}$ & $-.38^{* *}$ & $.78^{* *}$ & $.40^{* *}$ & $.74^{* *}$ & - & \\
CBWFR & .07 & -.02 & $.28^{* *}$ & $-.24^{* *}$ & $.64^{* *}$ & $.49^{* *}$ & $.30^{* *}$ & $.27^{* *}$ & - \\
\hline
\end{tabular}

Notes:

** Correlation is significant at the .01 level (2-tailed).

${ }^{*}$ Correlation is significant at the .05 level (2-tailed).

BSRIM = Bem Sex Role Inventory - Masculine Scale; BSRIF = Bem Sex Role Inventory - Feminine Scale; UCLA = Revised UCLA Loneliness Scale; RSES = Rosenberg Self Esteem Scale; GRCS = Gender Role Conflict Scale; SPC = GRCS "Success, Power, and Competition" Subcategory; RE = GRCS "Restrictive Emotionality" Subcategory; RAB = GRCS "Restrictive Affectionate Behavior" Between Men/Women Subcategory; CBWFR = GRCS "Conflict Between Work and Family Relations" Subcategory 
negative relationship with self-esteem (Allgood-Merten \& Stockard, 1991; Antill \& Cunningham, 1980; Bassoff \& Glass, 1982; Carlson \& Baxter, 1984; Feather, 1985; Long, 1990, 1993; Orlofsky, 1977; Stericker \& Johnson, 1977). Because the correlation between femininity and self-esteem was relatively small, accounting for approximately $3 \%$ of the common variance, the significance may have been due to the large sample size.

The correlation between self-esteem and loneliness was significantly negative, $r=-.59, p<.01$, indicating that they share approximately $35 \%$ of the common variance. This finding indicated that lower loneliness scores were correlated with higher selfesteem scores. The correlation between overall gender role conflict and the BSRIF was significant and negative, $r=-.27, p<.01$. Gender role conflict was also negatively correlated with self-esteem, $r=-.40, p<.01$ and positively correlated with loneliness, $r=.50, p<.01$. This finding indicated that higher levels of gender role conflict were correlated with higher loneliness scores and lower self-esteem scores. These findings also correspond to those reported by other researchers (D'Augelli \& Grossman, 2001; D’Augelli, Grossman, Hershberger, \& O’Connell, 2001; Ervin, 2004; Good \& Mintz, 1990; Good et al., 1985; Jones, 1998; Simonsen, Blazina, \& Watkins, Jr., 2000; Sharpe \& Heppner, 1991; Shepard, 2001).

Both the Restrictive Emotionality (RE) subcategory and the Restrictive Affectionate Behavior (RAB) subcategory of the GRCS were significantly and negatively correlated with both gender role scales. Increased levels of masculinity or femininity were affiliated with decreased levels of RE and RAB. Comparable to the results reported by Sharpe \& Heppner (1991), the Success, Power, and Competition (SPC) subcategory, however, was significantly and negativelycorrelated with the feminine scale only, 
$r=-.17, p<.01$. The correlation in the current study, however, was relatively weak. The correlation between SPC and the masculine scale was significant and positive, $r=.22, p$ $<.01$, although the relationship was still not particularly strong. The positive correlation between SPC and masculinity also corresponds to results reported in the literature (Zamarripa, Wampold, \& Gregory, 2003).

Conflict Between Work and Family Relations (CBWFR) was not significantly correlated with either of the psychological gender scales. This finding indicated that fluctuations in CBWFR had little to no relationship with psychological gender. Loneliness was positively and significantly correlated with $\mathrm{RE}, r=.48, p<.01$, RAB, $r=$ $.47, p<.01$, SPC $, r=.29, p<.01$, and CBWFR, $r=.28, p<.01$. The correlations between loneliness and RE, and loneliness and RABwere particularly strong, explaining $23 \%$ and $22 \%$ of the common variance, respectively. Self-esteem was negatively and significantly correlated with RE, $r=-.38, p<.01$, RAB, $r=-.38, p<.01$, SPC, $r=-.23, p$ $<.01$, and CBWFR, $r=-.24, p<.01$. This indicated that higher scores on all of the psychological gender subscales were associated with lower self-esteem scores.

\section{Gay Male Correlations}

Table 18 provides the detailed correlations of all variables by biological gender. Both psychological gender scales (i.e., BSRIM, BSRIF) were negatively and significantly correlated with loneliness in males, indicating that, as levels of masculinity and femininity increased, levels of loneliness decreased in the men sampled. As reported, this observation is congruent with the literature (Cramer \& Neyedley, 1998). Also similar to other researcher findings, the BSRIM was significantly and positively correlated with self-esteem in gay males, $r=.34, p<.01$ (Allgood-Merten \& Stockard, 1991; Antill \& 
Table 18.

Male and Female Correlation Analysis

Gay Males

\begin{tabular}{|c|c|c|c|c|c|c|c|c|c|c|}
\hline \multirow{10}{*}{ 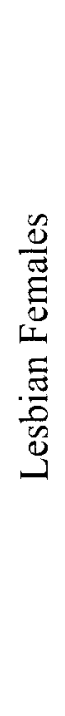 } & & BSRIM & BSRIF & UCLA & RSES & GRCS & SPC & $\mathrm{RE}$ & RAB & CBWFR \\
\hline & BSRIM & - & $.11^{*}$ & $-.20 * *$ & $.34 * *$ & .03 & $.22 * *$ & $-.14 * *$ & $-.13 *$ & .08 \\
\hline & BSRIF & $.15^{* *}$ & - & $-.29 * *$ & $.18^{* *}$ & $-.23 * *$ & -.10 & $-.30^{* *}$ & $-.27 * *$ & .01 \\
\hline & UCLA & $-.14^{*}$ & $-.22 * *$ & - & $-.62 * *$ & $.51 * *$ & $.30^{* *}$ & $.48^{* *}$ & $.47 * *$ & $.33 * *$ \\
\hline & RSES & $.32 * *$ & $.22 * *$ & $-.57 * *$ & - & $-.43 * *$ & $-.25 * *$ & $-.38 * *$ & $-.41 * *$ & $-.27 * *$ \\
\hline & GRCS & .08 & $-.31 * *$ & $.49^{* *}$ & $-.38 * *$ & - & $.78^{* *}$ & $.80^{* *}$ & $.79 * *$ & $.65^{* *}$ \\
\hline & $\mathrm{SPC}$ & $.23 * *$ & $-.25^{* *}$ & $.29 * *$ & $-.21 * *$ & $.80^{* *}$ & - & $.35 * *$ & $.39^{* *}$ & $.49 * *$ \\
\hline & $\mathrm{RE}$ & -.04 & $-.31 * *$ & $.49 * *$ & $-.39 * *$ & $.80^{* *}$ & $.38 * *$ & - & $.75^{* *}$ & $.31 * *$ \\
\hline & RAB & -.09 & $-.27 * *$ & $.48^{* *}$ & $-.36^{* *}$ & $.76^{* *}$ & $.40 * *$ & $.71 * *$ & - & $.30 * *$ \\
\hline & CBWFR & .06 & -.05 & $.20 * *$ & $-.19 * *$ & $.62 * *$ & $.49 * *$ & $.28 * *$ & $.22 * *$ & - \\
\hline
\end{tabular}

Notes:

** Correlation is significant at the .01 level (2-tailed)

*Correlation is significant at the .05 level (2-tailed).

BSRIM = Bem Sex Role Inventory - Masculine Scale; BSRIF = Bem Sex Role Inventory - Feminine Scale; UCLA = UCLA

Loneliness Scale; RSES = Rosenberg Self Esteem Scale; GRCS = Gender Role Conflict Scale; SPC = GRCS "Success, Power, and

Competition" Subcategory; RE = GRCS "Restrictive Emotionality" Subcategory; RAB = GRCS "Restrictive Affectionate Behavior"

Between Men/Women Subcategory; CBWFR = GRCS "Conflict Between Work and Family Relations" Subcategory 
Cunningham, 1980; Bassoff \& Glass, 1982; Carlson \& Baxter, 1984; Feather, 1985; Long, 1990, 1993; Orlofsky, 1977; Stericker \& Johnson, 1977). As masculinity increased, self-esteem increased accordingly. Although the correlations were not as strong, the femininity scales were also significantly correlated with self-esteem indicating that, as femininity increased in gay males, self-esteem increased accordingly. The significant correlation between femininity and self-esteem may have partially been a result of having a large sample size. The male correlation between self-esteem and loneliness was found to be significant and negative, $r=-.62, p<.01$. Higher levels of loneliness in gay men were associated with lower self-esteem levels. This finding was also consistent with the literature (D'Augelli, Grossman, Hershberger, \& O'Connell, $2001)$.

Gender role conflict was negatively correlated with the BSRIF, $r=-.23, p<.01$ indicating that, as femininity increased, gender role conflict decreased. Other researchers such as Sharpe \& Heppner (1991) have reported that certain subcategories of gender role conflict are negatively related to femininity. As overall gender role conflict increased, loneliness increased as well, $r=.51, p<.01$ and self-esteem decreased, $r=-.43, p<.01$. These findings were relatively strong and indicated that, as overall gender role conflict increased in men, levels of loneliness increased and levels of self-esteem decreased. In addition, the correlations demonstrated that $26 \%$ and $19 \%$ of the common variance was explained by the relationships between gender role conflict and loneliness, and gender role conflict and self-esteem, respectively. These findings were certainly congruent with those reported in the literature (D'Augelli \& Grossman, 2001; Ervin, 2004; Good \& Mintz, 1990; Good et al., 1985; Jones, 1998; Sharpe \& Heppner, 1991; Shepard, 2001). 
Similar to the combined male and female sample, the correlations between the psychological gender scales and both the RE and RAB components of the GRCS were significant and negative although neither of the correlations were particularly strong. The only significant correlation between a psychological gender scale and the SPC component of the GRCS was between SPC and the BSRIM, $r=.22, p<.01$. CBWFR did not significantly correlate with either of the psychological gender scales. All four of the GRCS subcategories were significantly and positively correlated with loneliness. In addition, all four subcategories were significantly and negatively correlated with selfesteem.

\section{Lesbian Female Correlations}

Similar to the male correlations, both psychological gender scales (i.e., BSRIM, BSRIF) were negatively and significantly correlated with loneliness in female participants. The strongest correlation was between the BSRIF and loneliness, $r=-.22, p$ $<.01$, explaining $5 \%$ of the common variance. The fact that both psychological gender scales were negatively correlated with loneliness indicated that higher masculinity and femininity scores corresponded to lower loneliness scores (i.e., decreased loneliness). This particular observation is inconsistent with the literature (Cramer \& Neyedley, 1998) and will be discussed further in the following chapter. In addition, both psychological gender scales were significantly correlated with self-esteem, with the strongest correlation being between the BSRIM and self-esteem, $r=.32, p<.01$. The correlations between psychological gender and self-esteem were both positive indicating that higher levels of masculinity or femininity were correlated with higher scores on the self-esteem scale. As reported earlier, this finding is incongruent with results reported by other 
researchers. Femininity is typically reported to either have no relationship or a slightly negative relationship with self-esteem (Allgood-Merten \& Stockard, 1991; Antill \& Cunningham, 1980; Bassoff \& Glass, 1982; Carlson \& Baxter, 1984; Feather, 1985; Long, 1990, 1993; Orlofsky, 1977; Stericker \& Johnson, 1977). This finding will be discussed further in the following chapter. The lesbian correlation between self-esteem and loneliness was found to be significant and negative, $r=-.57, p<.01$. As reported levels of self-esteem increased, loneliness scores decreased in female participants. Gender role conflict was negatively correlated with the BSRIF, $r=-.31, p<.01$, indicating that, as femininity increased, gender role conflict decreased. In addition, as gender role conflict increased in lesbian women, loneliness increased, $r=.49, p<.01$ and self-esteem decreased, $r=-.38, p<.01$. The correlation between overall gender role conflict and loneliness explained $24 \%$ of the common variance while the correlation between overall gender role conflict and self-esteem explained $14 \%$ of the common variance. All of these observations were consistent with other researcher observations (D’Augelli \& Grossman, 2001; D’Augelli, Grossman, Hershberger, \& O'Connell, 2001; Ervin, 2004; Good \& Mintz, 1990; Good et al., 1985; Jones, 1998; Simonsen, Blazina, \& Watkins, Jr., 2000; Sharpe \& Heppner, 1991; Shepard, 2001).

The SPC subcategory of the GRCS was positively correlated with the BSRIM, $r=$ $.23, p<.01$ and negatively correlated with the BSRIF, $r=-.25, p<.01$. As lesbian participants reported higher levels of masculinity, SPC levels increased accordingly. As higher levels of femininity were reported, SPC conflict decreased. In addition, the SPC subcategory was positively correlated with loneliness, $r=.29, p<.01$ and negatively correlated with self-esteem, $r=-.21, p<.01$. The RE subcategory was negatively and 
significantly correlated with the BSRIF, $r=-.31, p<.01$. RE in women was positively correlated with loneliness, $r=.49, p<.01$ and negatively correlated with self-esteem, $r=$ $-.39, p<.01$. As RE conflict increased in female participants, loneliness increased (explaining 24\% of the common variance) and self-esteem decreased (explaining 15\% of the common variance).

The Restrictive Affectionate Behavior Between Women (RABBW) subcategory of the GRCS was negatively and significantly correlated with the BSRIF, $r=-.27, p<$ .01 . RABBW was positively correlated with loneliness, $r=.48, p<.01$ and negatively correlated with self-esteem, $r=-.36, p<.01$. As lesbian participants reported higher RABBW, responses to loneliness questions indicated higher levels of loneliness. The correlation between RABBW and loneliness explained $23 \%$ of the common variance. CBWFR in females was positively correlated with loneliness, $r=.20, p<.01$ and negatively correlated with self-esteem, $r=-.19, p<.01$. This finding indicated that higher CBWFR scores were associated with higher loneliness scores in lesbians. In addition, as lesbians reported more CBWFR, levels of self-esteem were shown to decrease accordingly.

\section{Multivariate Analysis of Variance (MANOVA)}

Table 19 (page 131) displays the results from the $2 \times 4$ factorial MANOVA. Biological gender (two levels: male and female) and psychological gender (four levels: androgynous, masculine, feminine, and undifferentiated) as determined by the BSRI served as the independent variables. The dependent variables included self-esteem, loneliness, and overall gender role conflict scores. The subcategories of the GRCS were not used as dependent variables in the MANOVA analysis due to the large number of 
dependent variables required. The total dependent variable scores on each respective scale were summed and divided by the total number of responses per instrument. The resulting mean participant score on each scale served as the dependent variable for each analysis.

As was previously reported, Box's test for equality of covariance matrices revealed that there was significant variability between the male and female groups, $F(42$, $411327)=1.58, p=.01$. Tabachnick and Fidell (2007) theorized that MANOVAs are robust enough to overcome this assumption violation. Additionally, a more stringent alpha level of .01 was used to minimize the Type I error rate. The sample for the two-way MANOVA included 361 males and 246 females. Of the total 607 participants, 154 were categorized as androgynous, 131 as masculine, 172 as feminine, and 150 as undifferentiated. The overall MANOVA post hoc results are reported in Table 21.

The significance of the MANOVA multivariate effects was determined using the Wilks' Lambda statistic. The interaction of the BSRI psychological gender group and biological gender with the dependent variables was not found to be significant, $F(9$, $1453)=.21, p=.99$. The eta squared statistic, $\eta^{2}$, was .00 , a very small effect size per Cohen (1988). The main effect of biological gender, however, was significant, $F(3,597)$ $=4.02, p=.01$. The resulting eta squared, $\eta^{2}$, was .02 , a small to moderate effect size, with an observed power of 84 . An analysis of the univariate results revealed that the significant biological gender difference in the dependent variables was due to the gender role conflict scores as determined by the Gender Role Conflict Scale, $F(1,599)=5.34, p$ $=.02$. In addition, the psychological gender group main effect was found to be significant, $F(9,1453)=9.37, p=.00$. The resulting partial eta squared, $\eta^{2}$, was .05 , a 
small to moderate effect size, with an observed power level of 1.0. An analysis of the univariate results revealed that the significance in psychological gender and the dependent variables was due to self-esteem, $F(3,599)=15.31, p=.00$, loneliness, $F(3$, $599)=7.44, p=.00$, and gender role conflict, $F(3,599)=6.69, p=.00$. The resulting partial eta squared values, $\eta^{2}$, were .00 for loneliness, self-esteem, and gender role conflict, respectively. All three of these eta squared values were small in effect size.

\section{BSRI Post Hoc Analysis}

\section{Biological Gender and Gender Role Conflict}

The Bonferroni methodology was used in post hoc analysis. An analysis of the difference in biological gender on gender role conflict revealed a .02 level of significance. Statisticall significance, however, was not found when comparing differences in biological gender to loneliness or self-esteem means. The GRCS means were examined by biological gender. The overall male GRCS mean was 3.31 and the overall female GRCS mean was 3.14, indicating that male gender role conflict was higher than female gender role conflict. The eta squared statistic, $\eta^{2}$, was equal to .01 , a small effect size, indicating that $1 \%$ of the variance in gender role conflict was accounted for by the change in biological gender.

\section{Psychological Gender and Gender Role Conflict}

For the psychological gender and gender role conflict analysis, psychological gender, as defined by the BSRI (i.e., masculine, feminine, androgynous, and undifferentiated), served as the independent variable. Gender role conflict, as defined by the Gender Role Conflict Scale, served as the dependent variable. The gender role conflict means for each psychological gender group were previously reported in Table 12 
(page 112). Significance was found in the psychological gender main effect on the dependent variable overall gender role conflict. The significance was due to the difference between those categorized as androgynous and those grouped as masculine on gender role conflict, $p=.01$. The mean GRCS score for those grouped as androgynous was 3.16 and the mean for those participants categorized as masculine was 3.47. This indicated that masculine persons experienced higher levels of gender role conflict than did androgynous individuals.

Significance was also found in the main effects of psychological gender on gender role conflict due to a group mean difference in those categorized as feminine and those grouped as masculine on gender role conflict, $p<.00$. The mean GRCS score for those categorized as feminine was 3.09 and the mean for those grouped as masculine was 3.47 , indicating that masculine individuals experienced higher levels of gender role conflict than did feminine individuals. The eta squared statistic, $\eta^{2}$, was equal to .03 , a small to moderate effect size, indicating that approximately $3 \%$ of the change in gender role conflict, the dependent variable, could be accounted for by the change in psychological gender, the independent variable.

\section{Psychological Gender and Loneliness}

For the psychological gender and loneliness analysis, psychological gender as defined by the BSRI (i.e., masculine, feminine, androgynous, and undifferentiated), served as the independent variable. Loneliness, as defined by the UCLA Loneliness Scale, served as the dependent variable. Loneliness means for each psychological gender group were previously reported in Table 10 (page 110). Statistical significance was found in the psychological gender main effect on loneliness. The significant difference was a 
result of those participants categorized as androgynous and those grouped as masculine on loneliness, $p=.04$. The mean UCLA Loneliness Scale androgyny and masculinity mean scores were 2.09 and 2.26, respectively. This indicated that masculine persons were lonelier than were androgynous individuals. A significant loneliness difference was found between participants categorized as androgynous and those grouped as undifferentiated, $p$ $<.00$. The mean loneliness androgynous and undifferentiated scores were 2.09 and 2.37, respectively, indicating that undifferentiated participants were lonelier than were androgynous participants.

Finally, a significant difference was found in the mean loneliness scores of those grouped as feminine and those grouped as undifferentiated, $p=.01$. The mean feminine score on the UCLA Loneliness Scale was 2.18 and the mean undifferentiated score was 2.37, indicating that undifferentiated participants were lonelier than were feminine participants. The eta squared statistic, $\eta^{2}$, was equal to .04 , a small to moderate effect size, indicating that approximately $4 \%$ of the change in loneliness scores was accounted for by change in psychological gender.

\section{Psychological Gender and Self-Esteem}

For the psychological gender and self-esteem analysis, psychological gender as defined by the BSRI (i.e., masculine, feminine, androgynous, and undifferentiated), served as the independent variable. Self-esteem, as defined by the Rosenberg Self-Esteem Scale (RSES), served as the dependent variable. Self-esteem means for each psychological gender group were previously reported in Table 11 (page 111). Statistical significance was found in the psychological gender main effect on self-esteem. The significance was due to differences found in those participants categorized as 
androgynous and those grouped as feminine, $p=.00$. The androgynous and feminine RSES mean scores were 3.19 and 2.87 , respectively. This finding indicated that androgynous participants had higher levels of self-esteem than did feminine participants. Significance was also found between participants classified as androgynous and those participants categorized as undifferentiated participants, $p<.00$. Androgynous and undifferentiated RSES means were 3.19 and 2.68, respectively. Androgynous participants had higher levels of self-esteem than did undifferentiated participants.

With a mean RSES score of 3.08, masculine participants had higher self-esteem than did undifferentiated participants, $p<.00$. Finally, a significant difference emerged between the group self-esteem scores of those classified as feminine $(M=2.87)$ and those grouped as undifferentiated $(M=2.68)$ participants, $p=.03$. Feminine persons were found to have higher self-esteem levels than did undifferentiated participants. The eta squared statistic, $\eta^{2}$, was equal to .07 , a moderate to large effect size, indicating that slightly over $7 \%$ of the changes in self-esteem levelswe re a result of changes in psychological gender.

\section{Relationship Status MANOVA}

A separate MANOVA was generated to assess the relationship of "relationship status" on self-esteem and loneliness in gay men and lesbian women. Relationship status (four levels: single, in a non monogamous relationship, in a monogamous relationship, in a heterosexual marriage) served as the independent variable. The dependent variables included loneliness and self-esteem. The total dependent variable scores on each respective scale were summed and divided by the total number of responses per instrument. The resulting mean participant score on each scale served as the dependent 
variable for each analysis. The sample included 316 single participants, 43 non monogamous participants, 288 monogamous participants, and 4 participants who were in heterosexual marriages. Table 20 (page 130) displays the statistical results of the relationship status MANOVA. Because Box's test for equality of covariance matrices revealed no statistical significance, $F(9,638)=1.11, p=.35$, the assumption of Equality of Covariance of Matrices was sufficiently met.

The significance of the relationship status MANOVA multivariate effects was determined using the Wilks' Lambda statistic. The main effect of relationship status on loneliness and self-esteem was found to be significant, $F(6,1292)=16.66, p<.00$. The eta squared statistic, $\eta^{2}$, was .07 , a moderate to large effect size, indicating that $7 \%$ of the change in loneliness and self-esteem could be accounted for by a change in relationship status. An analysis of the univariate results revealed that the significance in relationship status and the dependent variables was related to both loneliness, $F(3,647)=34.10, p<$ .00 , and self-esteem, $F(3,647)=8.76, p<.00$.

\section{Relationship Status Post Hoc Analysis}

The Bonferroni methodology was once again used in post hoc analysis. An analysis of relationship status and loneliness revealed statistical significance between single participants $(M=2.42)$ and those participants in a non monogamous relationship $(M=2.13), p<.00$. Single participants were lonelier than participants who were in non monogamous relationships. Significance was also found between the loneliness mean of single participants $(M=2.42)$ and the loneliness mean of those participants in monogamous relationships $(M=2.02), p<.00$. Once again, single participants were lonelier than were monogamous participants. In addition, non monogamous participants 
$(M=2.13)$ appeared to be lonelier than participants who were in monogamous relationships $(M=2.02)$. The loneliness eta squared statistic, $\eta^{2}$, was equal to .14 , a large effect size, indicating that approximately $14 \%$ of the change in loneliness could be accounted for by the change in relationship status.

The only statistical significance found in self-esteem was due to the mean difference between single participants $(M=2.80)$ and those participants in monogamous relationships $(M=3.10), p<.00$. Those participants in monogamous relationships had higher levels of self-esteem than did single individuals. The self-esteem eta squared statistic, $\eta^{2}$, was equal to .04 , a small to moderate effect size, indicating that approximately $4 \%$ of the change in self-esteem could be accounted for by the change in relationship status. 
Table 19.

MANOVA Summary Table

\begin{tabular}{lcccccc}
\hline Source & Wilks' Lambda & F & Hypothesis df & Error df & Sig. & Partial Eta Squared \\
\hline Biological Gender & .98 & 4.02 & 3 & 597 & .01 & .02 \\
Psychological Gender & .87 & 9.37 & 9 & 1453 & .00 & .05 \\
Biological * Psychological & .99 & .21 & 9 & 1453 & .99 & .00 \\
\hline
\end{tabular}

Table 20 .

ш) MANOVA Summary Table (Relationship Status as IV)

\begin{tabular}{lcccccc} 
Source & Wilks' Lambda & F & Hypothesis df & Error df & Sig. & Partial Eta Squared \\
\hline Psychological Gender & .86 & 16.66 & 6 & 1292 & .00 & .07 \\
\hline
\end{tabular}


Table 21.

Results of MANOVA with Independent Variables Bem Sex Role Inventory (BSRI) Categories and Biological Gender

Source of Variance Group Differences on Dependent Variable Effect Size

Interaction of BSRI

categories and

biological gender None

N/A

Main effect of

Dependent variable GRC

Small

biological gender

Gay Males > Lesbian Females

Main effect of

BSRI

Dependent variable Gender Role Conflict

Small to

BSRI masculine $>$ BSRI androgynous

BSRI masculine $>$ BSRI feminine

Dependent variable Loneliness-

BSRI masculine $>$ BSRI androgynous

Small to

BSRI undifferentiated $>$ BSRI androgynous

moderate

BSRI undifferentiated $>$ BSRI feminine

Dependent variable Self-esteem

BSRI androgynous $>$ BSRI feminine

Moderate to

BSRI androgynous $>$ BSRI undifferentiated

large

BSRI masculine $>$ BSRI undifferentiated

BSRI feminine $>$ BSRI undifferentiated

Note: Effect sizes were determined using the Eta squared statistic. 


\section{Factor Analysis}

Research question 10 required an examination of the factor structure of the Gender Role Conflict Scale (GRCS). Confirmatory factor analyses (CFA) were used to explore the factorial validity of the scale. A separate, four-factor model CFA was run separately for gay men and lesbian women. By running a CFA, the researcher may specify which items are expected to load on a given factor based upon a priori theory. Other researchers have reported the results of a Gender Role Conflict Scale CFA. Some of the other researcher results will be reported concurrently with current study results.

Rogers and Abbey-Hines (1997), among others, reported an a priori factor structure of the GRCS which included four factors comprised of (a) Success, Power, and Competition, (b) Restrictive Emotionality, (c) Restrictive Affectionate Behavior Between Men, and (d) Conflicts Between Work and Family Relations. It was proffered that these four factors would encapsulate and explain what was truly being measured by the 37 -item GRCS. The objective of the CFA was to determine the ability of the 37 items to distinguish between the four separate types of gender role conflict using EQS (Bentler, 1995). As previously stated, two separate CFAs were run, one for gay males and one for lesbian females. For the current CFAs, a four first-order factor model identical to the one reported by Good, et al. was used.

Gay male item assignments are depicted in Figure 3. Identical lesbian female item assignments are depicted in Figure 4. Identical to the factors reported by Good, et al. and others, GRCS items 1, 5, 8, 12, 14, 18, 21, 23, 24, 28, 32, 34, 
and 37 were assigned to the factor labeled Success, Power and Competition. Items $2,6,9,13,15,19,22,25,29$, and 30 were assigned to a second factor labeled Restrictive Emotionality. The third factor, Restrictive Affectionate Behavior Between Men (for the male sample) and Restrictive Affectionate Behavior Between Women (for the female sample), was assigned items 3, 7, 10, 16, 20, 26, 33, and 35. Finally, the fourth factor, Conflict Between Work and Family Relations, were assigned items $4,11,17,27,31$, and 36 .

The last factor loading of the set of items for each factor was fixed to 1.0 statistical significance (Byrne, 1994). In addition to examining $\chi^{2}$ values, the goodness of fit index (GFI), normed fit index (NFI), nonnormed fit index (NNFI), comparative fit index (CFI), root mean-square error of approximation (RMSEA), and $\chi^{2} / d f$ ratio were examined to evaluate the goodness of the model's fit. The results are reported in Table 22. For the hypothesized gay male model, $\chi^{2}(623, N$ $=361)=1690.572, p<.00$. For the hypothesized lesbian female model, $\chi^{2}(623, N$ $=247)=1526.725, p<.00$. The results for both gay males and lesbian females were significant, indicating that the model, although moderate, was not a very good fit for the data.

As reported, a variety of fit measures was used to evaluate the hypothesized model. The chi-square $\left(\chi^{2}\right)$ minimum fit function test was utilized, and is an inferential statistical assessment of the likelihood that a model explains the data. The Chi square statistic is calculated from discrepancies between the original correlations and the reproduced correlations among items. As a result, smaller resulting values are indicative of a better fit of the model to the data used. 
The goodness of fit index (GFI) is commonly used to determine how well the model fits the data and ranges from 0 to 1 . Values of .9 or higher indicate a model that fits the data well. The GFIs for the gay male CFA and the lesbian female CFA were only .79 and .74 , respectively. The $\chi^{2}$ statistic indicated that the model did not fit the data very well at all.

The comparative fit index (CFI) is used to examine a model's fit as compared to a null model using noncentrality parameters (Benter, 1988). In addition, the normed fit index (NFI) represents the increment of fit for the hypothesized model relative to the fit of the null model (Stevens, 2002, p 432). Similar to the GFI, the CFI and NFI values range from 0 to 1 . Values of .9 or higher, once again, indicate that the model fits the data well. The CFI and NFI for the gay male model were .84 and .77 , respectively, indicating that the model was moderate but did not fit the data well. In addition, the CFI and NFI for the lesbian female model were .81 and .72 , respectively, indicating that, once again, that the model was moderate but did not fit the data well.

The root mean-square error of approximation (RMSEA) is a statistical representation of the lack of model fit as a result of reliability and model specification or misspecification. The RMSEA reports fit per degree of freedom. A resulting RMSEA of .1 or less represents a model with acceptable fit. A RMSEA of .05 or less represents a model with very good fit. The current study RMSEAs for gay men and lesbian women were .07 and .08 , respectively. The resulting RMSEAs indicated that the models had an acceptable fit of the data. 
The relatively moderate fit indices might serve as catalysts for questions regarding the construct validity of the GRCS. Figure 3 reports the standardized factor coefficients per GRCS item for gay male participants. Item 35, for example, was assigned to the Restrictive Affectionate Behavior Between Men factor and had a low standardized factor coefficient of .27. Item 35 was phrased, "Men who are overly friendly to me, make me wonder about their sexual preference". In addition, item 21, assigned to the Success, Power, and Competition factor, had a standardized factor coefficient of only .37 . This item was phrased, "I often feel that I need to be in charge of those around me."

Figure 4 demonstrates that the same two items (i.e., 21 and 35) resulted in low standardized factor coefficients when the instrument was taken by lesbian females as well. Item 21 resulted in a standardized factor coefficient of .43. Item 35 resulted in a standardized factor coefficient of .36 . The verbiage for Item 35 was changed for females to read, "Women who are overly friendly to me, make me wonder about their sexual preference." Item 16 on the lesbian instrument also resulted in a low standardized factor coefficient. This item was phrased, "Women who touch other women make me feel uncomfortable."

The fact that some of the items had low standardized factor coefficients leads one to proffer that perhaps those items are contributing little to theassigned factors. In addition, one may argue that those items with low standardized factor coefficients may be misassigned to inappropriate factors altogether. Perhaps if those items were phrased in a slightly different manner, resulting standardized factor coefficients could be improved. 


\section{Factor Analysis Summary}

The examination of the overall $\chi^{2}$ statistic and the fit indices indicated that the model, although moderate, was not the best fit for the data. Only one of the fit indices, the RMSEA, met the minimum criteria reported in the literature for reporting a good fit. In addition, although there have not been a large number of confirmatory factor analyses run on the GRCS, Rogers and Abbey-Hines (1997) reported fit indices that supported the assertion that the models were not very good fits for the data. The results of the current and past factor analyses seem to indicate thatthere is some degree of error in the model. 
Table 22.

Comparison of Fit Statistics - Gay Male/Lesbian Female CFA

\begin{tabular}{lcccccccc}
\hline Model & $\chi^{2}$ & Df & $\chi^{2} / d f$ & GFI & NFI & NNFI & CFI & RMSEA \\
\hline Gay Male Model & 1690.57 & 623 & 2.71 & .788 & .765 & .825 & .836 & .069 \\
Lesbian Female Model & 1526.73 & 623 & 2.45 & .742 & .723 & .801 & .814 & .077 \\
Rogers \& Abbey- Hines & 1590.57 & 623 & 2.55 & - & .827 & - & - & .054 \\
\hline
\end{tabular}

Note: GFI = goodness of fit index; NFI = normed fit index; NNFI = non-normed fit index; CFI = comparative fit index; RMSEA = root mean-square error of approximation. 


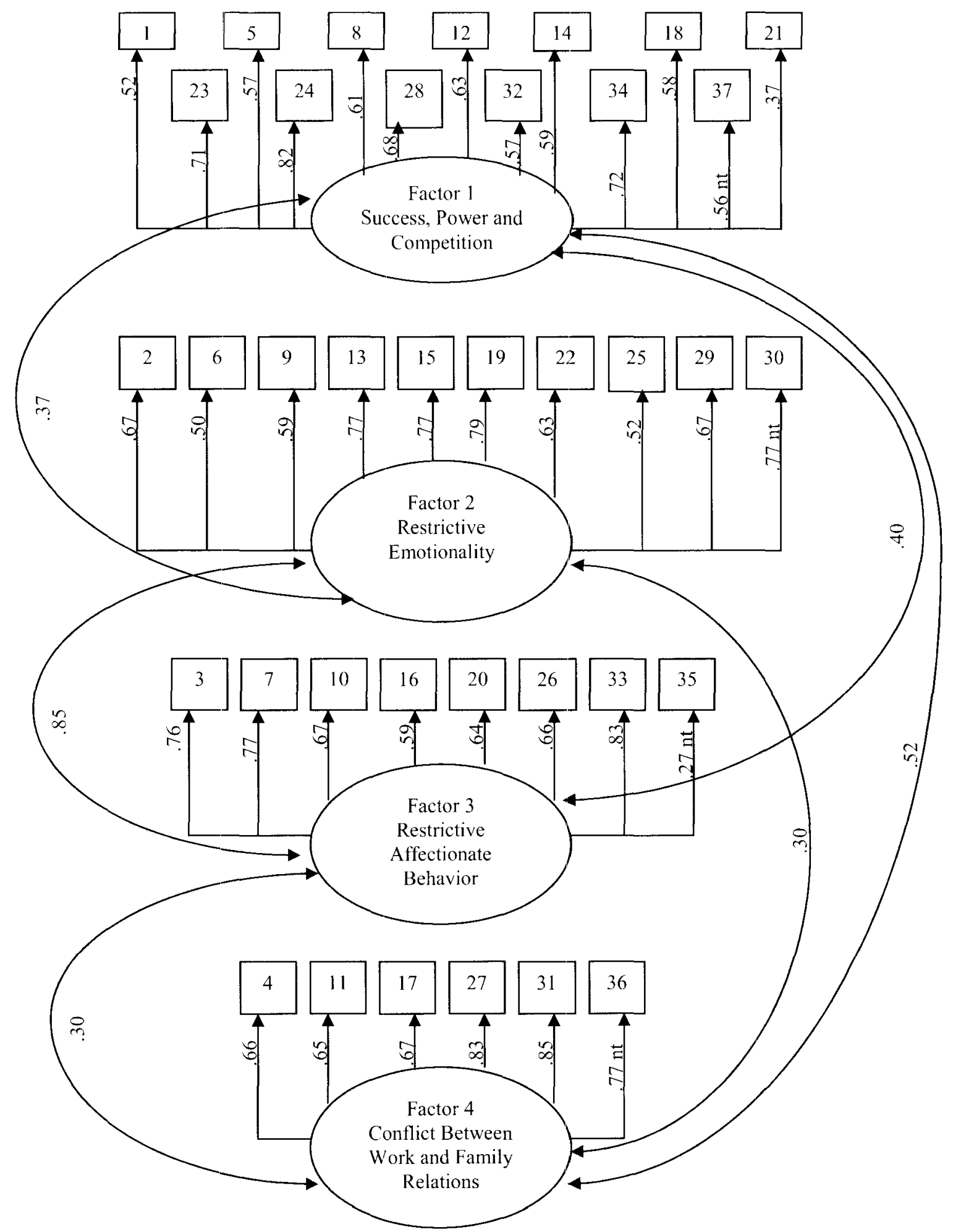

Figure 3. Intercorrelated Four-Factor Model for the GRCS-Gay Males

Note: Numbered boxes represent GRCS question numbers. $\chi^{2}(623, N=361)=1690.572$, $p<.00$. All of the standardized coefficients are significant $(\mathrm{p}<.05)$ except those not tested "nt." 


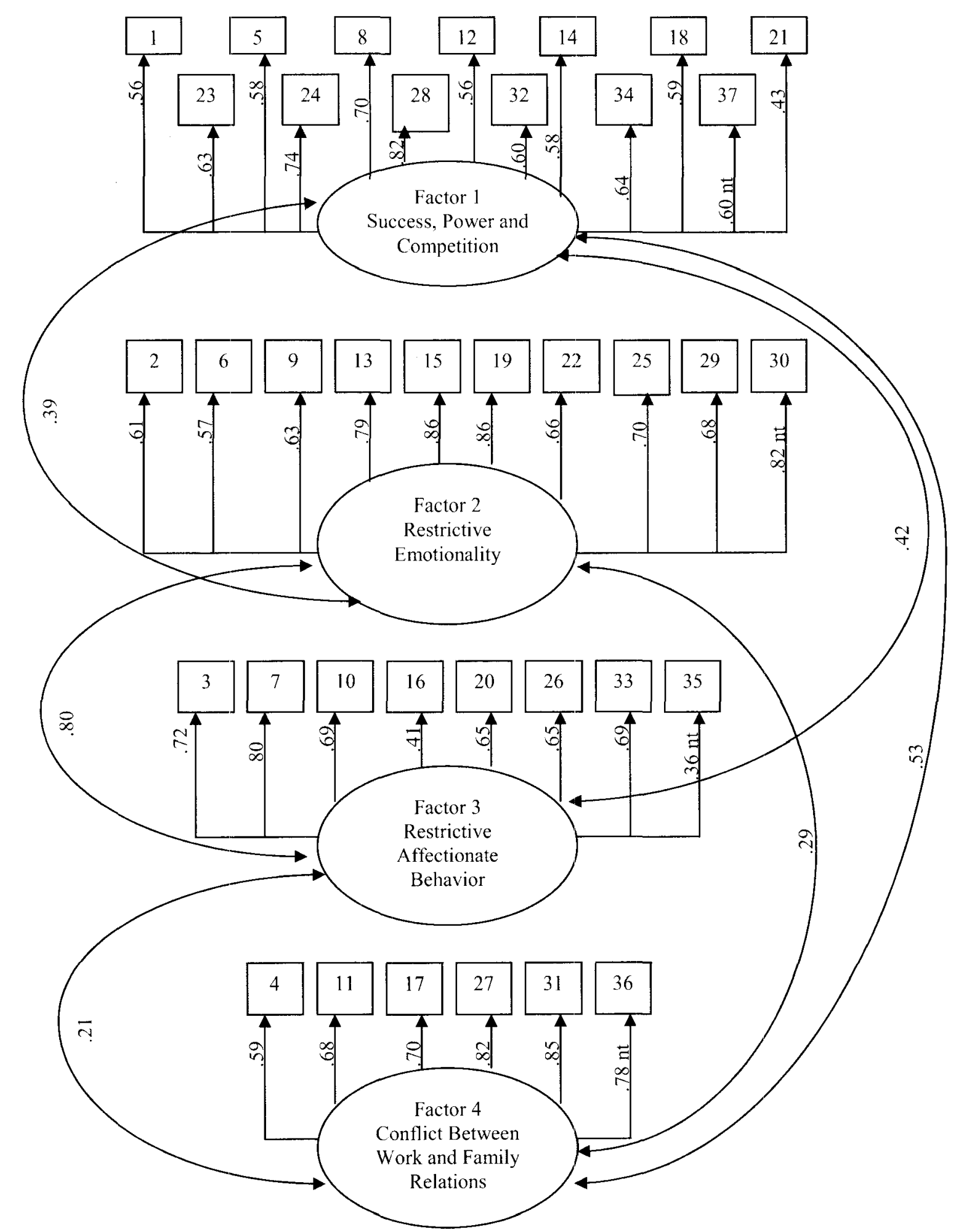

Figure 4. Intercorrelated Four-Factor Model for the GRCS-Lesbian Females

Note: Numbered boxes represent GRCS question numbers $\chi^{2}(623, N=247)=1526.725$, $p<.00$. All of the standardized coefficients are significant $(\mathrm{p}<.05)$ except those not tested "nt." 
1. For homosexual individuals, is there a significant interaction between psychological gender and biological gender on gender role conflict?

Results: No significant interaction was found.

2. Is there a significant main effect of psychological gender on gender role conflict?

Results: Significance was found in the main effects of androgyny and masculinity on gender role conflict. Masculine persons experienced higher levels of gender role conflict than did androgynous individuals. Significance was also found in the main effects of femininity and masculinity on gender role conflict. Masculine individuals experienced higher levels of gender role conflict than did feminine individuals. Gender role conflict was highest for masculine and undifferentiated participants.

3. Is there a significant main effect of biological gender on gender role conflict?

Results: An analysis of the biological gender and gender role conflict pairwise comparisons revealed a .02 level of significance. The overall male GRCS means were higher than the female GRCS means, indicating that male gender role conflict was higher than female gender role conflict.

4. For homosexual individuals, is there a significant interaction between psychological gender and biological gender on self-esteem?

Results: No significant interaction was found.

5. Is there a significant main effect of psychological gender on self-esteem?

Results: Statistical significance was found upon examination of the main effects of androgyny and femininity on self-esteem. Androgynous participants had higher levels 
of self-esteem than did feminine participants. Significance was also found between androgynous and undifferentiated participants. Androgynous participants once again had higher self-esteem than did undifferentiated participants. In addition, both masculine and feminine participants had significantly higher self-esteem than did undifferentiated participants. Self-esteem was the highest for androgynous participants followed by masculine participants. Feminine and undifferentiated participants had comparable levels of self-esteem

6. Is there a significant main effect of biological gender on self-esteem? Results: No significance was found.

7. For homosexual individuals, is there a significant interaction between psychological gender and biological gender on loneliness?

Results: No significant interaction was found.

8. Is there a significant main effect of psychological gender on loneliness?

Results: Statistical significance was found upon examination of the main effects of androgyny and masculinity on loneliness. Masculine persons were lonelier than were androgynous individuals. Significance was also found in the difference between androgynous and undifferentiated participants on loneliness. Undifferentiated participants were found to be lonelier than were androgynous participants. The mean difference in feminine and undifferentiated loneliness scores was also significant. Undifferentiated participants were lonelier than were feminine participants. Undifferentiated participants had the highest levels of loneliness while androgynous participants were found to be the least lonely psychological gender group.

9. Is there a significant main effect of biological gender on loneliness? 
Results: No significance was found.

10. For homosexual individuals, what is the factor structure of the Gender Role

\section{Conflict Scale?}

Results: The results of the confirmatory factor analysis were comparable to those found in the literature. Almost all of the fit indices determined that the model was not a good fit for the data, indicating that there is error in the model.

11. For homosexual individuals, is there a significant difference in self-esteem based upon relationship status (i.e., single, in a non monogamous relationship, in a monogamous relationship, in a heterosexual marriage)?

Results: A significant difference in self-esteem levels based upon relationship status was found between single participants and those participants involved in monogamous relationships. Single participants were found to have lower levels of selfesteem than did those participants in monogamous relationships.

12. For homosexual individuals, is there a significant difference in loneliness based upon relationship status (i.e., single, in a non monogamous relationship, in a monogamous relationship, in a heterosexual marriage)?

Results: Significant differences were found in the levels of loneliness between (a) single participants and those participants in non-monogamous relationships; and (b) single participants and those participants in monogamous relationships. Single participants reported more loneliness than did those participants in either monogamous or non-monogamous relationships. In addition, participants who were in non-monogamous relationships were lonelier than those participants in monogamous relationships. 


\section{CHAPTER V \\ DISCUSSION}

This chapter provides an overview of the major study results as well as a discussion relative to each of the findings. Conclusions surmised are followed by a section dedicated to implications and recommendations for future research.

\section{Summary of Major Findings}

The major research purpose in this study was to examine the effects of psychological gender (i.e., masculinity, femininity, androgyny, and undifferentiated) and biological gender (i.e., male and female) on selected dependent variables (i.e., gender role conflict, self-esteem, and loneliness) in gay men and lesbian women (GL). In addition, the effects of relationship status (i.e, single, in a non monogamous relationship, in a monogamous relationship, and in a heterosexual marriage) on selected dependent variables (i.e., self-esteem and loneliness) were examined. Although there were five broad research questions, due to the complexity of the analysis, each question was broken into a subset of questions and reported below.

1. For homosexual individuals, is there a significant interaction between psychological gender and biological gender on gender role conflict? It was hypothesized that a significant interaction would occur between psychological gender, biological gender, and gender role conflict. "An interaction is present when the effects of one independent variable on behavior change at the different levels of the second independent variable" (Keppel \& Wickens, 2004, p. 201). It was 
proffered that a significant interaction would occur in this studyfor a variety of reasons. The first reason to believe a significant interaction would occur was based upon the fact that the literature tends to report biological gender differences in overall gender role conflict as well as in the subcategories of gender role conflict (Silva, 2002; Zamarripa, Wampold, \& Gregory, 2003). Biological differences in gender role conflict were anticipated in the current study as well based upon the fact that society tends to be more comfortable with female lesbianism than it is with male homosexuality (McCreary, 1994).

The second reason to hypothesize a significant interaction might occur was due to the fact that the literature reports psychological gender differences in gender role conflict (Good et al., 1995; Sharpe \& Heppner, 1991; Silva, 2002; Simonsen, Blazina, \& Watkins, Jr., 2000). Psychological gender differences in gender role conflict were anticipated in the current study, for example, due to the fact that androgynous individuals are more adaptable to varying situations and masculinity tends to be more socially valued than is femininity (Bem, 1975; Bem, Martyna, \& Watson, 1976). In addition, it was posited that, because a GL sample was used, psychological gender differences would likely emerge in levels of gender role conflict based upon life experiences of GL persons that are often quite different from those of the heterosexual population based upon confounding factors such as the rigid gender role socialization process.

North American gender role socialization practices serve to further undergird the hypothesis for a significant interaction in biological gender, psychological gender, and gender role conflict. It was reported earlier that society tends to be less forgiving of male transgressions into femininity than of female transgressions into masculinity (Long, 
1989; McCreary, 1994; Safir, Rosenmann, \& Kloner, 2003). The literature also reports that gay males experience more discrimination than lesbian women (D’Augelli, 1989). These facts likely contribute to heightened gender role conflict in gay males. Because gay men have been reported to exhibit more feminine and androgynous traits than do heterosexual men while lesbian women are typically more masculine or androgynous than are heterosexual women (Bernard \& Epstein, 1978; Carlson \& Baxter, 1984; Heilbrun, Jr., \& Thompson, Jr., 1977; Hooberman, 1979; Lippa \& Arad, 1997; Mallen, 1983), GL individuals, especially gay males, often violate culturally defined gender role norms. It is for these reasons that a significant interaction between biological gender, psychological gender, and gender role conflict was hypothesized.

The results of the two-way MANOVA revealed no significant interaction between the independent variables on gender role conflict in this study. This finding means that the effect of psychological gender on gender role conflict was not related to biological gender. Although gay males were found to exhibit higher levels of gender role conflict than did lesbian females, biological gender reportedly had no significant relationship with psychological gender in levels of gender role conflict. One speculation for the non significant interaction is that it may be a reflection of increased societal tolerance of sexual orientation minorities within the North American culture. Perhaps it is beginning to matter less and less whether an individual conforms to antiquated, pre-defined psychological gender expectations. As society gravitates toward becoming more inclusive of sexual orientation minority groups, perhapsthe relationship between biological gender and psychological gender is beginning to affect gender role conflict to a lesser degree. 
Popular entertainment venues such as television and theatre, for example, regularly incorporate gay and lesbian themes and actors into scripts. In addition, GL themed shows such as "Queer Eye for the Straight Guy" have become hugely successful in America. The GL lifestyle appears to be becoming increasingly acceptable in the United States, perhaps resulting in less gender role conflict for members of the GL community.

Another speculation is that the current study results may have been different if the subcategories of the GRCS had been used as dependent variables as opposed to the overall GRCS mean score. Certain subcategories of the GRCS, for example, such as Success, Power, and Competition (SPC) may have reflected a significant interaction between biological gender and psychological gender due to corporate and career power struggles and intense desires for money and success. Males who are feminine, and females who are masculine, for example, might experience higher levels of gender role conflict as measured by the SPC subcategory of the GRCS than do more masculine males and feminine females. In fact, gay men are reported to be more feminine than are heterosexual men while lesbian women are reported to be more masculine than are heterosexual women (Bernard \& Epstein, 1998; Lippa \& Arad, 1997; Mallen, 1983).

Considering that the sample in the current study was composed of gay men and lesbian women, one can speculate a possible interaction between biological gender and psychological gender on gender role conflict. Due to the large number of dependent variables in this study, however, the totalmean composite score of the Gender Role Conflict Scale served as the overall measure of gender role conflict. This warrants an examination of an interaction between biological gender and psychological gender on gender role conflict reflecting all four dimensions of gender role conflict in future studies. 
2. Is there a significant main effect of psychological gender on gender role conflict?

Based upon the results of the literature review, it was hypothesized that the main effect of psychological gender on gender role conflict would be significant. The literature, for example, tends to report that masculinity has a positive relationship with gender role conflict and femininity often has a negative relationship with gender role conflict (Good et al., 1995; Silva, 2002; Simonsen, Blazina, \& Watkins, Jr., 2000; Sharpe and Heppner, 1991). It was believed that current study results would reveal that masculinity would have a significant, positive relationship with gender role conflict while androgyny would have the most significant, negative relationship with the construct. Androgyny was hypothesized to have a negative relationship with gender role conflict due to the fact that androgynous individuals more readily adapt psychological gender to the immediate environment. This unique, almost chameleon-like ability, leads to better mental health (Bem, Martyna, \& Watson, 1976).

The results indicated that the main effect of psychological gender on gender role conflict was significant. Masculine participants reported the highest gender role conflict followed by undifferentiated, androgynous, and feminine individuals. Based upon the literature and perceived societal expectations of gender role norms, it makes theoretical sense that those persons possessing masculine psychologicalgender s might feel pressures to conform, resulting in heightened levels of gender role conflict. It further makes sense that undifferentiated individuals might experience higher levels of gender role conflict simply based upon the belief that these individuals likely have difficulty adjusting psychological gender to any given situation due to the fact that they report low levels of 
both masculinity and femininity (Bem, 1974). Using the same logic, the fact that androgynous and feminine individuals reported the least amount of gender role conflict is not surprising. Androgynous persons are able to fluidly move from a masculine orientation to a feminine orientation based upon environmental cues, decreasing the potential to experience gender role conflict. Masculine and feminine females are much more socially acceptable than are feminine males; therefore, adding increased pressures for biological males to conform to masculine orientations (Bernard \& Epstein, 1998; Lippa \& Arad, 1997; Mallen, 1983). In addition, the minimal femininity effect was congruent with the literature (Good et al., 1995; Silva, 2002; Simonsen, Blazina, \& Watkins, Jr., 2000; Sharpe and Heppner, 1991).

3. Is there a significant main effect of biological gender on gender role conflict? As previously reported, the literature shows a significant relationship between biological gender and gender role conflict (Silva, 2002; Zamarripa, Wampold, \& Gregory, 2003). Men typically have more heightened levels of gender role conflict than do women. Because gay men and lesbian women often do not conform to the rigid gender role socialization processes, greater levels of gender role conflict may ensue - especially when significant figures such as parents and teachers apply increased pressures for conformity. A young male, for example, who enjoys exploring his expressive side through studying the fine arts such as dance or theatre may experience parental pressures to become involved in sports; whereas, a young female who enjoys sports may be encouraged to study dance or theatre.

As hypothesized, gay males reported higher levels of gender role conflict than did lesbian female participants. It is possible that gay males in this study reported higher 
levels of gender role conflict than lesbian females due to the fact that male transgressions into femininity are less socially acceptable than female transgressions into masculinity (McCreary, 1994). As previously stated, a "tomboy" girl is typically more acceptable than is a "sissy" boy (Long, 1989; Safir, Rosenmann, \& Kloner, 2003). One might speculate that this finding is a result of continued societal pressures for males to be "manly" while simultaneously being somewhat more critical of male femininity than of female masculinity (Long, 1989; McCreary, 1994; Safir, Rosenmann, \& Kloner, 2003).

4. For homosexual individuals, is there a significant interaction between psychological gender and biological gender on self-esteem?

It was hypothesized that a significant interaction would occur between psychological gender, biological gender, and self-esteem. Once again, this hypothesis was made for several reasons. Researchers in the literature report that significant biological gender differences exist in the self-esteem levels of men and women. Males typically report higher self-esteem levels than do females in both the heterosexual and homosexual communities(Allgood -Merten \& Stockard, 1991; Bassoff \& Glass, 1982; Feather, 1985).

In addition, much empirical research supports the fact that psychological gender roles are related to self-esteem levels. Masculinity has been shown to have the strongest positive relationship with self-esteem followed by androgyny (Allgood-Merten \& Stockard, 1991; Antill \& Cunningham, 1980; Burnett, Anderson, \& Heppner, 1995; Carlson \& Baxter, 1984; Feather, 1985; Hooberman, 1979; Long, 1990, 1993; Lu \& Wu, 1998; Lundy \& Rosenberg, 1987; Orlofsky, 1977; Spence \& Helmreich, 1980; Stericker \& Johnson, 1977). Conversely, femininity and undifferentiated status typically have little 
or even slightly negative relationships with self-esteem (Allgood-Merten \& Stockard, 1991; Antill \& Cunningham, 1980; Bassoff \& Glass, 1982; Carlson \& Baxter, 1984; Feather, 1985; Long, 1990, 1993; Orlofsky, 1977; Stericker \& Johnson, 1977). It was proffered that the impact of psychological gender on self-esteem would be related to biological gender based upon the findings reported in the multiple studies cited above. As one moved from female to male, for example, and masculine to androgynous, it would seem logical that some type of interaction between the variables might occur.

Contrary to the expectation, the results of the two-way MANOVA revealed no significant interaction between psychological gender and biological gender on selfesteem in this study. This indicates that the effects of psychological gender on selfesteem were not related to biological gender. Reported self-esteem levels were the same based upon psychological gender irrespective of biological gender. Conversely, reported self-esteem levels were the same based upon biological gender irrespective of psychological gender. One might speculate that these findings support the position that society encourages and approves of certain psychological gender role orientations over others (i.e., androgyny and masculinity) whether in male or female persons. Males, for example, seem be more and more comfortable expressing their feminine side (e.g., cooking and nurturing) while females seem to be more comfortable expressing masculinity (e.g., sporting events and leadership positions). In addition, the fact that society values masculinity over femininity (Long, 1989; McCreary, 1994; Safir, Rosenmann, \& Kloner, 2003), under girds the probability that males, who are typically more masculine than females, would have higher self-esteem levels than do females, irrespective of psychological gender roles. 
5. Is there a significant main effect of psychological gender on self-esteem?

As previously noted, the literature clearly shows that a significant relationship exists between psychological gender and self-esteem. The common theme in the literature tends to be that masculine or androgynous participants have the highest levels of selfesteem followed by feminine or undifferentiated participants (Allgood-Merten \& Stockard, 1991; Antill \& Cunningham, 1980; Burnett, Anderson, \& Heppner, 1995; Carlson \& Baxter, 1984; Feather, 1985; Hooberman, 1979; Long, 1990, 1993; Lu \& Wu, 1998; Lundy \& Rosenberg, 1987; Orlofsky, 1977; Spence \& Helmreich, 1980; Stericker \& Johnson, 1977).

As was expected, the main effect of psychological gender on self-esteem was significant in the current study. Androgynous persons reported the highest self-esteem levels followed by masculine participants. Feminine and undifferentiated participants, with comparable levels, reported the lowest self-esteem. Once again, it makes theoretical sense that androgynous persons would have high self-esteem based upon their abilities to shift gender role orientation dependent upon their milieu. In addition, because masculinity is more highly valued than is femininity, it makes sense that those persons of a masculine orientation would report high self-esteem.

It was somewhat unusual, however, that the correlation between the BSRIF and self-esteem $(r=.22, p<.01)$ was positive. This positive correlation was found in both male and female participants. These findings were unusual due to the fact that the literature tends to report either no relationship between femininity and self-esteem or a slightly negative relationship between the two variables (Allgood-Merten \& Stockard, 1991; Antill \& Cunningham, 1980; Bassoff \& Glass, 1982; Carlson \& Baxter, 1984; 
Feather, 1985; Long, 1990, 1993; Orlofsky, 1977; Stericker \& Johnson, 1977). It is even more intriguing, however, that an increase in femininity in gay male participants in particular correlated with increased self-esteem. One possibility for this finding is that society is beginning to relax rigid, gender roles and is beginning to embrace or tolerate psychological gender differences. Perhaps feminine attributes in a biological male are not as socially unacceptable as they were in the past. Another possibility for the finding is the fact that the large sample size may have contributed to the statistical significance.

6. Is there a significant main effect of biological gender on self-esteem?

Because the literature is proliferate with studies, both heterosexual and homosexual, showing that males report higher self-esteem levels than do females (Allgood-Merten \& Stockard, 1991; Bassoff \& Glass, 1982; Feather, 1985), it was hypothesized that comparable findings would emerge in the current study. No statistical significance was found, however, in the main effect of biological gender on self-esteem. This finding is certainly incongruent with the literature. Because the current sample consisted solely of GL individuals, it is possible that participants, both male and female, developed similar defense or coping mechanisms in response to a lifetime of verbal or physical attacks based upon sexual orientation. The literature shows that GL persons sometimes maintain high levels of self-esteem by attributing discriminatory actions and behaviors to intolerance and ignorance of an entire group of sexual minorities as opposed to viewing the assault as a personal attack on the individual (Crocker, J., \& Major, B., 1989). This coping mechanism permits the individual to deflect the attack by assuming that the actions or behaviors were not personal per se. 
Another possible reason for the lack of significance found between gay men and lesbian women in self-esteem might relate to the type of self-esteem measured in this study. Global self-esteem was evaluated as opposed collective self-esteem. Collective self-esteem refers to the evaluation of the worthiness or value of a social group of which an individual is a member. Theoretically, a person may hold his or her social group in low-esteem, yet have high levels of personal self-worth (Crocker \& Major, 1989, p. 609). If collective self-esteem had been evaluated as opposed to global self-esteem, perhaps a biological gender difference in levels of self-esteem would have emerged.

7. For homosexual individuals, is there a significant interaction between psychological gender and biological gender on loneliness?

It was hypothesized that a significant interaction would result between psychological gender, biological gender, and loneliness. Similar to the other research questions involving interactions between variables, it was believed that a significant interaction would occur between psychological gender and biological gender on loneliness for multiple reasons. The literature is relatively clear that biological males tend to be lonelier than biological females (Cramer \& Neyedley, 1998; Russell, Peplau, \& Cutrona, 1980; Solano, Batten \& Parish, 1982; Stokes \& Levin, 1986). Researchers have reported that females tend to form close, dyadic relationships while males form large groups of general acquaintances (Stokes \& Levin, 1986). In addition, psychological gender has been shown to have a significant relationship with loneliness. Loneliness is negatively related to masculinity in both males and females (Cramer \& Neyedley, 1998). Femininity, however, is negatively related to loneliness in males and not related to loneliness in females at all (Cramer \& Neyedley, 1998). It was posited that a significant 
interaction would likely occur as one moved from female to male (as males are often reported to be lonelier in the literature), and from androgynous to other psychological gender roles often found lonelier in the literature such as undifferentiated.

The results of the two-way MANOVA revealed no significant interaction between psychological gender and biological gender on loneliness in this study. This finding implies that the effect of psychological gender on loneliness was not related to biological gender. One speculation is that, as reported earlier, society is becoming less inclined to adhere to antiquated, rigid gender role stereotypes, irrespective of biological gender. Males, for example, are no longer shamed for experimenting or even mastering culinary skills. Many men are becoming stay-at-home dads while female (or sometimes male) partners work outside of the home. Conversely, females often enjoy the freedom to serve in the military or work in the construction industry. It seems likely that, as society becomes increasingly tolerant of males exhibiting stereotypically feminine traits such as showing affection, biological males may be more comfortable in forming close, dyadictype relationships formerly experienced primarily by females. Perhaps as individuals nurture various traits, both masculine and feminine, new experiences are used as catalysts to forming close friendships and relationships that may not have been possible prior to cultivating the new psychological gender traits. As a result of these new experiences and traits, perhaps decreased loneliness is the inevitable result. It seems that an increased tolerance of psychological gender, irrespective of biological gender, impacts dependent variables such as loneliness and self-esteem. 
8. Is there a significant main effect of psychological gender on loneliness?

Because the literature reports clear differences in the effects of psychological gender on loneliness, it was hypothesized that a significant difference would be found in the current study as well. As reported, loneliness has been shown to be negatively related to masculinity in both males and females (Cramer \& Neyedley, 1998). Femininity, although still negatively related to loneliness in males, was not shown to be related to loneliness in females at all (Cramer \& Neyedley, 1998). Current study results revealed that loneliness was indeed negatively related to both masculinity and femininity in gay males. Incongruent with the literature, however, loneliness was also negatively related to both masculinity and femininity in lesbian participants. Perhaps the fact that femininity in females was negatively related to loneliness has something to do with femininity being more highly valued among lesbian women than it is among heterosexual women. Because many lesbian women are considered "butch" (e.g., exhibiting stereotypically masculine traits), perhaps this valued femininity in lesbian women is due to the possibility that femininity might be less common among lesbians than is masculinity. Another potential reason for femininity in females being negatively related to loneliness is, once again, the fact that there seems to be an integration of psychological gender roles occurring. Masculine and feminine traits are becoming increasingly acceptable in both biological males and females alike. This is true in both heterosexual and homosexual communities.

The overall results of the current study revealed that undifferentiated participants reported the highest levels of loneliness while androgynous participants reported the lowest loneliness scores. Masculine and feminine participants reported loneliness scores 
in between those of the undifferentiated and androgynous participants. These findings, similar to those found in the self-esteem construct, make theoretical sense. Androgynous persons are able to modify psychological gender orientation based upon the environment. The fact that these people are able to adjust their behaviors and actions likely contributes greatly to higher levels of confidence and self-esteem - leading to relationships and decreased loneliness. Undifferentiated persons, however, are not able to modify behaviors and actions as readily. It also makes sense that this lack of behavior modification ability would contribute to decreased levels of confidence or self-esteem leading to increased loneliness and isolation.

9. Is there a significant main effect of biological gender on loneliness?

Because other researchers have demonstrated that biological males tend to be lonelier than biological females (Cramer \& Neyedley, 1998; Russell, Peplau, \& Cutrona, 1980; Solano, Batten \& Parish, 1982; Stokes \& Levin, 1986), it was hypothesized that similar results would emerge in the current sample. A significant difference in biological gender on loneliness, however, was not observed in the current study. There are potential reasons for this finding including the possibility that, because GL persons are minorities, perhaps close relationships are formed with similar others in an attempt to cultivate emotionally supportive friendships. Some of the lesbian participants, for example, reported that it might be difficult finding lesbian participants because "We tend to be nesters." Anecdotal reports obtained during the data collection process suggest that lesbian women often enter relationships with another woman then simply choose to spend the majority of their time with each other as opposed to socializing outside of the home. 
The gay men used in this sample, on the other hand, would not necessarily be categorized as "nesters." Some of the male participants were located using the snowball sampling technique. Many of the participants were recruited from an email directory used to organize social events such as parties attended primarily by gay males. These male participants would obviously be more social and active within the gay community. Although the men might not be necessarily be categorized as "nesters," it seems that occasions to socialize with other gay men are often sought - perhaps minimizing feelings of isolation or loneliness. Males reported in the literature obviously report greater feelings of loneliness than do females. Perhaps the fact that sample participants in the current study were GL persons, no differences in loneliness levels emerged, due to mechanisms implemented by each respective gender to ameliorate feelings of loneliness.

10. For homosexual individuals, what is the factor structure of the Gender Role Conflict Scale?

Similar to the results found by other researchers, moderate fit indices of the four factor model: (a) Success, Power, and Competition; (b) Restrictive Emotionality; (c) Restrictive Affectionate Behavior Between Men/Women; and (d) Conflict Between Work and Family Relations were obtained in this study. The fit indices revealed that the GRCS model, although moderate in fit, was not an overall good fit for the data. An examination of the standardized factor coefficients revealed that some items had low path coefficients indicating that the corresponding items did not fit the assigned factor well. Perhaps those items would have been better assigned to a different factor or even phrased in a different manner in the hopes of improving the fit. Once again, however, the overall fit to the data was moderate at best. 
11. Is there a significant difference in self-esteem based upon relationship status (i.e., single, non monogamous relationship, monogamous relationship, heterosexual marriage)?

A statistically significant difference was observed in the self-esteem mean scores of single participants and those participants in monogamous relationships. This finding makes theoretical sense and is congruent with the findings of other researchers (D’Augelli, Grossman, Hershberger, \& O'Connell, 2001; Hills, Francis, \& Jennings, 2006). An individual in a committed partnership with another person would likely feel better about him or herself than would a single person. Those persons in committed relationships have the validation that someone loves them in the most intimate manner; whereas, a single individual would not necessarily have that assurance.

12. Is there a significant difference in loneliness based upon relationship status (i.e., single, non monogamous relationship, monogamous relationship, heterosexual marriage)?

Significant differences were observed in the levels of loneliness between (a) single participants and those participants in non-monogamous relationships; and (b) single participants and thoseparticipants in monogamous relationships. Single participants reported more loneliness than did those participants in either monogamous or non-monogamous relationships. In addition, participants who were in non-monogamous relationships were lonelier than those participants in monogamous relationships. Although one would expect single individuals to be lonelier than those in committed relationships, it was interesting that those participants involved in sexual activities outside of their own respective relationships reported more loneliness than those couples 
involved in monogamous relationships. Perhaps participants in non monogamous relationships attempt to fulfill needs missing in their own relationships by involving other sexual partners. Assuming that speculation is true, however, based upon the fact that their loneliness scores were higher than those in monogamous relationships, affairs outside of the relationship are not, perhaps, fulfiling those missing needs.

\section{Implications}

Given the significant lack of empirical research that continues to surround many GL topics, this particular study was salient and timely. Members of the GL community have endured many years of discrimination, violence, and intolerance based upon "sexual deviancy" status. It was not all that long ago that homosexuality was considered a psychological disorder and was treated as such. A patient at the therapist's office would often be subjected to myriad "treatments" and techniques that were designed to rid them of their homosexual desires and urges. These treatments sometimes included psychoanalysis, hypnosis, hormone medication, pharmacologic shock, aversion therapy, electroshock, castration, hysterectomy, and even lobotomies (Bem, 1993, p. 170). The psychiatric community eventually realized that homosexuality was not a disease at all and discontinued the egregious treatments. It was only in 1975, however, that the American Psychological Association finally supported the removal of homosexuality from the list of official mental disorders (Perez, DeBord, \& Bieschke, 2000, p. 3). This was obviously a relatively recent occurrence.

Education and the passage of time are necessary to ameliorate inaccurate and often negative perceptions of GL individuals. Merely removing homosexuality from a list of mental disorders does not erase a lifetime of negative stereotypes, beliefs, and 
perceptions. Many people continue to stereotype gay men as feminine renegades and gay women as mannish deviants (Bailey \& Zucker, 1995; Sandfort, 2005). Although society has made a tremendous amount of progress over recent years, a significant amount of work remains to be done. Significant accomplishments made within (and for) the GL community include the fact that many employers have begun to offer domestic partner benefits to partners of GL employees. In addition, GL partners are often welcomed at company events. There remain many GL persons, however, who do not feel comfortable revealing their sexual orientations to employers or others for fear of negative retaliations. In addition, the climate surrounding the United States 2004 Presidential campaign was replete with attacks on the GL community by the "moral majority," including a President who campaigned on a promise to ban the legality of same-sex marriages. Some cities have been successful in passing hate-crime legislation that includes sexual orientation in the definition of "minority group" while others have not been as successful.

It seems that such attacks on members of the GL community could only have a detrimental impact upon levels of self-worth or self esteern. Is it possible that a human being could hear acrimonious and polemical verbiage from political leaders and the "moral majority" without having negative feelings about the self? In addition, it seems likely that, legalizing GL unions, would only serve to reduce levels of loneliness within the GL community. By legally recognizing a committed GL couple in the same manner that a heterosexual couple is recognized would likely serve to undergird the permanency of the relationship, hence, reducing long-term levels of loneliness. 
Past researchers, as previously reported, revealed that gay men are typically more androgynous and feminine than are heterosexual men, and lesbian women are typically more androgynous and masculine than are heterosexual women. As a result, gay men and lesbian women might suffer from increased levels of gender role conflict. It seems that, as homosexuality slowly makes progress toward cultural acceptance, variations from traditionally assigned gender roles are becoming more acceptable today than in previous years. In addition, more stereotypically "alpha" males are feeling comfortable enough to reveal their homosexual persuasions. This has occurred in recent years with celebrities, athletes, and military personnel publicly admitting their GL persuasions. Females such as Ellen DeGeneres and Portia de Rossi have also advanced the GL agenda by demonstrating to mainstream society that GL individuals are merely flesh and bone people with feelings, no different from heterosexuals, capable of being in a loving and committed relationship. As society becomes more comfortable with GL persons, levels of gender role conflict are likely to decrease even more. Many GL individuals, along with many heterosexuals, appear to be increasingly more and more comfortable expressing both masculine and feminine traits.

This study provided new and salient information that can be used to help employers, mental health professionals, and society in general to better understand the needs and experiences of GL individuals. Indeed, this study provided information that could help GL persons themselves to better understand their own community. In addition, this study had great implications for college and university administrators and faculty. Because a large percentage of participants were affiliated with colleges and universities across the nation, study results could be useful to administrators and faculty in 
understanding the unique traits and needs of GL students. Differences and similarities between gay men and lesbian women were enlightening. The fact that no differences emerged in self-esteem and loneliness between gay men and lesbian women was highly surprising. Admittedly, based upon self-perceived differences in GL life experiences, significant differences in the dependent variables by biological gender were expected to emerge. This study perhaps served to demonstrate that gay men and lesbian women are more alike than previously speculated. This is very interesting due to the fact that gay men are often found to socialize with primarily other gay men while lesbian women are found to often socialize primarily with lesbians. Perhaps if GL persons realize that more similarities exist between them than previously believed, more meaningful relationships could develop across genders -- potentially ameliorating more loneliness.

\section{Recommendations}

Differing methods were used in trying to find a relatively heterogeneous sample of GL participants. College and university Listservs were by far the most effective venue for locating research participants. Snowball sampling provided a relatively small number of participants and required a great deal of effort compared to the Listservs. Other attempted methods that proved to be ineffective were advertisements placed in liberal newspapers, coffee shops, and GL chatrooms. While in gay, male chatrooms, the men rarely wanted to discuss dissertation research or surveys. It seemed that the male chatrooms were often used as a catalyst for potential sexual encounters.

Gaining access to a lesbian chatroom was extremely difficult; and, once there, the women were often hostile toward a known male entering the room. It was often suggested that the intentions were not honorable. It was suggested that heterosexual 
males often frequent lesbian chatrooms as an avenue to fulfill sexual fantasies involving two women. Having said that, it would be extremely interesting to examine whether individuals who frequent chatrooms are lonelier and have lower self-esteem levels than individuals who socialize with others in person.

Although this study included participants from several age groups, the majority of the participants were between the ages of 21 and 30 . It would be interesting to complete a similar study that included a more representative sample of GL persons. It would be enlightening, for example, to compare levels of loneliness and self-esteem in older GL persons to those of younger GL individuals. In addition, a study designed to compare GL individuals to heterosexual males and females on the same variables used in this study would add significantly to the literature. No study to date has compared, for example, gender role conflict in lesbian women to gender role conflict in heterosexual women.

Many complaints were received from members of the transgender community due to the fact that the survey options to the question asking for biological gender included choices limited to either males or females alone. The survey was designed in this manner because the study was limited to gay men and lesbian women. Much time would have been saved, however, in responding to transgender individuals if a "transgender" category had been included on the instrument and eliminated from the study analyses. This is precisely how the heterosexual and bisexual populations were handled. It is believed that the life experiences of transgender individuals are likely significantly different from the life experiences of the general GL population. It is for this reason that it was proffered that the survey results of a GL individual could not be empirically 
compared to responses from a transgender person. Transgender individuals represent a unique population and are deserving of a study limited to that group alone.

The only other question that proved to be somewhat problematic was the demographic question inquiring about relationship status. Although the surveys were anonymous in nature, it was discovered that individuals have very different opinions regarding the definition of monogamy. When the survey was designed, the nonmonogamous category was included for those couples who actively had sexual relations with individuals other than their life-partners. It was believed that sexual relations implied any form of sexual intimacy.

Certain participants later admittedhat their opinions of the definition of monogamy/non-monogamy were very different than that of the researcher. One couple, for example, stated that, even though they had sexual relations with people outside of their relationship, they believed they were monogamous. The difference in monogamy and non-monogamy to this specific couple referred to emotionalintimacy not sexual intimacy. As long as one of the partners did not fall in love with someone else, the couple deemed themselves monogamous. Another couple stated that one believed he was in a "monogamous" relationship while the other reported being in a "non-monogamous" relationship. The one who responded that he was in a monogamous relationship reported doing so because he only had sexual relations with other individuals when his life-partner agreed to let him do so. Although it was believed that the definition of monogamous/nonmonogamous was axiomatic, that was clearly not the case.

Gender role conflict as a whole was used as a dependent variable in this study. Whether or not the subcategories of gender role conflict would impact the study variables 
in the same manner than overall gender role conflict was left unanswered. This was done primarily because, by adding the subcategories of GRC as dependent variables, there would have been seven dependent variables in this study. Seven dependent variables were considered excessive for the current study. A study using (a) Success, Power, and Competition; (b) Restrictive Emotionality; (c) Restrictive Affectionate Behavior Between Men; and (d) Conflict Between Work and Family Relations as dependent variables might add significantly to the existing gender role conflict literature.

It would be noteworthy to complete a similar study that examines "collective" self-esteem in addition to, or instead of, global self-esteem. Self-esteem based upon membership in a stigmatized group may provide results that differ substantially from overall levels of global self-esteem.

Although this study provided enlightening information that can ultimately be used to better understand the unique needs of the GL community, there continues to be so much more work awaiting those interested in changing "inclusiveness" from the latest "buzz" word into an undeniable reality. The GL population is a unique group of individuals with varying experiences of societal acceptance. Because individual experiences can be so vastly different, the fact that there were so many similarities found between gay men and lesbian women was somewhat surprising. Perhaps this lends support to the assertion that, whether one is gay or lesbian, or homosexual or heterosexual, people share more similarities than dissimilarities. Perhaps if all members of society took the time to learn about and embrace individual differences, high levels of gender role conflict, low levels of self-esteem, and high levels of loneliness would be foreign concepts that no longer require empirical studies. 


\section{REFERENCES}

Allgood-Merten, B., \& Stockard, J. (1991). Sex role identity and self-esteem: A comparison of children and adolescents. Sex Roles, 25, 129-139.

Antill, J. K., \& Cunningham, J. D. (1980). The relationship of masculinity, femininity, and androgyny to self-esteem. Australian Journal of Psychology, 32, 195-207.

Bailey, J. M., \& Zucker, K. J. (1995). Childhood sex-typed behavior and sexual orientation: A conceptual analysis and quantitative review. Developmental Psychology, 31, 43-55.

Balsam, K. F., Beauchaine, T. P., Mickey, R. M., \& Rothblum, E. D. (2005). Mental health of lesbian, gay, bisexual, and heterosexual siblings: Effects of gender, sexual orientation, and family. Journal of Abnormal Psychology, 114, 471-476.

Bassoff, E. S., \& Glass, G. V. (1982). The relationship between sex roles and mental health: A meta-analysis of twenty-six studies. The Counseling Psychologist, 10, 105-112.

Baumeister, R. F., Campbell, J. D., Krueger, J. I., \& Vohs, K. D. (2003). Does high selfesteem cause better performance, interpersonal success, happiness, or healthier lifestyles? Psychological Science in the Public Interest, 4, 1-44.

Bem, S. L. (1974). The measurement of psychological androgyny. Journal of Consulting and Clinical Psychology, 42, 155-162.

Bem, S. L. (1975). Sex role adaptability: One consequence of psychological androgyny. Journal of Personality and Social Psychology, 31, 634-643.

Bem, S. L. (1976). Probing the promise of androgyny. In A. G. Kaplan, \& J. P. Bean (Eds.), Beyond sex-role stereotypes: Readings toward a psychology of androgyny (1st ed., pp. 48-62). Boston, MA \& Toronto, Canada: Little, Brown and Company.

Bem, S. L. (1981). A manual for the Bem Sex Role Inventory. Palo Alto, CA: Consulting Psychologist Press.

Bem, S. L. (1993). The lenses of gender: Transforming the debate on sexual inequality. New Haven and London, CT: Yale University Press. 
Bem, S. L., \& Lenney, E. (1976). Sex typing and the avoidance of cross-sex behavior. Journal of Personality and Social Psychology, 33, 48-54.

Bem, S. L., Martyna, W., \& Watson, C. (1976). Sex typing and androgyny: Further explorations of the expressive domain. Journal of Personality and Social Psychology, 34, 1016-1023.

Bentler, P. M. (1988). Comparative fit indexes in structural models. Psychological Bulletin, 107, 238-246.

Bentler, P. M. (1994). EQS Structural Equations Program manual. Encino, CA: Multivariate Software, Inc.

Bernard, L. C., \& Epstein, D. J. (1978). Sex role conformity in homosexual and heterosexual males. Journal of Personality Assessment, 42, 505-511.

Brewer, M. B., \& Weber, J. G. (1994). Self-evaluation effects of interpersonal versus group social comparison. Journal of Personality and Social Psychology, 66, 268275.

Burnett, J. W., Anderson, W. P., \& Heppner, P. P. (1995). Gender roles and self-esteem: A consideration of environmental factors. Journal of Counseling and Development, 73, 323-326.

Byrne, B. M. (1994). Structural equation modeling with EQS and EQS/Windows. Thousand Oaks, CA: Sage.

Carlson, H. M., \& Baxter, L. A. (1984). Androgyny, depression, and self-esteem in Irish homosexual and heterosexual males and females. Sex Roles, 10, 457-467.

Carter, R. T., Williams, B., Juby, H. L., \& Buckley, T. R. (2005). Racial identity as mediator of the relationship between gender role conflict and severity of psychological symptoms in Black, Latino, and Asian men. Sex Roles, 53, 473486.

Choi, N. (2004). A psychometric examination of the Personal Attributes Questionnaire. The Journal of Social Psychology, 144, 348-352.

Choi, N., \& Fuqua, D. R. (2003). The structure of the Bem Sex Role Inventory: A summary report of 23 validation studies. Educational and Psychological Measurement, 63, 872-887.

Chung, Y. B. (1995). The construct validity of the Bem Sex-Role Inventory for heterosexual and gay men. Journal of Homosexuality, 30, 87-97. 
Chusmir, L. H., \& Koberg, C. S. (1986). Development and validation of the sex role conflict scale. The Journal of Applied Behavioral Science, 22, 397-409.

Cohen, J. (1988). Statistical power analysis for the behavioral sciences $\left(2^{\text {nd }}\right.$ ed.). Hillsdale, NJ: Lawrence Earlbaum Associates.

Constantinople, A. (1973). Masculinity-femininity: An exception to a famous dictum? Psychological Bulletin, 80, 389-407

Cramer, K. M., \& Neyedley, K. A. (1998). Sex differences in loneliness: The role of masculinity and femininity. Sex Roles, 38, 645-653.

Crocker, J. (1998). Social stigma and self-esteem: Situational construction of self-worth. Journal of Experimental Social Psychology, 35, 89-107.

Crocker, J., \& Major, B. (1989). Social stigma and self-esteem: The self-protective properties of stigma. Psychological Review, 96, 608-630.

Crocker, J., \& Park, L. E. (2004). The costly pursuit of self-esteem. Psychological Bulletin, 130, 392-414.

D'Augelli, A. R. (1989). Lesbians' and gay men's experiences of discrimination and harassment in a university community. American Journal of Community Psychology, 17, 317-321.

D’Augelli, A. R., \& Grossman, A. H. (2001). Disclosure of sexual orientation, victimization, and mental health among lesbian, gay, and bisexual older adults. Journal of Interpersonal Violence, 16, 1008-1027.

D'Augelli, A. R., Grossman, A. H., Hershberger, S. L., \& O'Connell, T. S. (2001). Aspects of mental health among older lesbian, gay, and bisexual adults. Aging \& Mental Health, 5, 149-158.

Day, N. E., \& Schoenrade, P. (2000). The relationship among reported disclosure of sexual orientation, anti-discrimination policies, top management support and work attitudes of gay and lesbian employees. Personnel Review, 29, 346-363.

Deaux, K., \& Kite, M. E. (1987). Thinking about gender. In B. B. Hess, \& M. M. Ferree (Eds.), Analyzing gender: A handbook of social science research (pp. 92-117). Newbury Park, CA: Sage Publications, Inc.

Dillman, D. A. (2000). Mail and internet surveys: The tailored design method ( $2^{\text {nd }}$ ed.). New York: John Wiley \& Sons, Inc. 
Ervin, A. M. (2004). Male gender role conflict and internalized homonegativity: The impact on gay men's psychological well-being. Dissertation Abstracts International 65(07). (UMI No. 3141835)

Feather, N. T. (1985). Masculinity, femininity, self-esteem, and subclinical depression. Sex Roles, 12, 491-500.

Frable, D. E., Hoey, S., \& Platt, L. (1998). Concealable stigmas and positive selfperceptions: Feeling better around similar others. Journal of Personality and Social Psychology, 74, 909-922.

Frable, D. E., Wortman, C., \& Joseph, J. (1997). Predicting self-esteem, well-being, and distress in a cohort of gay men: The importance of cultural stigma, personal visibility, community networks, and positive identity. Journal of Personality, 65 , 599-624.

Good, G. E., \& Mintz, L. B. (1990). Gender role conflict and depression in college men: Evidence for compounded risk. Journal of Counseling and Development, 69, 1721 .

Good, G. E., Robertson, J. M., O’Neil, J. M., Fitzgerald, L. F., Stevens, M., DeBord, K. A., \& Bartels, K. M. (1995). Male gender role conflict: Psychometric issues and relations to psychological distress. Journal of Counseling Psychology, 42, 3-10.

Greenberg, J. S. (1973). A study of the self-esteem and alienation of male homosexuals. The Journal of Psychology, 83, 137-143.

Heilbrun Jr., A. B., \& Thompson Jr., N. L. (1977). Sex-role identity and male and female homosexuality. Sex Roles, 3, 65-79.

Herek, G. M. (1984). Attitudes toward lesbians and gay men: A factor-analytic study. Journal of Homosexuality, 10, 39-50.

Herek, G. M., \& Berrill, K. T. (1992). Hate crimes: Confronting violence against lesbians and gay men. Newbury Park, CA: Sage.

Hills, P. R., Francis, L. J., \& Jennings, P. (2006). Religious behavior, personality, and dimensions of self-esteem among 13- to 15-year-old adolescents. Journal of Research on Christian Education, 15, 61-76.

Hoffman, R. M., Borders, L. D., \& Hattie, J. A. (2000). Reconceptualizing femininity and masculinity: From gender roles to gender self-confidence. Journal of Social Behavior and Personality, 15, 475-503. 
Hooberman, R. E. (1979). Psychological androgyny, feminine gender identity and selfesteem in homosexual and heterosexual males. The Journal of Sex Research, 15, 306-315.

Hu, L. T., \& Bentler, P. M. (1999). Cutoff criteria for fit indices in covariance structure analysis: Conventional criteria versus new alternatives. Structural Equation Modeling, 1, 1-55.

Huebner, D. M., Rebchook, G. M., \& Kegeles, S. M. (2004). Experiences of harassment, discrimination, and physical violence among young gay and bisexual men. American Journal of Public Health, 94, 1200-1203.

Hunter, J. (1990). Violence against lesbian and gay male youths. Journal of Interpersonal Violence, 5, 295-300.

Joiner, T. E. Jr., \& Rudd, M. D. (1996). Disentangling the interrelations between hopelessness, loneliness, and suicidal ideation. Suicide and Life Threatening Behavior, 26, 19-26.

Jones, D. A. (1998). Gender role conflict, coping, and psychological distress in gay men. Dissertation Abstracts International 59(08). (UMI No. 9900851)

Kaplan, A. G., \& Bean, J. P. (1976). Beyond sex-role stereotypes: Readings toward a psychology of androgyny. Boston \& Toronto: Little, Brown and Company.

Keppel, G., \& Wickens, T. D. (2004). Design and analysis: A researcher's handbook ( $4^{\text {th }}$ ed., pp. 201-202). Upper Saddle River, NJ: Pearson: Prentice Hall.

Kohlberg, L. (1966). In E. E. Macoby (Ed.), A cognitive-developmental analysis of children's sex-role concepts and attitudes (pp. 82-173). Stanford, CA: Stanford University Press.

LaTorre, R. A., \& Wendenburg, K. (1983). Psychological characteristics of bisexual, heterosexual and homosexual women. Journal of Homosexuality, 9, 87-97.

Leets, L., \& Giles, H. (1997). Words as weapons-When do they wound? Investigations of harmful speech. Human Communication Research, 24, 260-301.

Lippa, R., \& Arad, S. (1997). The structure of sexual orientation and its relation to masculinity, femininity, and gender diagnosticity: Different for men and women. Sex Roles, 17, 187-207.

Long, V. O. (1989). Relation of masculinity to self-esteem and self-acceptance in male professionals, college students, and clients. Journal of Counseling Psychology. $36,84-87$. 
Long, V. O. (1990). Masculinity, femininity, and women scientists' self-esteem and selfacceptance. The Journal of Psychology, 125, 263-270.

Long, V. O. (1993). Masculinity, femininity, and male scientists' self-esteem and selfacceptance. The Journal of Psychology, 127, 213-220.

Lu, L., \& Wu, H. (1998). Gender-role traits and depression: Self-esteem and control as mediators. Counseling Psychology Quarterly, 11, 95-107.

Lueptow, L. B. (1980). Social structure, social change and parental influence in adolescent sex-role socialization: 1964-1975. Journal of Marriage and the Family, 42, 93-103.

Lundy, A., \& Rosenberg, J. A. (1987). Androgyny, masculinity, and self-esteem. Social Behavior and Personality, 15, 91-95.

Lynn, D. B. (1976). Fathers and sex-role development. The Family Coordinator, 25, 403409.

Mahalik, J. R., Cournoyer, R. J., DeFranc, W., Cherry, M., \& Napolitano, J. M. (1998). Men's gender role conflict and use of psychological defenses. Journal of Counseling Psychology, 45, 247-255.

Mallen, C. A. (1983). Sex role stereotypes, gender identity and parental relationships in male homosexuals and heterosexuals. Journal of Homosexuality, 9, 55-74.

Martin, A. D., \& Hetrick, E. S. (1988). The stigmatization of the gay and lesbian adolescent. Journal of Homosexuality, 15, 163-183.

Marx, R., \& Katz, M. (2006). Attempted suicide among transgender persons: The influence of gender-based discrimination and victimization. Journal of Homosexuality, 51, 53-69.

McCreary, D. R. (1994). The male role and avoiding femininity. Sex Roles, 31, 517-531.

McKee, M. B., \& Hayes, S. F. (1994). Challenging heterosexism in college health service delivery. Journal of American College Health, 42, 211-216.

Merriam-Webster's collegiate dictionary (10 ${ }^{\text {th }}$ ed.). (2003). Springfield, MA: MerriamWebster.

Meyer, C., Blissett, J., \& Oldfield, C. (2001). Sexual orientation and eating psychopathology: The role of masculinity and femininity. International Journal of Eating Disorders, 29, 314-318. 
Meyer, I. H. (1995). Minority stress and mental health in gay men. Journal of Health and Social Behavior, 36, 38-56.

Norland, S., James, J., \& Shover, N. (1978). Gender role expectation of juveniles. The Sociological Quarterly, 19, 545-554.

O'Connor, K., Mann, D. W., \& Bardwick, J. M. (1978). Androgyny and self-esteem in the upper-middle class: A replication of Spence. Journal of Consulting and Clinical Psychology, 46, 1168-1169.

O'Heron, C. A., \& Orlofsky, J. L. (1990). Stereotypic and nonstereotypic sex role trait and behavior orientations, gender identity, and psychological adjustment. Journal of Personality and Social Psychology, 58, 134-143.

O’Neil, J. M., Helms, B. J., Gable, R. K., David, L., Wrightsman, L. S. (1986). Genderrole conflict scale: College men's fear of femininity. Sex Roles, 14, 335-350.

Orlofsky, J. L. (1977). Sex-role orientation, identity formation, and self-esteem in college men and women. Sex Roles, 3, 561-575.

Oshagen, H., \& Allen, R. L. (1992). Three loneliness scales: An assessment of their measurement properties. Journal of Personality Assessment, 59, 380-409.

Parsons, T., \& Bales, R. F. (1955). Family socialization and interaction process. London \& New York: Routledge.

Pelham, B. W., \& Swann, W. B. Jr. (1989). From self-conceptions to self-worth: On the sources and structure of global self-esteem. Journal of Personality and Social Psychology, 57, 672-680.

Pedhazur, E. J. (1997). Multiple regression in behavior research: Explanation and prediction. Australia, Canada, Mexico, Singapore, Spain, United Kingdom \& United States: Wadsworth: Thomson Learning.

Perez, R. M., DeBord, K. A., \& Bieschke, K. J. (2000). Introduction: The challenge of awareness, knowledge, and action. In R. M. Perez, K. A. DeBord, \& K. J. Bieschke (Eds.), Handbook of counseling and psychotherapy with lesbian, gay, and bisexual clients (1st ed., pp. 3-7). Washington, DC: American Psychological Association.

Ragins, B. R., \& Cornwell, J. M. (2001). Pink triangles: Antecedents and consequences of perceived workplace discrimination against gay and lesbian employees. Journal of Applied Psychology, 86, 1244-1261. 
Robertson, A. E. (1998). The mental health experiences of gay men: A research study exploring gay men's health needs. Journal of Psychiatric and Mental Health Nursing, 5, 33-40.

Rogers, J. R., \& Abbey-Hines, J. (1997). Confirmatory factor analysis of the gender role conflict scale: Ac ross validation of Good et al., 1995. Measurement \& Evaluation in Counseling \& Development, 30, 137-141.

Rosenberg, M. (1965). Society and the adolescent self-image. Princeton: Princeton University Press.

Rosenberg, M. (1979). Conceiving the self. New York: Basic Books.

Rossman, G. B., \& Rallis, S. F. (2003). Learning in the field: An introduction to qualitative research $\left(2^{\text {nd }}\right.$ ed.). Thousand Oaks, CA: Sage Publications.

Russell, D. W. (1996). UCLA Loneliness Scale (Version 3): Reliability, validity, and factor structure. Journal of Personality Assessment, 66, 20-40.

Russell, D., Peplau, L. A., \& Cutrona, C., E. (1980). The revised UCLA Loneliness Scale: Concurrent and discriminant validity evidence. Journal of Personality and Social Psychology, 39, 472-480.

Safir, M. P., Rosenmann, A., \& Kloner, O. (2003). Tomboyism, sexual orientation, and adult gender roles among Israeli women. Sex Roles, 48, 401-410.

Sanchez, D. T., \& Crocker, J. (2005). How investment in gender ideals affects wellbeing: The role of external contingencies of self-worth. Psychology of Women Quarterly, 29, 63-77.

Sandfort, T. G. (2005). Sexual orientation and gender: Stereotypes and beyond. Archives of Sexual Behavior, 34, 595-611.

Savin-Williams, R. C., \& Ream, G. L. (2003). Suicide attempts among sexual-minority male youth. Journal of Clinical Child and Adolescent Psychology, 32, 509-522.

Sharpe, M. J., \& Heppner, P. P. (1991). Gender role, gender-role conflict, and psychological well-being in men. Journal of Counseling Psychology, 38, 323-330.

Shepard, W. D. (2001). Masculine gender role conflict and psychological well-being: A comparative study of heterosexual and gay men. Dissertation Abstracts International 63(09). (UMI No. 3065601)

Silva, D. D. (2002). A study of Latino and Latina university student's gender role expectations: Gender role conflict, acculturation, ethnic identity, and worldview. Dissertation Abstracts International 63(05). (UMI No. 3053648) 
Simonsen, G., Blazina, C., \& Watkins, C. E., Jr. (2000). Gender role conflict and psychological well-being among gay men. Journal of Counseling Psychology, 47, 85-89.

Smith, N. G., \& Ingram, K. M. (2004). Workplace heterosexism and adjustment among lesbian, gay, and bisexual individuals: The role of unsupportive social interactions. Journal of Counseling Psychology, 51, 57-67.

Solano, C. H., Batten, P. G., \& Parish, E.A. (1982). Loneliness and patterns of selfdisclosure. Journal of Personality and Social Psychology, 43, 524-531.

Spence, J. T. (1986). A manual for the Personal Attributes Questionnaire. Unpublished manuscript.

Spence, J. T. (1991). Do the BSRI and PAQ measure the same or different concepts? Psychology of Women Quarterly, 15, 141-165.

Spence, J. T. (1993). Gender-related traits and gender ideology: Evidence for a multifactorial theory. Journal of Personality and Social Psychology, 64, 624-635.

Spence, J. T., \& Buckner, C. (1995). Masculinity and femininity: Defining the undefinable. In P. J. Kalbfleisch, \& M. J. Cody (Eds.), Gender, power, and communication in human relationships (pp. 105-138). Hillsdale, NJ: Lawrence Erlbaum Associates.

Spence, J. T., \& Helmreich, R. L. (1978). Masculinity \& femininity: Their psychological dimensions, correlates, and antecedents. Austin \& London: University of Texas Press.

Spence, J. T., \& Helmreich, R. L. (1980). Masculine instrumentality and feminine expressiveness: Their relationships with sex role attitudes and behaviors. Psychology of Women Quarterly, 5, 147-163.

Spence, J. T., Helmreich, R., \& Stapp, J. (1975). Ratings of self and peers on sex role attributes and their relation to self-esteem and conceptions of masculinity and femininity. Journal of Personality and Social Psychology, 32, 29-39.

Stericker, A. B., \& Johnson, J. E. (1977). Sex-role identification and self-esteem in college students: Do men and women differ? Sex Roles, 3, 19-26.

Stevens, J. P. (2002). Applied multivariate statistics for the social sciences $\left(4^{\text {th }} \mathrm{ed}\right.$.). Mahway, NJ: Lawrence Erlbaum Associates. 
Stokes, J., \& Levin, I. (1986). Gender differences in predicting loneliness from social network characteristics. Journal of Personality and Social Psychology, 51, 10691074.

Swaim, R. C., \& Wayman, J. C. (2004). Multidimensional self-esteem and alcohol use among Mexican American and white non-Latino adolescents: Concurrent and prospective effects. American Journal of Orthopsychiatry, 74, 559-570.

Tabachnick, B. G., \& Fidell, L. S. (2007). Using multivariate statistics $\left(5^{\text {th }}\right.$ ed.). Boston, MA: Allyn \& Bacon.

Taylor, A. (1983). Conceptions of masculinity and femininity as a basis for stereotypes of male and female homosexuals. Journal of Homosexuality, 9, 37-53.

Taylor, S. E., \& Brown, J. D. (1988). Illusion and well-being: A social psychological perspective on mental health. Psychological Bulletin, 103, 193-210.

Van Der Meer, T. (2003). Gay bashing-A rite of passage? Culture, Health \& Sexuality, 5, 153-165.

Vincke, J. \& Van Heeringen, K. (2002). Confidant support and the mental wellbeing of lesbian and gay young adults: A longitudinal analysis. Journal of Community \& Applied Social Psychology, 12, 181-193.

Waldo, C. R. (1999). Working in a majority context: A structural model of the antecedents and outcomes of heterosexism in the workplace. Journal of Counseling Psychology, 46, 218-232.

Whitley, B. E. Jr. (2001). Gender role variables and attitudes toward homosexuality. Sex Roles, 45, 691-721.

Zamarripa, M. X., Wampold, B. E., \& Gregory, E. (2003). Male gender role conflict, depression, and Anxiety: Clarification and generalizability to women. Journal of Counseling Psychology, 50, 333-338. 


\section{APPENDICES}

\section{PAGE}

Appendix A - IRB Approval Letter................................. 178

Appendix B - (Male Version of Survey)............................ 180

Appendix C - (Female Version of Survey)........................ 186 


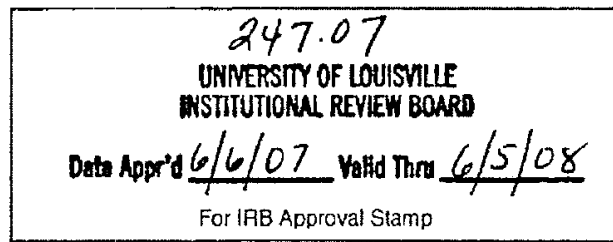

The Effects of Psychological and Biological Gender on Gender Role Conflict and Mental Health of Gay and Lesbian Individuals

Dear Participant:

You are being invited to participate in a research study conducted by Dr. Namok Choi, Dr. Joseph Petrosko, and Kevin J. Herdman. The study is sponsored by the University of Louisville, College of Education and Human Development. The study will take place at the University of Louisville. Approximately 350 persons will be asked to participate in this study. The survey will take approximately 20 minutes to complete. The purpose of this study is to examine the interrelationship of gender, gender role orientation, gender role conflict, self-esteem, and loneliness in a sample of gay and lesbian individuals. You are invited to answer the attached surveys about gender role orientation, gender role conflict, self-esteem, and loneliness. There are no known risks for your participation in this research study. There may, however, be unforeseeable risks associated with your participation in the study. The information collected may not benefit you directly. The information learned in this study may be helpful to others. The information you provide will result in empirical support for understanding the interrelationship of gender, gender role orientation, gender role conflict, self-esteem, and loneliness in gay and lesbian individuals. Your completed survey will be stored at the personal residence of the principal investigator.

Individuals from the College of Education and Human Development, the Institutional Review Board (IRB), the Human Subjects Protection Program Office (HSPPO), and other regulatory agencies may inspect these records. In all other respects, however, the data will be held in confidence to the extent permitted by law. Should the data be published, your identity will not be disclosed. Survey data will be collected in an anonymous manner to the extent possible to minimize potential for participant identification. In the event that participant identifying information becomes accessible, such information will be shredded upon receipt of the surveys.

Taking part in this study is voluntary. By completing this survey you agree to take part in this research study. You do not have to answer any questions that make you uncomfortable. You may choose not to take part at all. If you decide to be in this study you may stop taking part at any time. If you decide not to be in this study or if you stop taking part at any time, you will not lose any benefits for which you may qualify.

If you have any questions, concerns, or complaints about the research study, you have three options. You may contact Dr. Namok Choi (502-852-4014) or Kevin J. Herdman (502-523-5559).

If you have any questions about your rights as a research subject, you may call the Human Subjects Protection Program Office at (502) 852-5188. You can discuss any questions about your rights as a research subject, in private, with a member of the Institutional Review Board (IRB). You may also call this number if you have other questions about the research, and you cannot reach the research staff, or want to talk to someone eise. The IRB is an independent committee made up of people from the University community, staff of the institutions, as well as people from the community not connected with these institutions. The IRB has reviewed this research study. 
If you have concerns or complaints about the research or research staff and you do not wish to give your name, you may call 1-877-852-1167. This is a 24 hour hot line answered by people who do not work at the University of Louisville.

Sincerely,

Mevin t terdmam

Kevin J. Herdman

Revision Date 05/30/07 

1. Age
$\square$ 10-20
$\square 21-30$
$\square_{31-40}$
ए41-50
$\square 51-60$
$\square 61+$

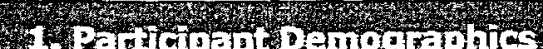

Aithough completeness is desired, you do not have to answer any questions that make you feel uncomfortable or that you simply do not want to answer.

\section{Gender}

$\square$ Maie

Femare

\section{Sexual Orientation}

$\square$ Gay Male
$\square$ Bisexual Male
$\square$ Heterosexual
$\square$ Other

\section{Education}

$\square$ High School

$\square$ Some college

$\square$ College Graduate

7 Masters Degree

$\square$ Professional Degree

$\square$ other

\section{Relationship Status}

$\square$ single

In non monogamous gay male relationship

$\square$ in monogamous gay male relationship

$\square$ In heterosexual marriage 


\section{Income}

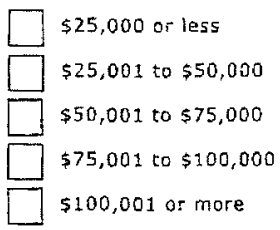

\section{State of Residence}

State/Province: - select state -

\section{BSRI}

1. Instructions: A number of personality characteristics are listed below. We would like you to use those characteristics to describe yourself, that is, we would like you to indicate, on a scale from 1 to 7 , how true of you each of these characteristics is. Please do not leave any characteristics unmarked. Although completeness is desired, you do not have to answer any questions that make you feel uncomfortable or that you simply do not want to answer.

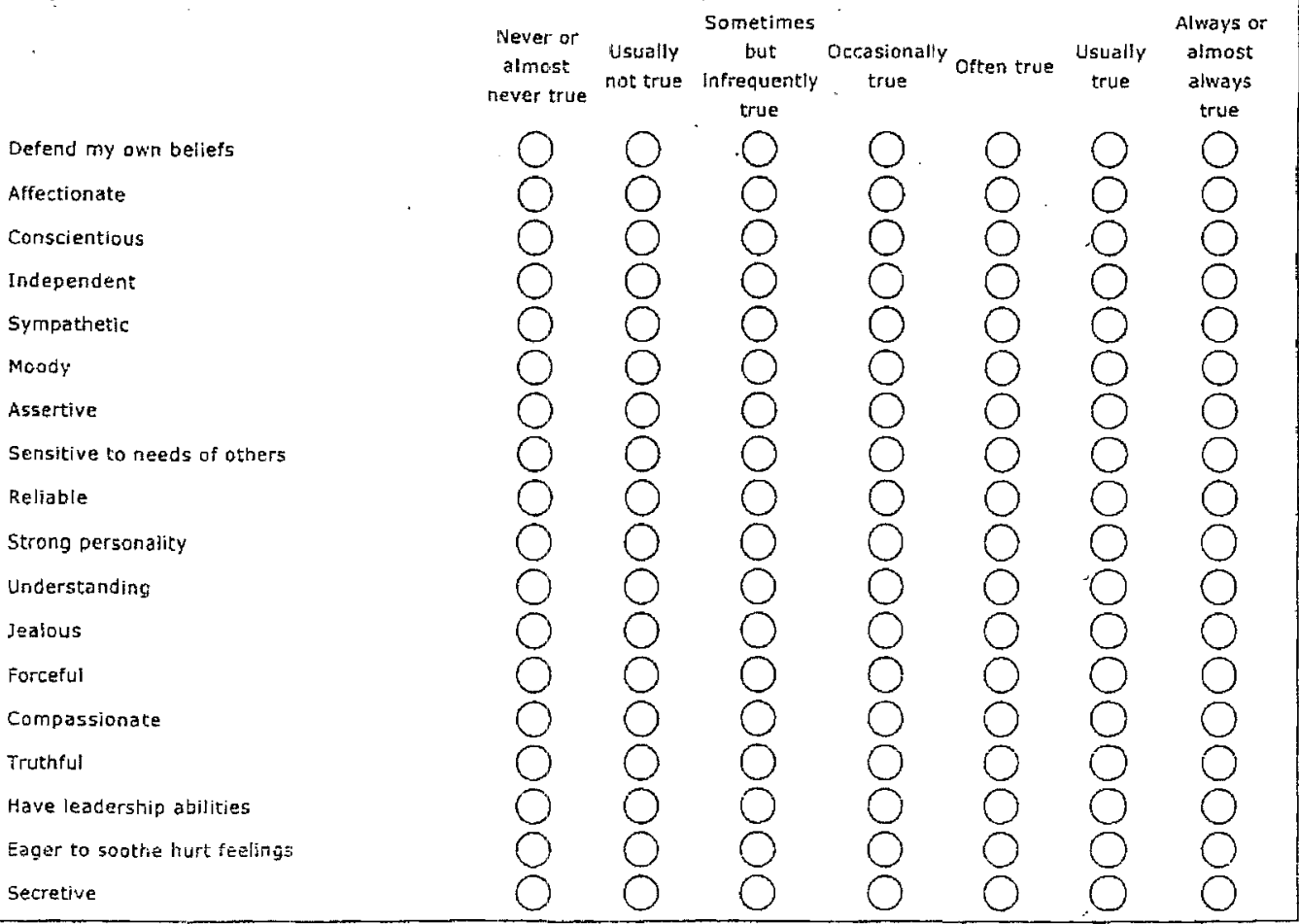




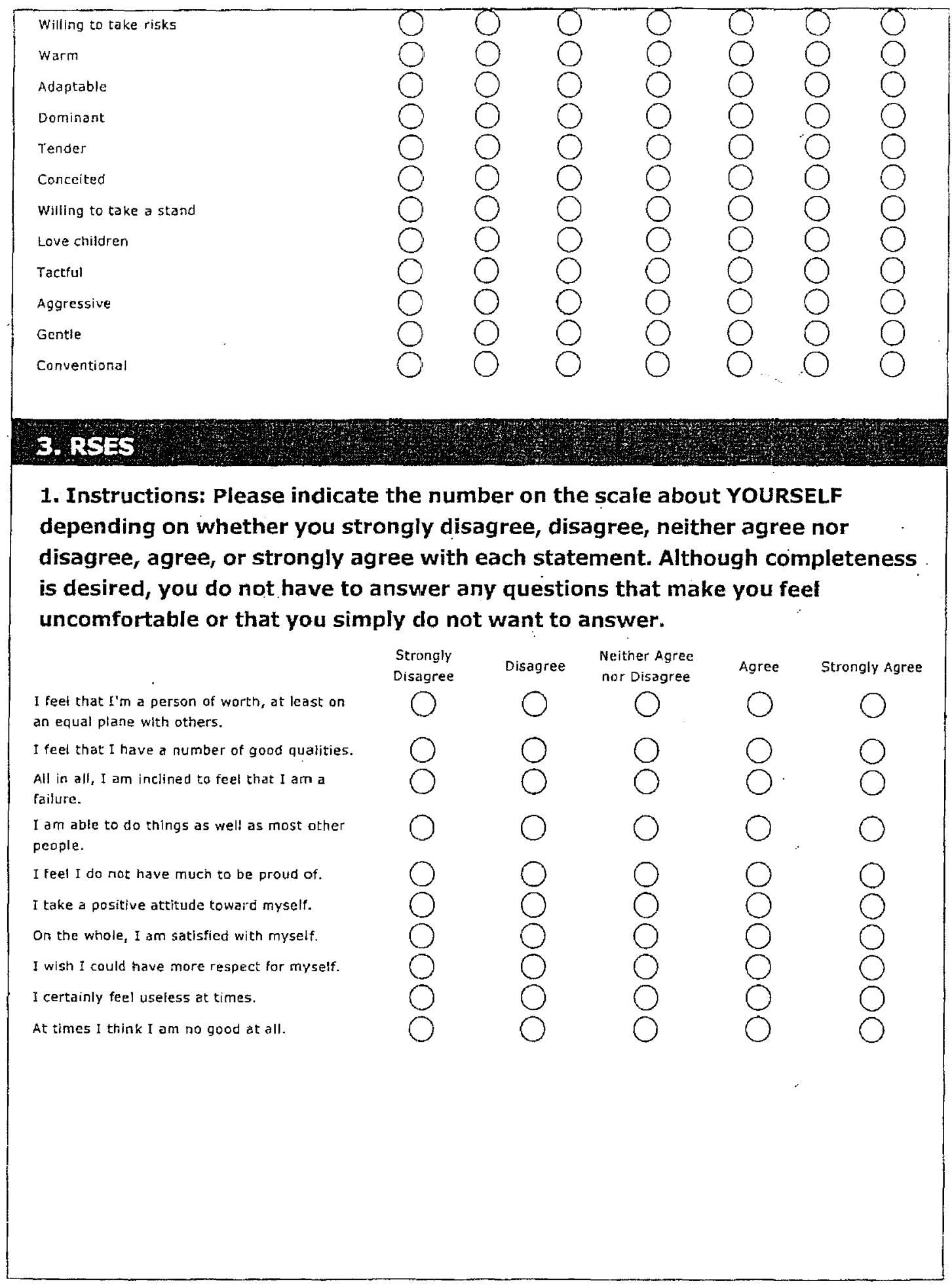


1. Instructions: The following statements describe how people sometimes feel. For each statement, please indicate how often you feel the way described by writing a number in the space provided. Here is an example:

\section{How often do you feel happy?}

If you never felt happy, you would respond "never"; if you always feel happy, you would respond "always." Although completeness is desired, you do not have to answer any questions that make you feel uncomfortable or that you simply do not want to answer.

How often do you feel that you are "in tune" with the people around you?

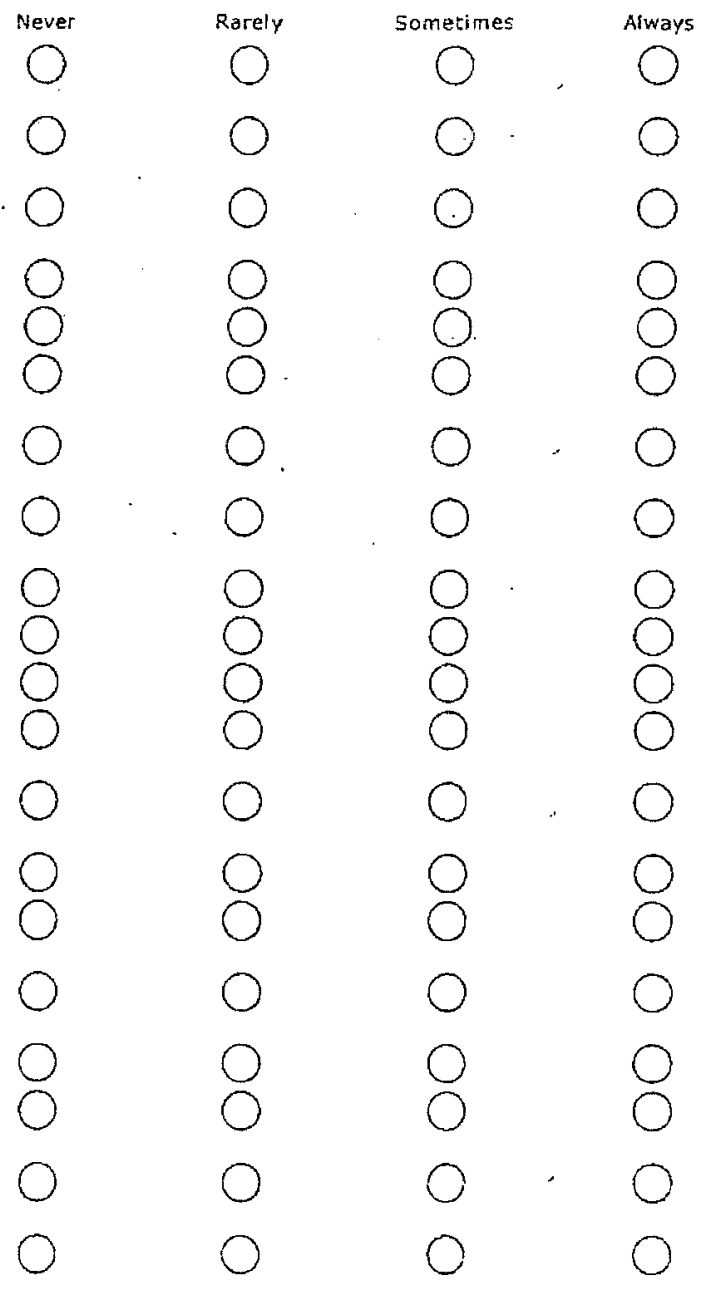

How often do you feel like you lack

companionship?

How often do you feel that there is no ane you can turn to?

How often do you feel alone?

How often do you feel part of a group of friends?

How often do you feel that you have a lot in

common with the people around you?

How often do you feel that you are no longer close to anyone?

how often do you feel like your interests and ideas are not shared by those around you?

How often do you feel outgoing and friendly? How often do you feel close to people?

How often do you feel left cut?

How often do you feel that your relationships with others are not meaningful?

How often do you feel that no one really knows you well?

how often do you feel isolated from others?

How often do yau feel you can find companionship when you wart it?

How often do you feel that there are people who really understand you?

How often do you feel shy?

How often do you feel that people are around you but not with you?

How often do you feel that there are peopic you can talk to?

How often do you feal that there are people you can turn to? 
3. chas

1. Instructions: In the space to the left of each sentence below, write the number which most closely represents the degree that you Agree or Disagree with the statement. There is no right or wrong answer to each statement; your own reaction is what is asked for. Although completeness is desired, you do not have to answer any questions that make you feel uncomfortable or that you simply do not want to answer.

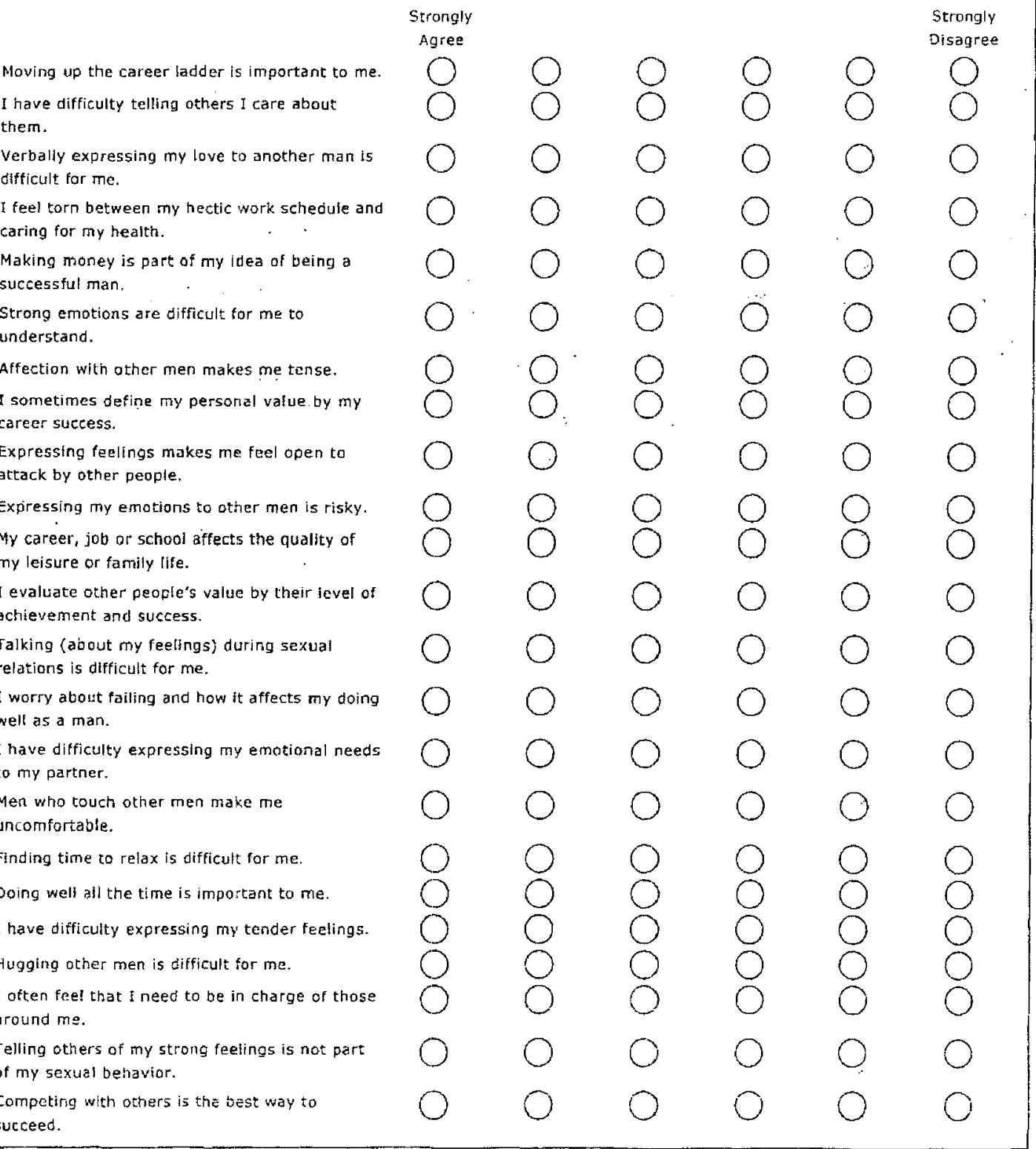




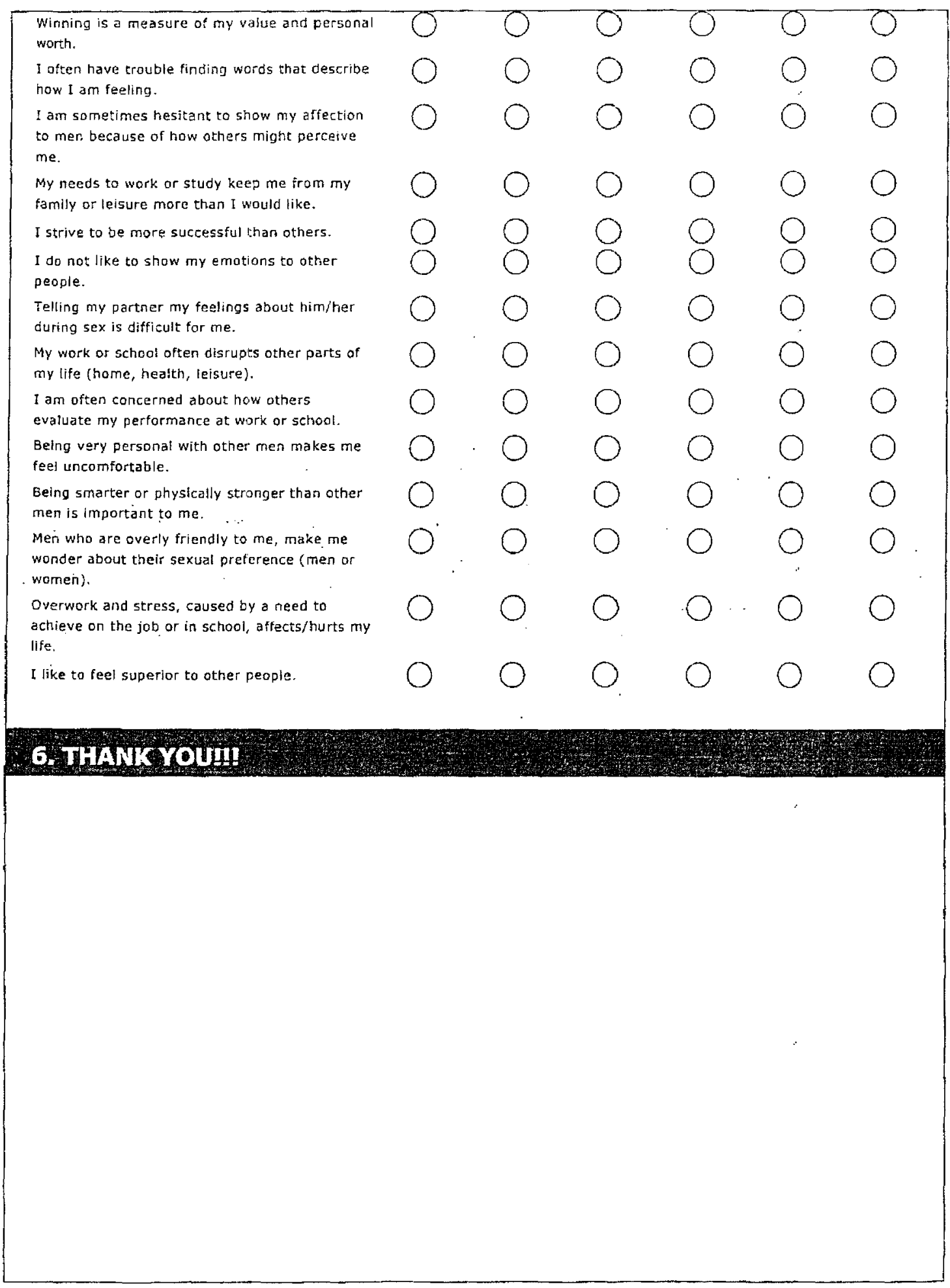


Although completeness is desired, you do not have to answer any questions that make you feel uncomfortable or that you simply do not want to answer.
1. Age
$\square^{10 \cdot 20}$
$\square 21-30$
$\square 31-40$
71-50
$\square$ 51-60
$\square^{61+}$

\section{Gender}

$\square$ Mate

Female

\section{Sexual Orientation}
C Lesbian Female
Bisexual Female
7 Heterasexual
Other

\section{Education}

$\square$ High School
$\square$ Some College
$\square$ College Graduate
$\square$ Masters Degree
$\square$ Professionat Degree
$\square$ Other

\section{Relationship Status}
$\square$ single
In non monogamous lestian relationship
- In monogamous iesbian relationship
In heterosexuat marriage 


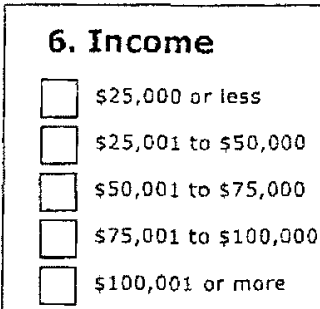

\section{State of Residence}

State/Province: - select state -

\section{BSFI}

1. Instructions: A number of personality characteristics are listed below. We would like you to use those characteristics to describe yourself, that is, we would like you to indicate, on a scale from 1 to 7, how true of you each of these characteristics is. Please do not leave any characteristics unmarked. Although completeness is desired, you do not have to answer any questions that make you feel uncomfortable or that you simply do not want to answer.

Detend my own beliefs




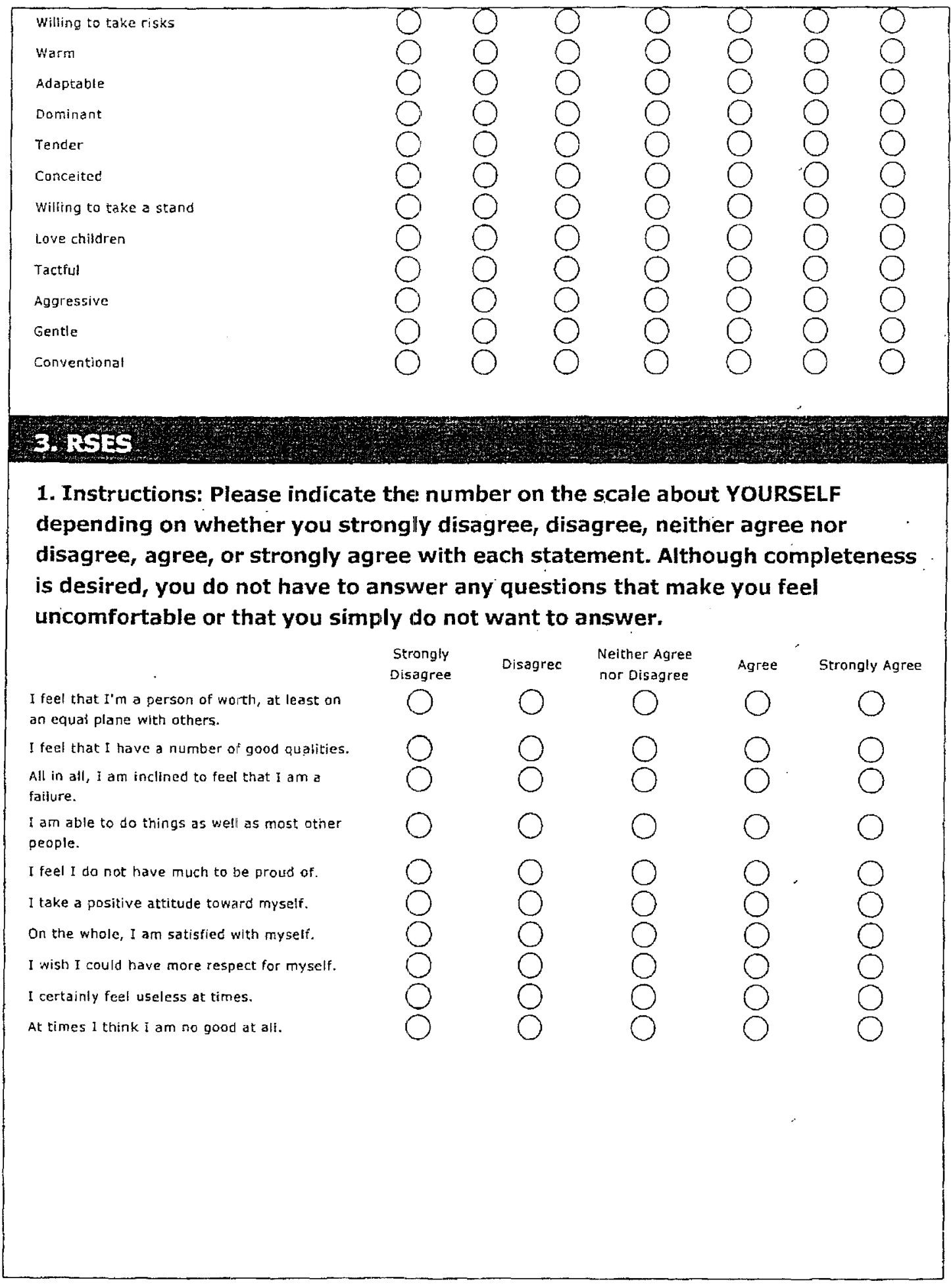


1. Instructions: The following statements describe how people sometimes feel. For each statement, please indicate how often you feel the way described by writing a number in the space provided. Here is an example:

\section{How often do you feel happy?}

If you never felt happy, you would respond "never"; if you always feel happy, you would respond "always." Although completeness is desired, you do not have to answer any questions that make you feel uncomfortable or that you simply do not want to answer.

How often do you feel that you are "In tune" with the people around you?

How often do you feel like you lack companionship?

How often do you feel that there is no one you can turn to?

How often do you feel alone?

How often do you fee! part of z group of friends? How often do you feel that you have a lot in common with the people around you?

How often do you feel that you are no longer close to aryone?

How often do you feel like your interests and ideas are not shared by those around you?

How often do you feel outgoingl and friendly?

How often do you feel close to peopie?

How often do you feel left out?

How often do you feel that your relationships with others are not meaningful?

How often do you feel that no one really knows you well?

How often do you feel isolated from others?

How often do you feel you can find companionship when you want it?

How often do you feel that there are people who really understand you?

How often do you feel shy?

How often do you feel that people are around you but not with you?

How often do you feel that there are people you can talk to?

How often do you feel that there are people you can turn to?
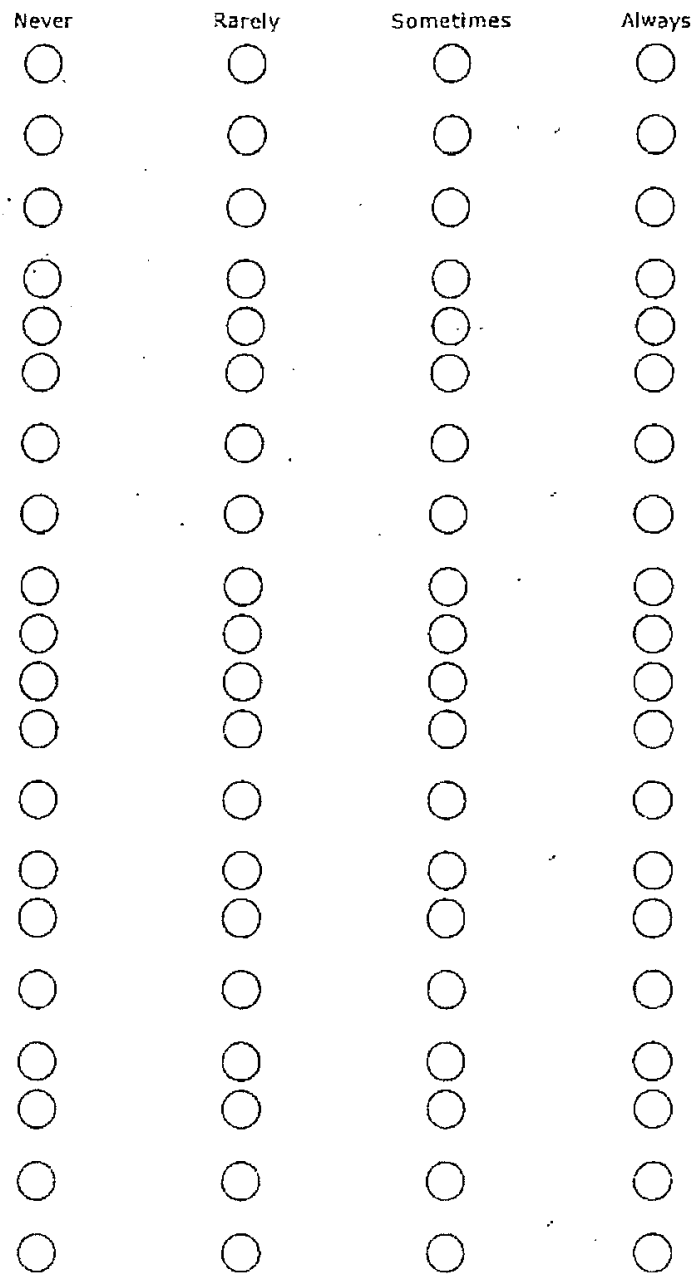
1. Instructions: In the space to the left of each sentence below, write the number which most closely represents the degree that you Agree or Disagree with the statement. There is no right or wrong answer to each statement; your own reaction is what is asked for. Although completeness is desired, you do not have to answer any questions that make you feel uncomfortable or that you simply do not want to answer.

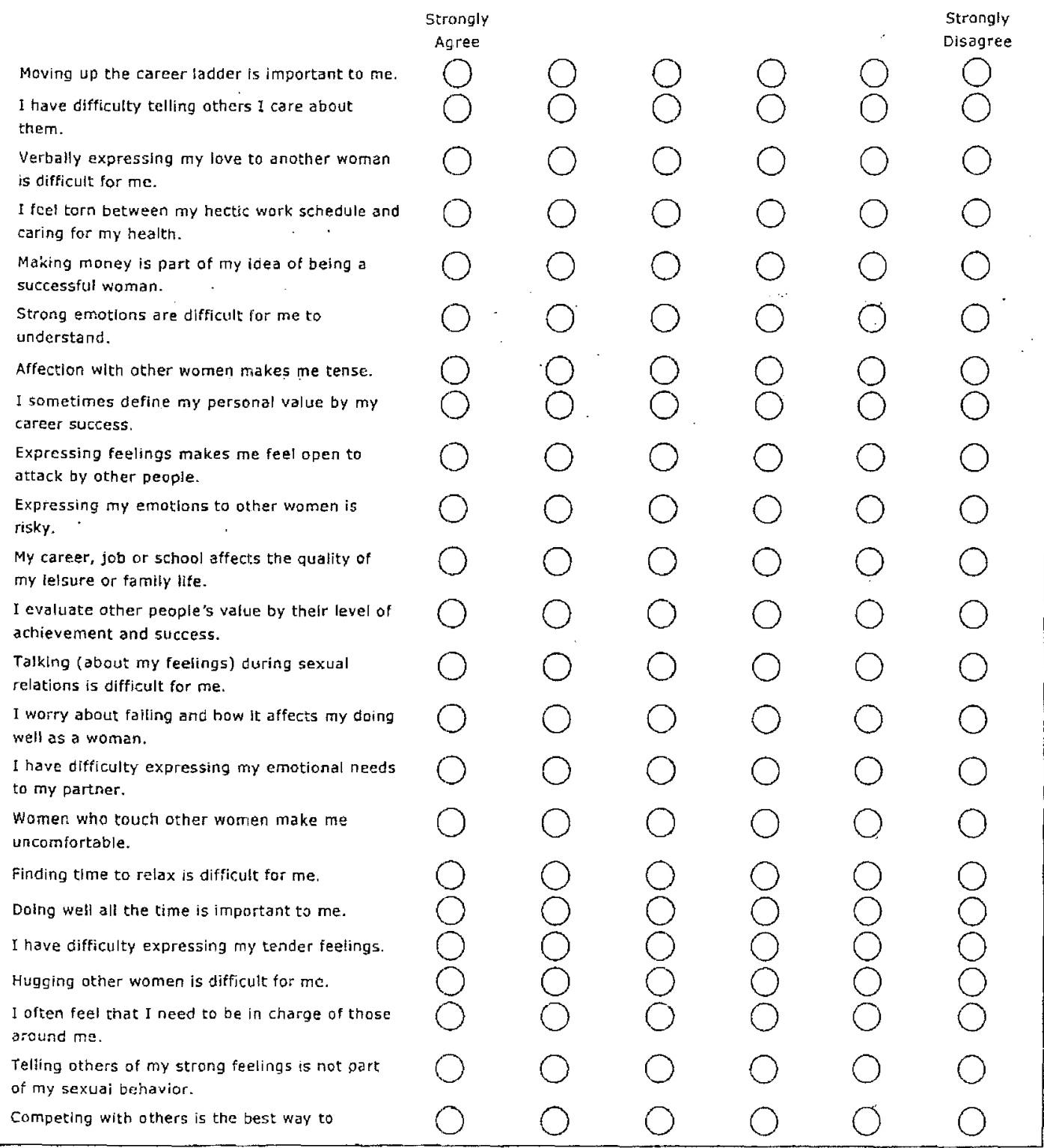




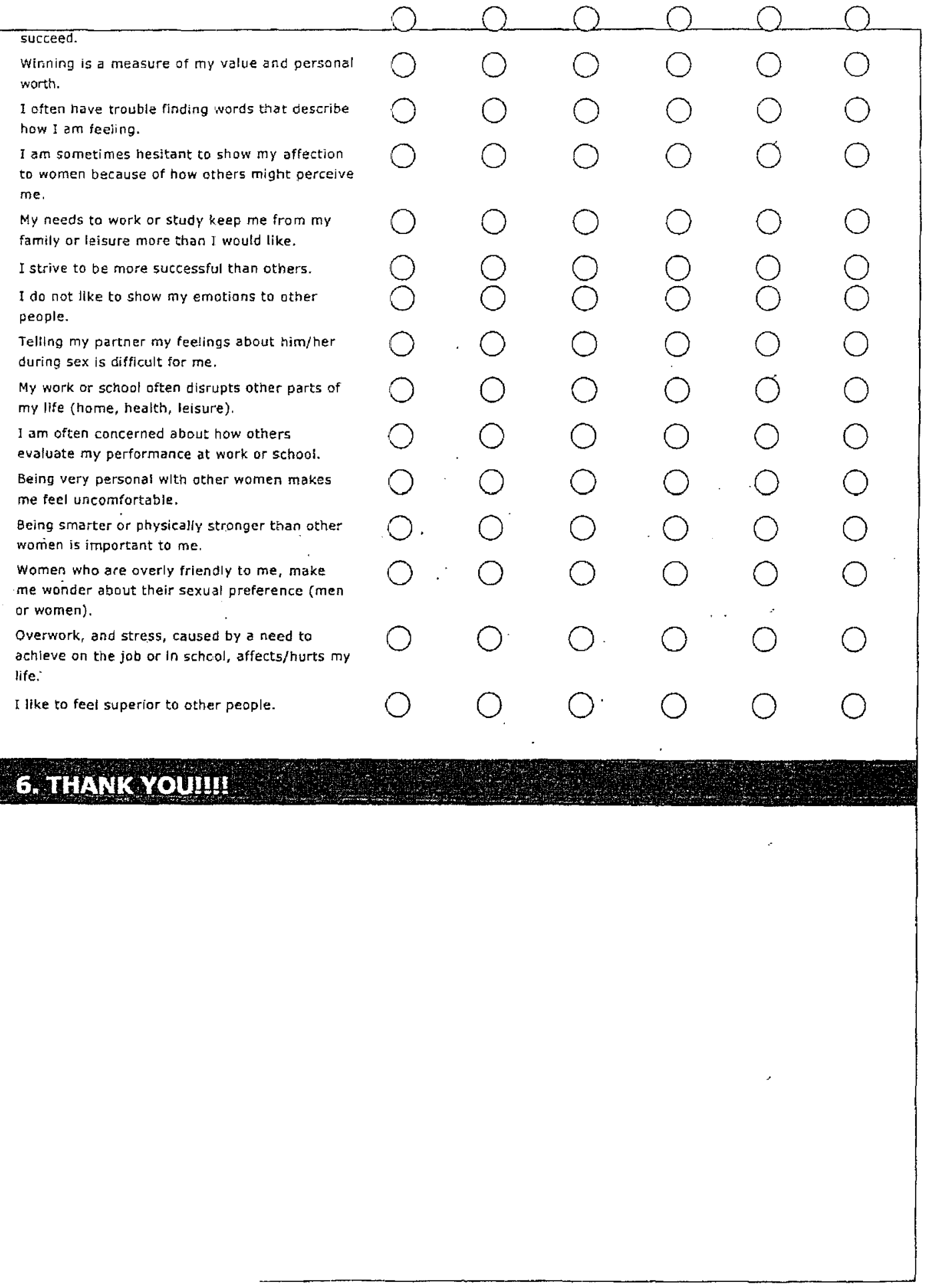




\section{CURRICULUM VITAE}

NAME:

Kevin James Herdman

ADDRESS:

226 Sage Road

Louisville, KY 40207

DOB:

Springville, NY - July 18, 1969

EDUCATION

\& TRAINING:

B.S., Business Administration/Accounting

West Virginia State University

$1989-1993$

Certified Public Accountant

Licensed in WV - 1995

Licensed in KY - 1997

Master of Business Administration (MBA)

Indiana University Southeast

$1997-1999$

M.S., Human Resource Management

Webster University, Jeffersonville IN

2002 - 2004

Ph.D., Organizational Development/Human Resource Education University of Louisville

2004-2007

PROFESSIONAL

SOCIETIES:

American Educational Research Association

CONFERENCES: Mid-Western Educational Research Conference - Presenter

Columbus, $\mathrm{OH}$

October 2006

Analysis of the Bem Sex Role Inventory 